\title{
Effect of different administration and dosage of dexmedetomidine in the reduction of emergence agitation in children: a meta-analysis of randomized controlled trials with sequential trial analysis
}

\author{
Xu Zhang ${ }^{1}$, Yan $\mathrm{Bai}^{2}$, Min Shi ${ }^{1}$, Shaopeng Ming ${ }^{3}$, Xiaogao Jin ${ }^{4}$, Yubo Xie ${ }^{1 \wedge}$ \\ ${ }^{1}$ Department of Anesthesiology, The First Affiliated Hospital of Guangxi Medical University, Nanning, China; ${ }^{2}$ Department of Anesthesiology, The \\ Second Affiliated Hospital of Guilin Medical University, Guilin, China; ${ }^{3}$ Department of Anesthesiology, The Second Affiliated Hospital of Guangxi \\ Medical University, Nanning, China; ${ }^{4}$ Department of Anesthesiology, The Affiliated Hospital of Guilin Medical University, Guilin, China \\ Contributions: (I) Conception and design: Y Xie; (II) Administrative support: Y Xie; (III) Provision of study materials or patients: X Zhang, Y Bai; \\ (IV) Collection and assembly of data: X Zhang, M Shi; (V) Data analysis and interpretation: M Shi, S Ming; (VI) Manuscript writing: All authors; \\ (VII) Final approval of manuscript: All authors. \\ Correspondence to: Yubo Xie, PhD. Department of Anesthesiology, The First Affiliated Hospital of Guangxi Medical University, 6 Shuangyong Road, \\ Nanning 530021, China. Email: xybdoctor2020@163.com.
}

Background: Beneficial effects of dexmedetomidine (DEX) against emergence agitation (EA) in children remain controversial. We performed a more comprehensive meta-analysis to evaluate the protective effect of different administration routes, timing, patterns, and doses of DEX on EA in children.

Methods: The randomized controlled trials about DEX preventing EA in children were searched in PubMed, Cochrane Library, Embase, and Web of Sciences up to October 7, 2020. The traditional meta-analysis and subgroup analysis were performed to study the influence of DEX on EA in children. The sequential trial analysis (TSA) further analyzed the pooled results to evaluate meta-analyses' robustness. Grading of recommendation, assessment, development, and evaluation (GRADE) was used to assess evidence quality.

Results: Sixty-seven studies with 5,688 pediatric patients were included. DEX significantly decreased EA in children compared to placebo [RR 0.29, 95\% confidence intervals (CI): 0.25-0.34] and midazolam (RR 0.34, 95\% CI: 0.25-0.45), with firm evidence from TSA. Notably, using DEX significantly reduced severe EA incidence (RR 0.23, 95\% CI: 0.16-0.32), with firm evidence by TSA and high quality of GRADE. Pre-specified subgroup analyses revealed firm and high-quality evidence for a reduction of EA, only if the perineural route administers DEX (RR 0.24, 95\% CI: 0.14-0.41), as premedication (RR 0.27, 95\% CI: 0.200.36), as continuous dosage (RR 0.25, 95\% CI: 0.18-0.33), at high dose (RR 0.24, 95\% CI: 0.18-0.31). The pooled results also showed that DEX reduced the incidence of PONV compared to placebo (RR 0.43, 95\% CI: 0.33-0.55). Evidence for DEX's influence on other secondary outcomes (emergence time, time in PACU, rescue analgesia, hypotension, and bradycardia) is insufficient to draw any conclusion.

Conclusions: Our findings confirm the beneficial effects of DEX on EA, severe EA, and PONV in children. There was firm and high-quality evidence for the efficacy of DEX in preventing EA in children when perineural routes administered DEX, as premedication, as continuous dosage, and at a high dose. The best dose, route, patterns, and timing of DEX and influence on other outcomes call for further studies.

Keywords: Dexmedetomidine (DEX); emergence agitation (EA); children; general anesthesia; meta-analysis; sequential trial analysis (TSA)

Submitted Jan 19, 2021. Accepted for publication Apr 20, 2021.

doi: $10.21037 / \mathrm{tp}-21-105$

View this article at: http://dx.doi.org/10.21037/tp-21-105

$\wedge$ ORCID: 0000-0002-7198-7506. 


\section{Introduction}

Emergence agitation (EA) is a state of perceptual disturbances and psychomotor agitation that occurs most commonly in preschool children during the early postanesthetic period (1). The negative behavioral symptoms of EA include combative movements, excitability, thrashing, disorientation, and inconsolable crying. Although these events are often short-lived, they increase the risk of selfinjury and delayed discharge from the PACU, require added nursing care, and increase medical costs (2). EA incidence varies from $10 \%$ to $80 \%$ in children, and $42 \%$ of pediatric anesthesiologists consider it a troublesome clinical situation $(3,4)$.

Various drugs have been investigated to prevent EA in pediatric patients, including dexmedetomidine (DEX), midazolam, propofol, opioids, ketamine, and ketofol (2). Among these drugs, DEX, a highly selective $\alpha 2$ adrenoreceptor agonist, is the most prevalent drug used in pediatric anesthesia due to its sedative, analgesic, amnesic, anxiolytic, and sympatholytic properties with minimal respiratory depression (5). In recent years, DEX has been put at the forefront of pediatric clinical practice for its potential organ-protective effects and preservation of neurocognitive functions (6). The efficacy of DEX on EA prevention has been reported in many clinical trials, using different administration routes and different dosages. However, the sample size of all these trials was too small to supply a definite conclusion. Some of their results were inconsistent.

Several systematic reviews and meta-analyses assess using DEX to prevent EA in children (7-13). However, the results of the existing meta-analyses were prone to bias due to the limited sample size (7-12), high heterogeneity of included studies $(11,13)$, or including non-randomized case-control studies (13). Moreover, none of these metaanalyses evaluated the evidence quality using either TSA or Grading of recommendation, assessment, development, and evaluation (GRADE) tools, which conclusions would not be dependable. Therefore, from the latest evidence, the present updated meta-analysis of RCTs was conducted to evaluate the effect of different administration and dosage of DEX in reducing EA in children. And the sequential trial analysis (TSA) was performed to determine whether the findings achieved the required information size (IS) to conclude.

We present the following article in accordance with the PRISMA reporting checklist (available at http://dx.doi. org/10.21037/tp-21-105).

\section{Methods}

\section{Search strategy}

Publications on randomized controlled clinical trials (RCTs) for EA in children were searched in biomedical databases including PubMed, Cochrane Library, EMBASE, Web of Sciences up to October 7, 2020. The keywords for searching were ("dexmedetomidine") and ("emergence agitation" or "delirium" or "excitement") and ("child" or "infant" or "pediatric"). There were no language restrictions. The references of related studies were manually searched to identify added eligible studies. The search strategy for each database is detailed in Table S1.

\section{Selection criteria}

Two independent reviewers (Xu Zhang and Yan Bai) removed duplicate references, screened the titles and abstracts of the remaining articles, and then examined the articles' full text to identify eligible RCTs. A third reviewer (Xiaogao Jin) was consulted for finalization if there were any differences in opinions between the reviewers. The trials selected for this meta-analysis met the following inclusion/ exclusion criteria:

The inclusion criteria included (I) human randomized controlled trials; (II) the children with age ranged from 0 to 18 yrs old; (III) DEX as an intervention was compared with placebo and/or active comparator; (IV) the incidence of EA was addressed in the trial.

The exclusion criteria contained: (I) no validated EA evaluation method was mentioned; (II) the data was questionable or inconsistent; (III) articles published only as an abstract or letter; (IV) duplicated articles or data.

\section{Data extraction}

The details of the methodologies and publication data were extracted independently by the two reviewers (Xu Zhang and Min Shi). The following data were extracted, including primary author, publication year, types of surgery, study design, child characteristics, anesthesia used, intervention and control (type, dosage, time, route), the definition of EA, incidence of EA, and severe EA, several periods related to anesthesia recovery, and adverse events, including rescue analgesia, PONV, hypotension, bradycardia. The primary 
outcomes of our review were the incidence of EA and the incidence of severe EA.

\section{Risk of bias assessment}

Two reviewers (Min Shi and Shaopeng Ming) independently evaluated the quality of included trials using the Cochrane Risk of Bias 2.0 tool for assessing the risk of bias in randomized trials. There are seven items to assess the risk of bias: random sequence generation, allocation concealment, blinding of participants and personnel, blinding of outcome assessment, incomplete outcome data, selective reporting, and other bias using the high, low, or unclear risk of bias. A consensus resolved all disagreements through discussion among authors, and the corresponding author made the final decision (Yubo Xie).

\section{Statistical analysis}

We performed all meta-analyses using Review Manager (version 5.4.1; Cochrane Collaboration, Copenhagen, Denmark) or STATA (version 14.0; Stata Corp, College Station, TX, USA). The pooled effect, risk ratio (RR) were calculated for dichotomous variables, and the mean difference (MD) was calculated for continuous variables. Assessment of heterogeneity was set up using the Chisquare test and I-squared $\left(\mathrm{I}^{2}\right)$ test. If the $\mathrm{I}^{2}>50 \%$ or the $\mathrm{P}$ value $<0.10$, significant heterogeneity of effect sizes was present, and a random-effects model was used instead of a fixed-effect model. All statistical outcomes were reported with $95 \%$ confidence intervals (CI). A two-sided $\mathrm{P}$ value $<0.05$ was assumed as statistically significant. Funnel plots were visually inspected, and Egger's linear regression test was performed to assess publication bias if at least ten trials were identified. If the outcomes showed significant publication bias, the trim and fill method was used for added analysis.

The TSA was performed to reduce the risks of random errors, increase the meta-analyses' robustness, and determine whether the current sample size was sufficient $(14,15)$. We calculated the required IS and trial sequential monitoring boundaries (TSMB) that determined whether the evidence in our meta-analysis was reliable and conclusive. If the cumulative $Z$-curve entered the futility area or crossed TSMB, the anticipated intervention effect showed firm evidence. Otherwise, evidence was rated as absent (16). The risk of a type 1 error was set to $5 \%$ with a power of $80 \%$. We set the effect measure as 'Relative
Risk' and model as 'Random-effects (DL)' in TSA software for dichotomous outcomes. Relative risk reduction (RRR) was defined as $30 \%$, the incidence in the control arm was calculated from the average incidence in the control group, heterogeneity correction was set as model variance-based; For continuous outcomes, we set the effect measure as "Mean Difference" and the model as "Random Effects (DL)" in TSA software. We calculated the IS from the low risk of bias studies. We used trial sequential analysis software (version 0.9.5.10 beta; http://www.ctu.dk/tsa) to perform this analysis.

The Grading of Recommendations Assessment, Development, and Evaluation (GRADE) approach was used to assess the quality of evidence and strength of recommendations. The quality of all primary and secondary outcomes was independently assessed by two reviewers (Xu Zhang and Xiaogao Jin). On the risk of bias (of the included studies), inconsistency (for the $\mathrm{I}^{2}$ statistic), indirectness (outcome data through direct or indirect comparisons of interest), imprecision (for the TSA), and publication bias (for the egg's test), the quality was classified as high, moderate, low, or very low. GRADEpro GDT software online (version 3.0; https://gdt.gradepro.org/app/) was used to evaluate the quality of evidence.

\section{Results}

\section{Search results}

We retrieved 1,032 literatures from PubMed ( $n=158)$, Cochrane Library $(n=252)$, EMBASE $(n=283)$ and Web of Sciences ( $\mathrm{n}=339)$. After removing 577 duplicate records and excluding 337 citations by screening their titles and abstracts, 123 full-text articles were examined. We then excluded 55 articles because they were commentary articles, not RCT designs or studies without relevant outcomes. Also, one study (17) was excluded because the result of EA incidence was inconsistent between the text and the figure. Finally, 67 studies were included, which assessed the effectiveness of DEX in reducing the risk of incidence of EA in children. Figure 1 displays our study screening and selection strategy.

\section{Characteristics of the studies included}

Five thousand six hundred eighty-eight children's data were pooled, including 1,616 EA events. The effectiveness of DEX against EA was assessed in 2,920 patients, while 2,768 


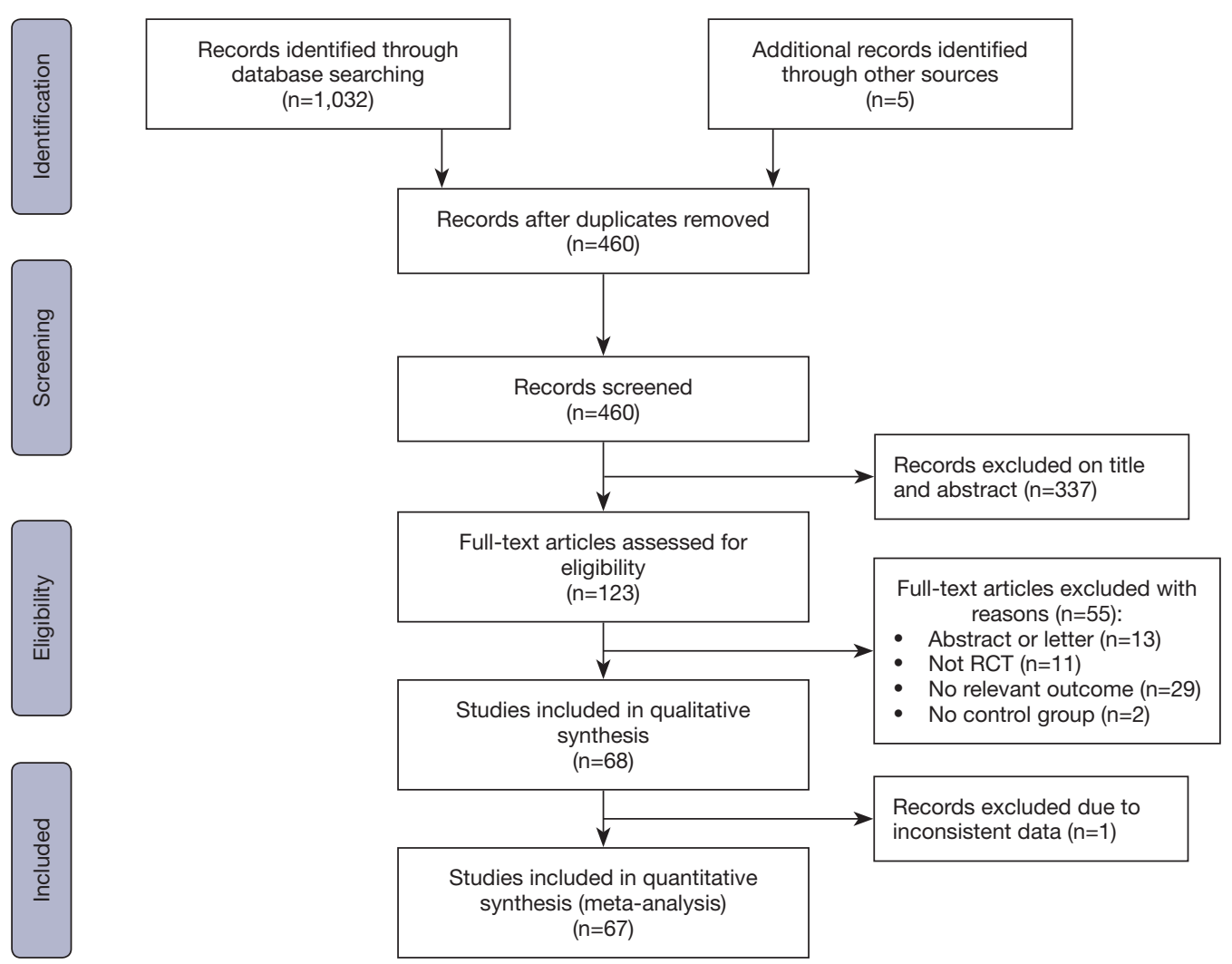

Figure 1 PRISMA flow chart depicting study selection criteria.

patients received various comparators, including placebo, midazolam, fentanyl, propofol, ketamine, ketofol, and clonidine. DEX was administered through different routes, including intravenous (bolus and continuous infusion), intranasal, perineural (caudal or nerve block), and oral. The detailed characteristics of the included studies are presented in Table 1.

\section{Risk of bias in included studies}

We assessed the risk of bias for each RCT included in the study. Most identified studies were rated to have a low risk of bias. The Cochrane Risk of bias analysis is shown in Figure 2.

\section{Meta-analysis of outcomes}

\section{Primary outcome 1: EA incidence}

\section{$D E X$ vs. placebo}

Fifty-five studies with 4,402 patients were included, which assessed the effects of DEX compared to placebo in reducing the risk of EA in children. There was evidence that DEX significantly decreased EA incidence compared to placebo (RR 0.29, 95\% CI: 0.25-0.34, $\mathrm{P}<0.00001$ ) (Figure 3). Moderate heterogeneity within the results $\left(\mathrm{I}^{2}=44 \%, \mathrm{P}=0.0003\right)$ was shown, which is because of including three studies $(42,70,75)$ according to the Galbraith plot analysis (Figure 4). Sensitivity analysis was performed by excluding data from these studies, the heterogeneity reduced to $\mathrm{I}^{2}=9 \%(\mathrm{P}=0.29)$, and the summary estimate was essentially unchanged (RR 0.27, 95\% CI: 0.24-0.31, $\mathrm{P}<0.00001$ ) (Figure 5). Egger's tests showed there might be a publication bias $(\mathrm{P}=0.000)$. Therefore, trim and fill analysis were performed to identify the bias. It showed no trimming, revealing that the result was reliable (Figure 6). TSA's outcome proved that the cumulative Z-curve crossed the TSMB and reached the IS (calculated as 801) (Figure 7, Table 2). It suggested that the answer to such a clinical question was definitively clear, and the sample size of patients was enough. Further studies are unlikely to change the conclusions. However, we downgraded the GRADE evidence from high to moderate due to publication bias (Appendix 1).

\section{DEX vs. active comparators}

Twelve trials $(18,19,27,28,35,58,60,65,68,71,78,82)$ 


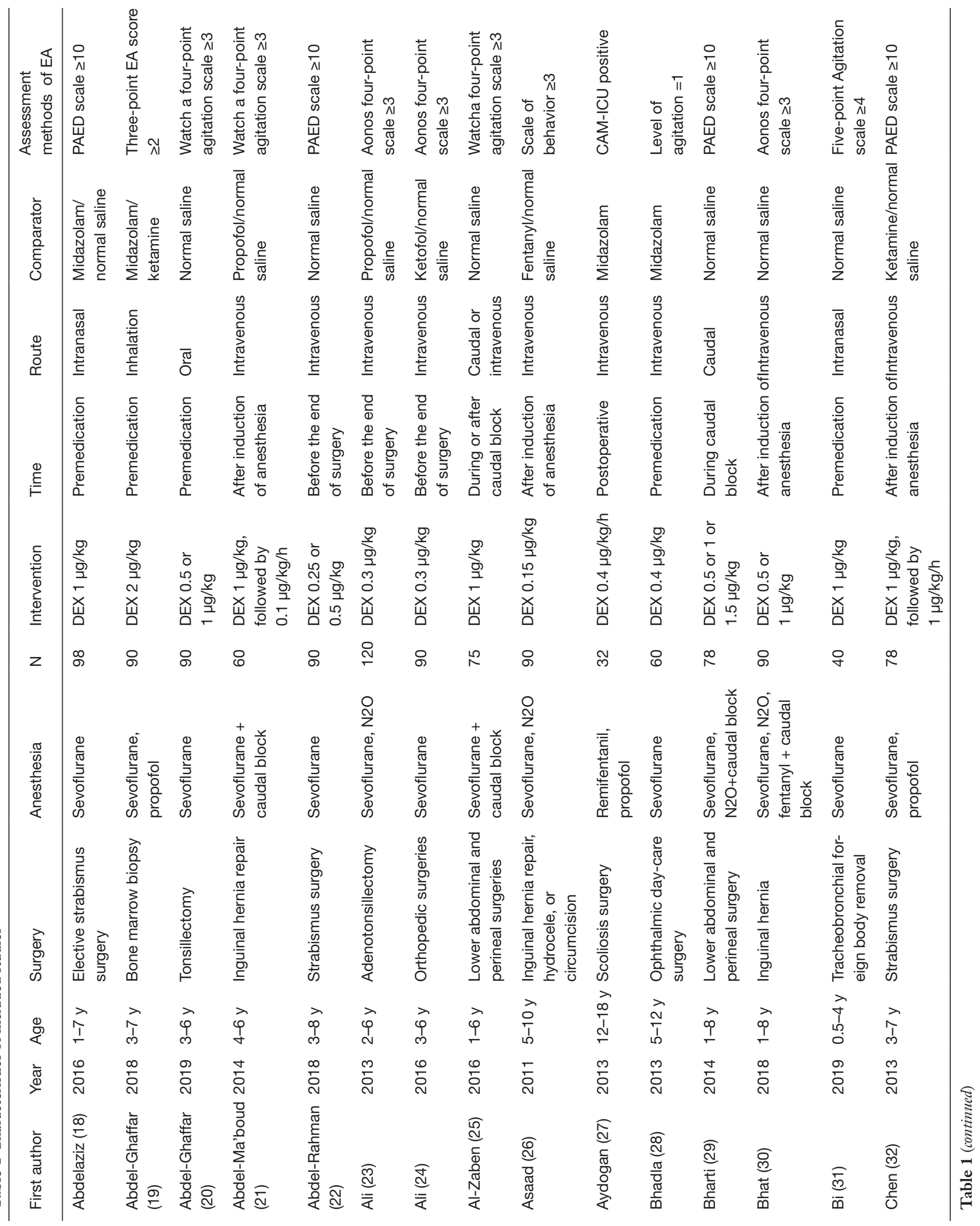




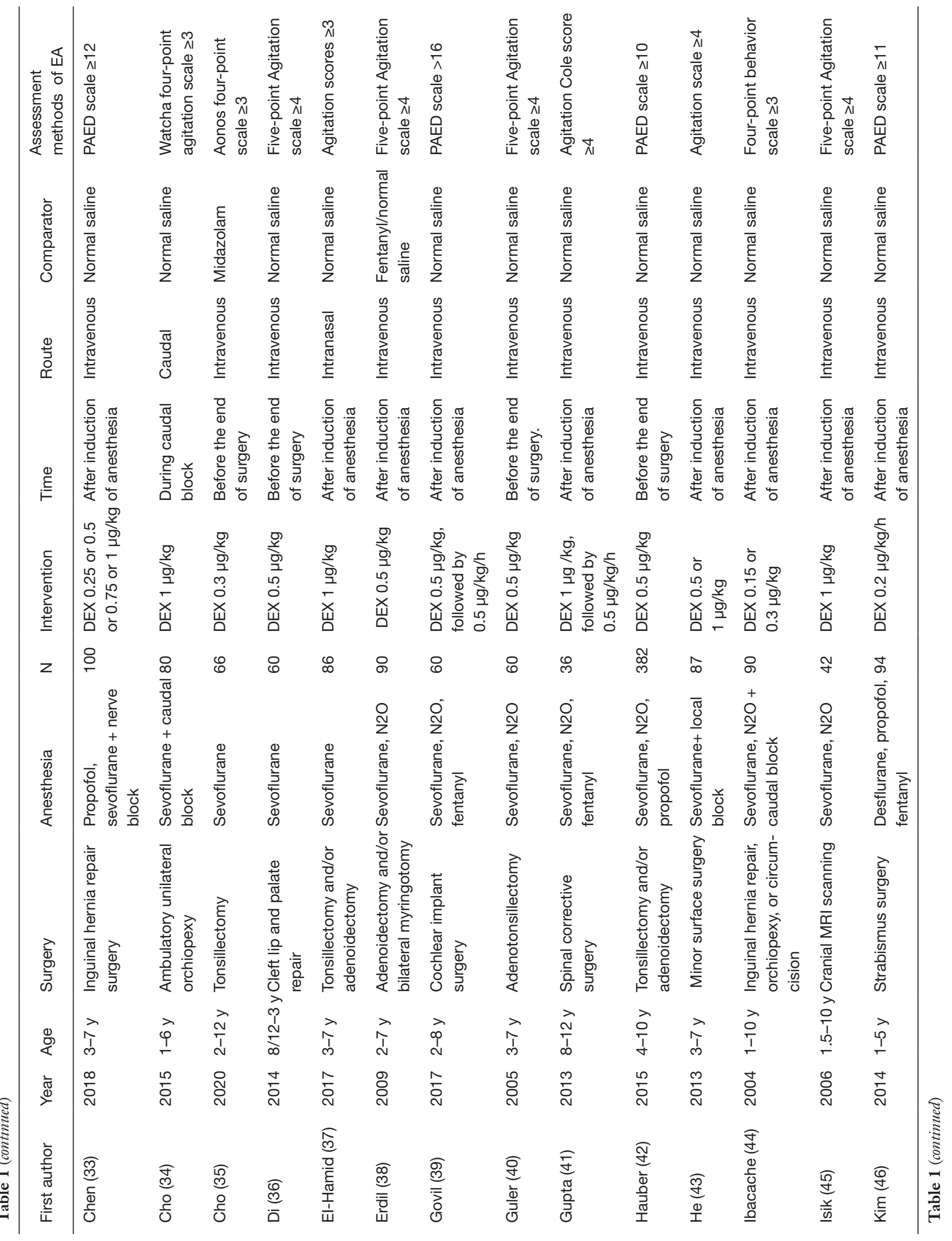




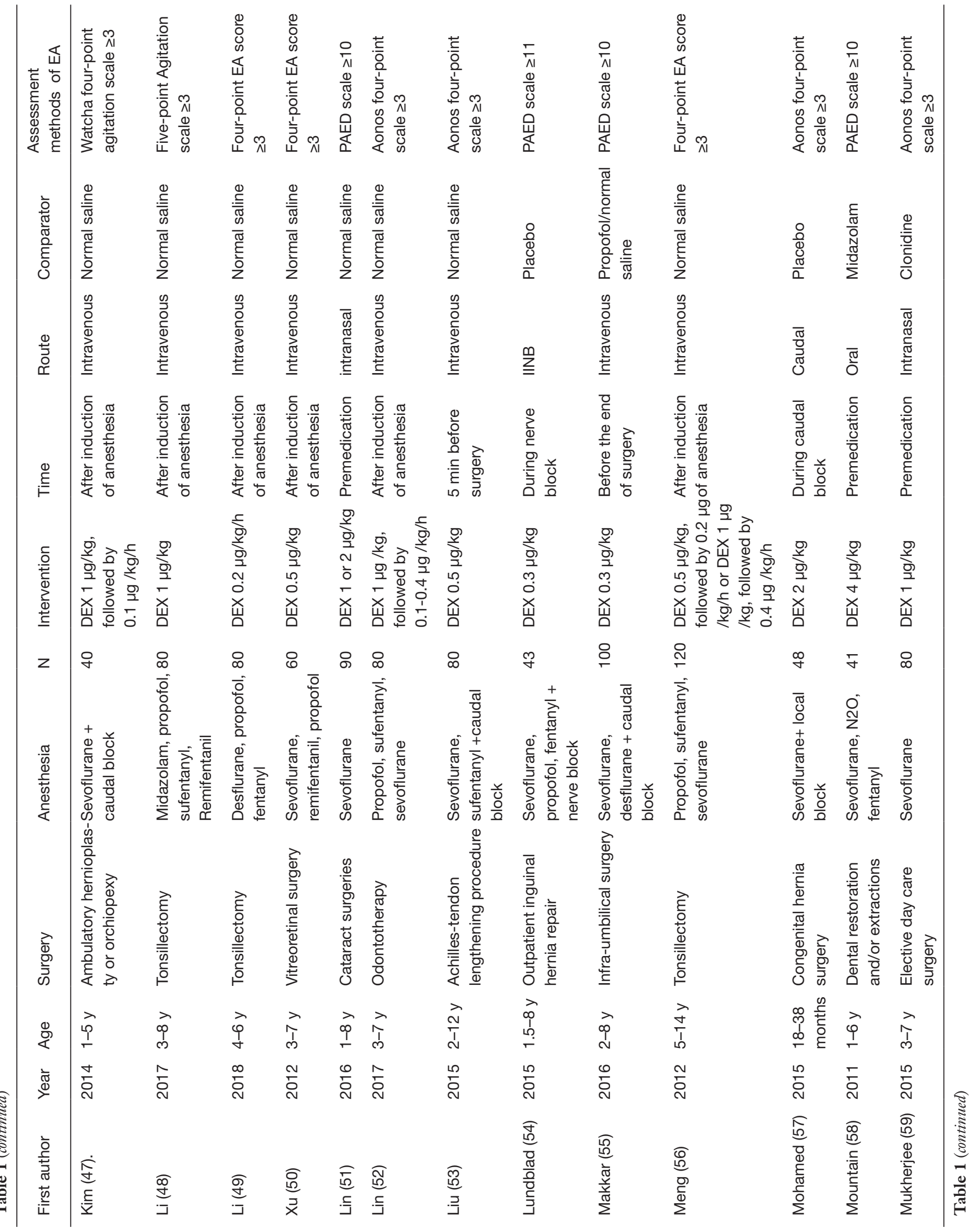




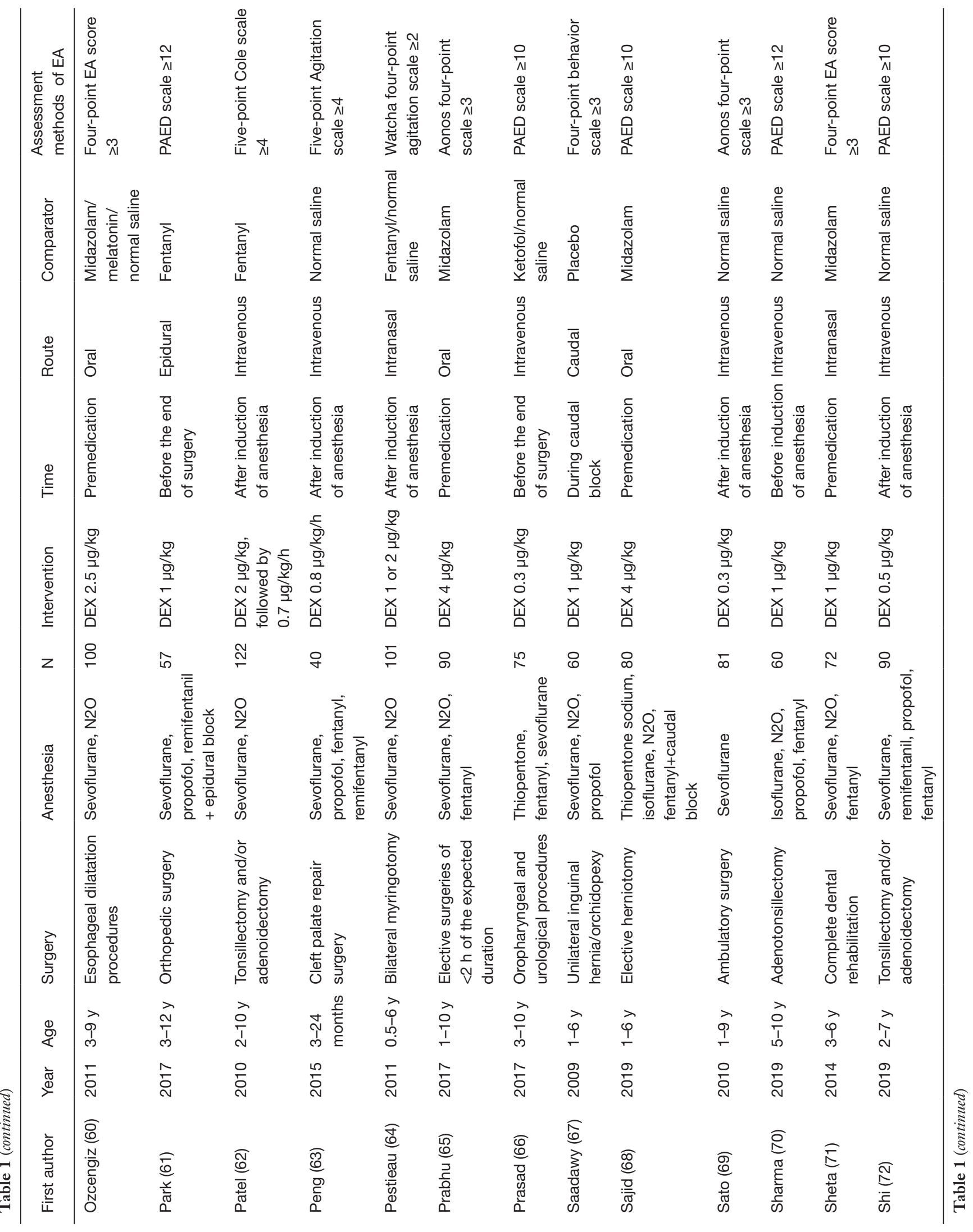




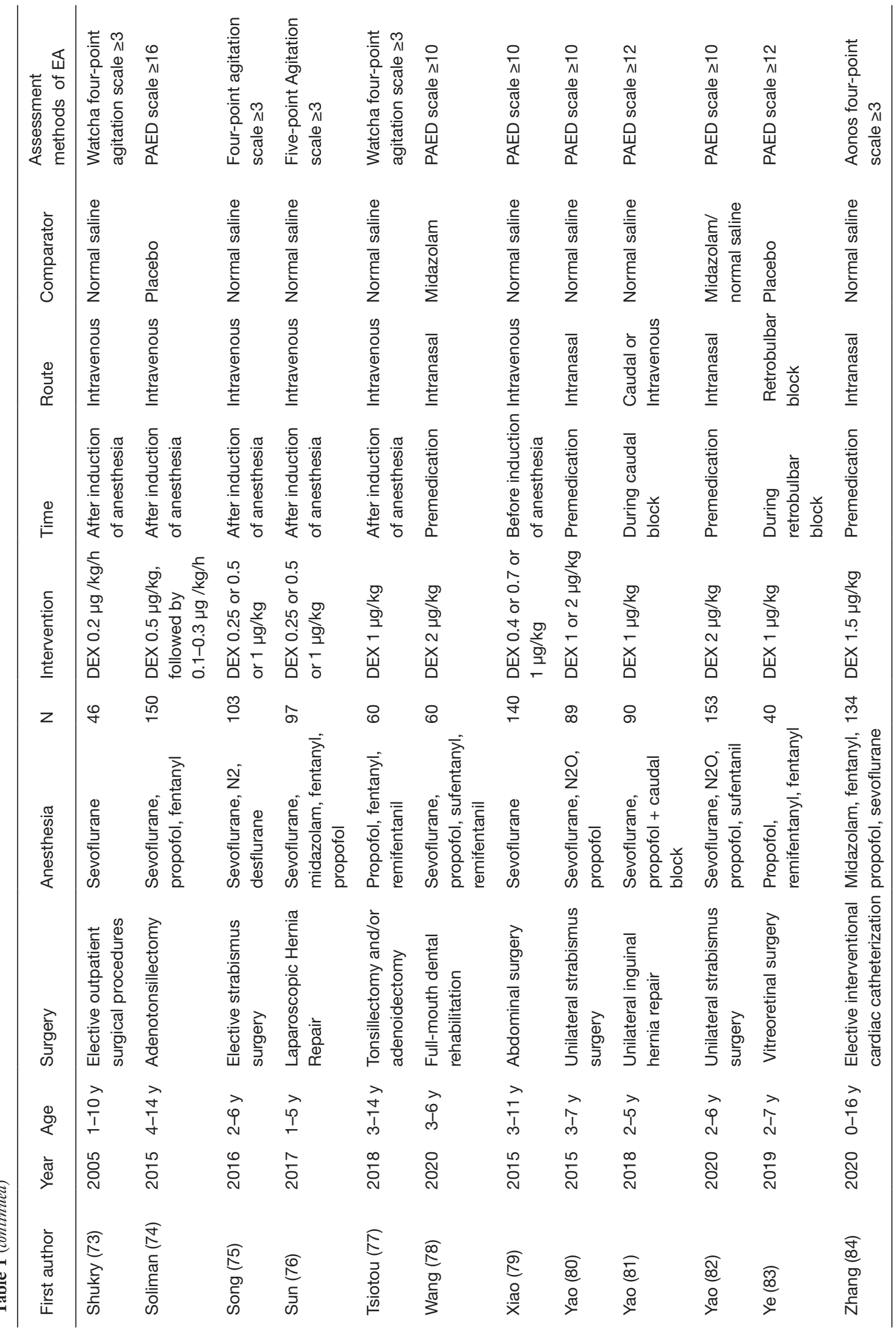



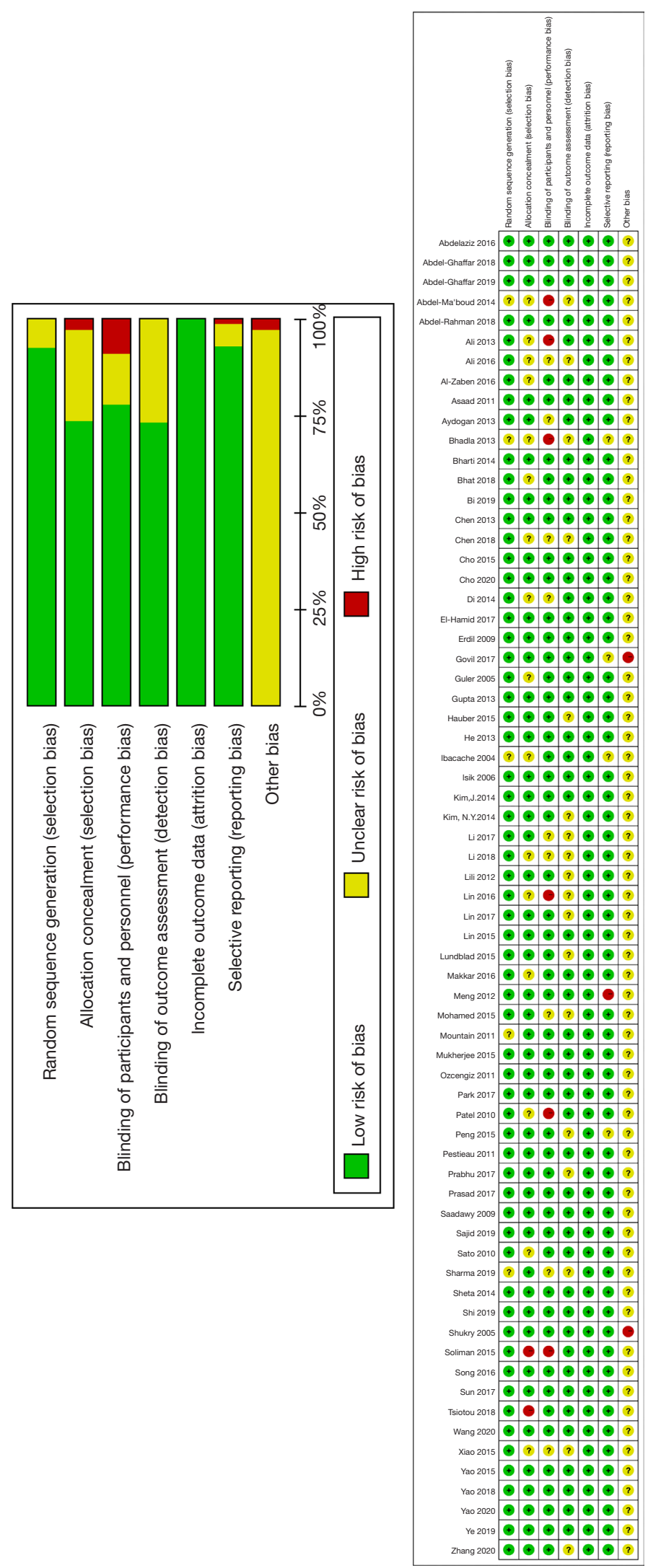

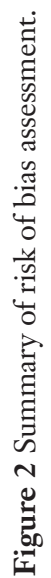




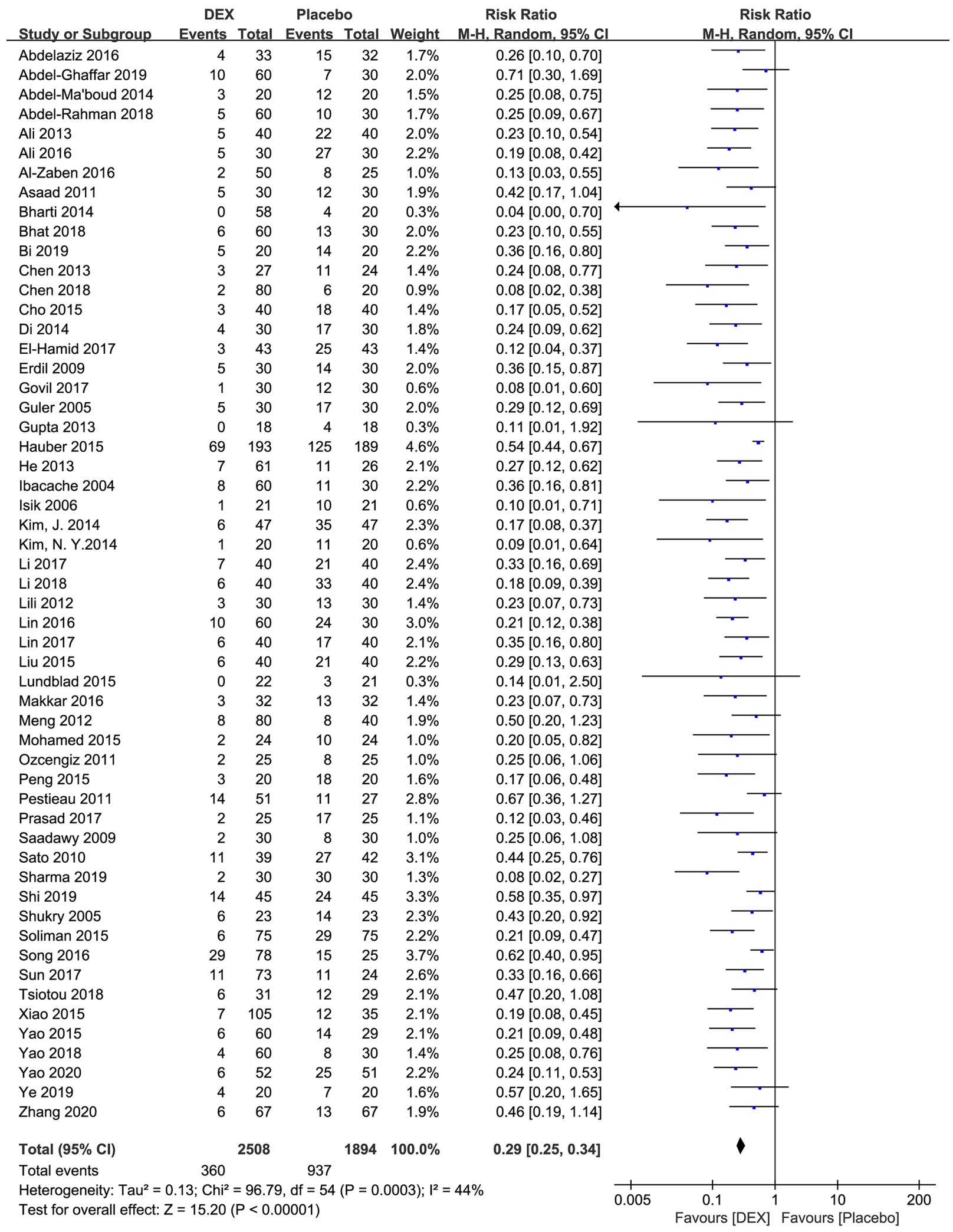

Figure 3 Forest plot for EA incidence: DEX vs. placebo. EA, emergence agitation; DEX, dexmedetomidine. 


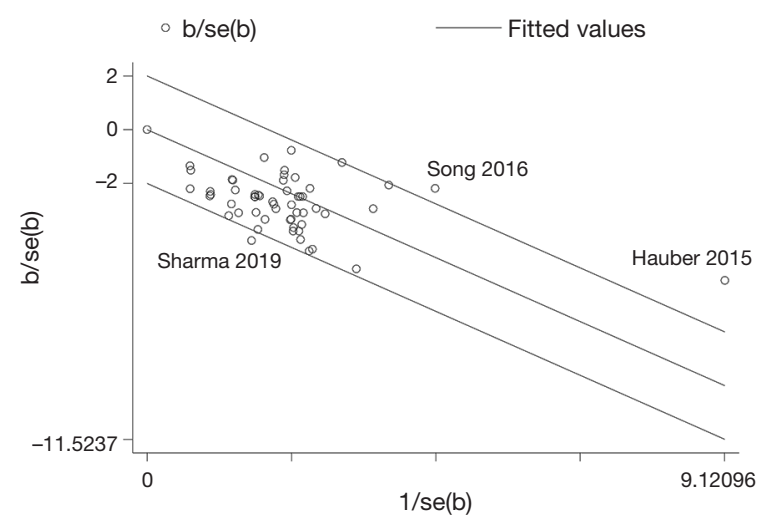

Figure 4 Galbraith plot analysis indicated three studies were the potential source of heterogeneity.

compared the effects of DEX and midazolam on preventing EA. Three hundred ninety-three patients received DEX, and 386 patients received midazolam. The pooled results showed that EA incidence was lower in the DEX group than in the midazolam group (RR 0.34, 95\% CI: $0.25-0.45$, $\mathrm{P}<0.00001, \mathrm{I}^{2}=24 \%$ ) (Figure $8 A$ ). Egger's tests did not suggest publication bias $(\mathrm{P}=0.886)$. Although cumulative $Z$-curves did not reach the IS, TSA's results showed the curves crossed both the conventional boundary and TSMB (Figure 8B, Table 2). It suggested that the level of evidence about the DEX's superiority over midazolam in reducing EA incidence was sufficient. And the GRADE-rated evaluation showed the high quality of evidence (Appendix 1).

Five studies $(26,38,61,62,64)$ compared DEX and fentanyl, three studies $(21,23,55)$ compared DEX and propofol, two studies compared DEX and ketamine $(19,32)$ or ketofol $(24,66)$, respectively, showed no significant differences between them in EA incidence $(\mathrm{P}>0.05)$ (Figure 9). TSA results showed that $Z$-curves did not cross any of the boundaries (Table 2), and further evidence with large sample size is needed. Only one article (59) compared DEX and clonidine and reported that intranasal DEX was more effective than clonidine in decreasing EA incidence and severity, so we could not perform a meta-analysis for trials in the group of clonidine.

\section{Primary outcome 2: severe EA incidence}

Eleven studies $(18,23,32,39,46,51,53,55,72,74,75)$ with 927 patients evaluated severe EA incidence of DEX compared to placebo. A score of 4 was defined to severe EA in the two studies $(46,75)$ that used a 4-point EA scale, while a score of $\geq 15$ was used to define severe EA in the nine studies $(18,23,32,39,51,53,55,72,74)$ that used the PAED scale. The pooled results revealed that DEX significantly reduced severe EA incidence (RR 0.23, 95\% CI: 0.16-0.32, $\mathrm{P}<0.00001$ ) (Figure 10A). No heterogeneity was found for severe EA incidence in the eleven studies $\left(\mathrm{I}^{2}=0 \%, \mathrm{P}=0.97\right)$. Egg's test $(\mathrm{P}=0.171)$ showed that publication bias was not found in the analysis. The TSA proved the $Z$-curves crossed the conventional boundary, TSMB, and reached IS (calculated as 657). TSA of pooled meta-analysis had firm evidence for the anticipated intervention effect (Figure 10B, Table 2). GRADE evidence for severe EA incidence within all included studies was strong (Appendix 1).

\section{Subgroup analysis}

To further investigate the effects of DEX on EA incidence, we conducted subgroup analyses from four perspectives base on priori hypothesis: different administration routes (intravenous, intranasal, oral, and perineural), different administration time (premedication, after induction of anesthesia, before the end of surgery), different administration patterns (bolus dosage, continuous dosage) and different dose [low dose $(<0.5 \mu \mathrm{g} / \mathrm{kg})$, moderate dose $(\geq 0.5,<1 \mu \mathrm{g} / \mathrm{kg})$, and high dose $(\geq 1 \mu \mathrm{g} / \mathrm{kg})]$. The subgroup analysis results are shown in Table 3.

\section{Different administration routes}

Our study suggested that DEX effectively decreased the incidence of EA when administered through intravenous (RR 0.29, 95\% CI: $0.24-0.35, \mathrm{P}<0.00001, \mathrm{I}^{2}=47 \%$ ), intranasal (RR 0.29, 95\% CI: 0.20-0.43, P<0.00001, $\mathrm{I}^{2}=45 \%$ ) and perineural route (RR 0.24; 95\% CI: 0.14-0.41, $\left.\mathrm{P}<0.00001, \mathrm{I}^{2}=0 \%\right)$. However, there was no significant difference when DEX administered orally (RR 0.50; 95\% CI: $0.18-1.34, \mathrm{P}=0.17, \mathrm{I}^{2}=35 \%$ ) (Figure S1, Table 3). TSA revealed firm evidence for the intravenous, intranasal, and perineural subgroup (Table 2). GRADE for intravenous, intranasal, and oral subgroups showed the moderate quality of evidence due to publication bias, inconsistency, imprecision, respectively. It should be noted the results for EA incidence were more robust with high GRADE evidence when DEX was administered through the perineural route (Appendix 1).

\section{Different administration timing}

Added subgroup analyses were performed for different administration timing. The pooled results showed that using DEX decreases EA incidence regardless of the 


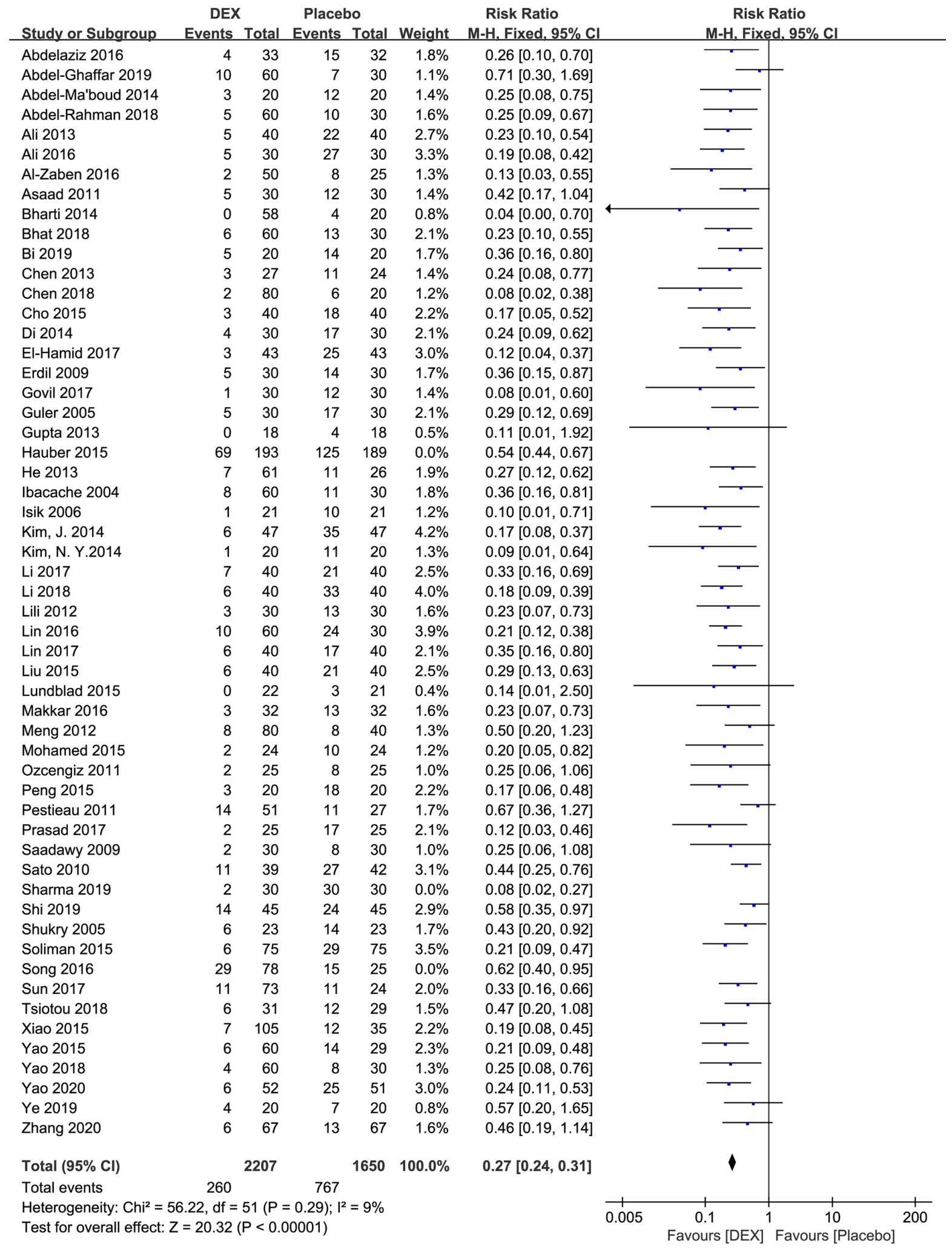

Figure 5 Forest plot for EA incidence after sensitivity analysis. EA, emergence agitation. 
timing when administered preoperatively (RR $0.27,95 \%$ CI: $\left.0.20-0.36, \mathrm{P}<0.00001, \mathrm{I}^{2}=20 \%\right)$, after induction of anesthesia (RR 0.30, 95\% CI: 0.25-0.37, P<0.00001, $\mathrm{I}^{2}=35 \%$ ), and before the end of surgery (RR $0.26,95 \%$ CI: 0.16-0.43, $\mathrm{P}<0.00001, \mathrm{I}^{2}=66 \%$ ) (Figure S2, Table 3). TSA showed Z-curves crossed TSMB and reached the IS for premedication and 'after induction of anesthesia' subgroup; needed IS was not reached in 'before the end of surgery' subgroup Z-curve crossed TSMB. Therefore, TSA revealed

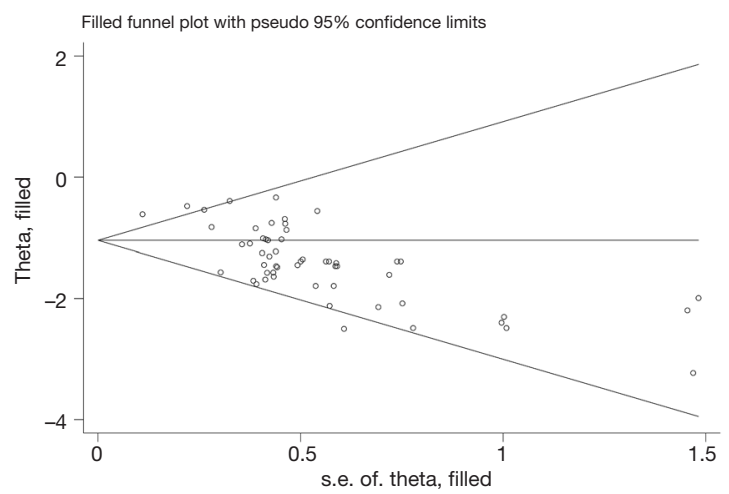

Figure 6 Filled funnel plots for publication bias test of EA incidence. EA, emergence agitation. firm evidence for each subgroup (Table 2). The GRADErated evaluation showed the moderate and low quality of evidence for after-induction and before-the-end-ofsurgery administration, respectively. However, the GRADE evidence for premedication was of high quality (Appendix 1).

\section{Different administration patterns}

Further subgroup analysis was performed according to the DEX administration patterns. Compared with placebo, DEX administered as bolus dosage (RR 0.30, 95\% CI: $\left.0.25-0.36, \mathrm{P}<0.00001, \mathrm{I}^{2}=46 \%\right)$ or as continuous dosage $(\mathrm{RR}$ 0.25, 95\% CI: $\left.0.18-0.33, \mathrm{P}<0.00001, \mathrm{I}^{2}=0 \%\right)$ significantly reduced EA incidence (Figure S3, Table 3). TSA showed $Z$-curves reached the IS and crossed TSMB for both patterns (Table 2). GRADE evidence for bolus dosage subgroup showed low due to inconsistency and publication bias (Egger's tests $\mathrm{P}=0.000$ ). However, GRADE for the continuous dosage subgroup had high-quality evidence, showing that the beneficial effects of continuous DEX on EA incidence were more reliable (Appendix 1).

\section{Different administration dose}

To further investigate the effect of DEX on EA incidence, we perform additional subgroup analysis according to the different DEX dose for intravenous administration.

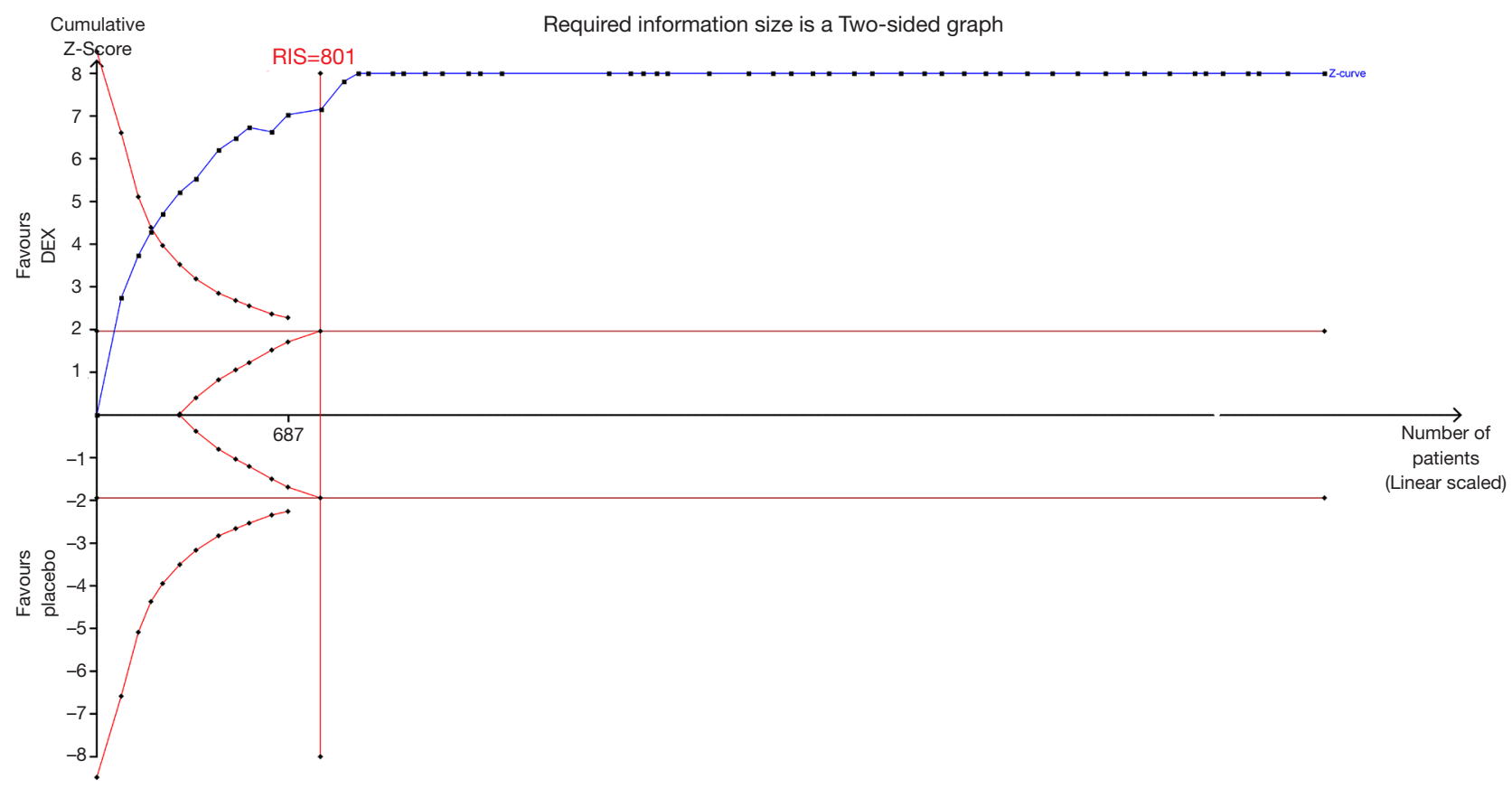

Figure 7 Trial sequential analyses for EA incidence: DEX vs. placebo. EA, emergence agitation; DEX, dexmedetomidine. 
Table 2 TSA for subgroup analysis of EA incidence and secondary outcomes

\begin{tabular}{|c|c|c|c|c|c|c|c|c|c|}
\hline Outcomes/subgroup & RRR\% (MD) & IIA\% (Variance) & ICA\% & $D^{2} \%$ & Required IS & Reach IS & Cross TSMB & Cross FB & Evidence \\
\hline \multicolumn{10}{|l|}{ Dichotomous outcomes } \\
\hline \multicolumn{10}{|l|}{ Incidence of EA } \\
\hline DEX vs. placebo & 30 & 34.63 & 49.47 & 57 & 801 & Yes & Yes & No & FE \\
\hline \multicolumn{10}{|l|}{ Different administration routes } \\
\hline Intranasal & 30 & 33.01 & 47.16 & 47 & 716 & No & Yes & No & $\mathrm{FE}$ \\
\hline Oral & 30 & 19.09 & 27.27 & 45 & 1,508 & No & No & No & $\mathrm{AE}$ \\
\hline Perineural & 30 & 22.00 & 31.43 & 0 & 692 & Yes & Yes & No & $\mathrm{FE}$ \\
\hline \multicolumn{10}{|l|}{ Different administration timing } \\
\hline \multicolumn{10}{|l|}{ Different administration patterns } \\
\hline Bolus dosage & 30 & 34.27 & 48.96 & 59 & 870 & Yes & Yes & No & $\mathrm{FE}$ \\
\hline Continuous dosage & 30 & 35.97 & 51.39 & 0 & 325 & Yes & Yes & No & $\mathrm{FE}$ \\
\hline \multicolumn{10}{|l|}{ Different administration dose } \\
\hline Low dose & 30 & 39.22 & 56.03 & 56 & 624 & Yes & Yes & No & FE \\
\hline Medium dose & 30 & 34.60 & 49.43 & 67 & 1,068 & Yes & Yes & No & $\mathrm{FE}$ \\
\hline High dose & 30 & 31.99 & 45.70 & 0 & 397 & Yes & Yes & No & FE \\
\hline \multicolumn{10}{|l|}{ Incidence of severe EA } \\
\hline DEX vs. placebo & 30 & 22.83 & 32.62 & 0 & 657 & Yes & Yes & No & FE \\
\hline \multicolumn{10}{|l|}{ Patients requiring rescue analgesia } \\
\hline DEX vs. placebo & 30 & 26.18 & 37.40 & 87 & 4,217 & No & Yes & No & $\mathrm{FE}$ \\
\hline DEX vs. midazolam & 30 & 11.07 & 15.82 & 0 & 1,620 & No & No & No & $\mathrm{AE}$ \\
\hline DEX vs. fentanyl & 30 & 21.68 & 30.97 & 0 & 706 & No & No & No & $\mathrm{AE}$ \\
\hline \multicolumn{10}{|l|}{ Incidence of PONV } \\
\hline DEX vs. placebo & 30 & 11.99 & 17.13 & 0 & 1,479 & Yes & Yes & No & FE \\
\hline DEX vs. midazolam & 30 & 8.67 & 12.38 & 0 & 2,149 & No & No & No & $\mathrm{AE}$ \\
\hline DEX vs. ketamine & 30 & 23.33 & 33.33 & 89 & 5,584 & No & No & No & $\mathrm{AE}$ \\
\hline Incidence of hypotension & -30 & 2.95 & 2.27 & 0 & 17,259 & No & No & No & $\mathrm{AE}$ \\
\hline
\end{tabular}

Table 2 (continued) 
Table 2 (continued)

\begin{tabular}{|c|c|c|c|c|c|c|c|c|c|}
\hline Outcomes/subgroup & RRR\% (MD) & IIA\% (Variance) & ICA\% & $D^{2} \%$ & Required IS & Reach IS & Cross TSMB & Cross FB & Evidence \\
\hline \multicolumn{10}{|l|}{ Continuous outcomes } \\
\hline \multicolumn{10}{|l|}{ Emergence time } \\
\hline DEX vs. placebo & 2.48 & 5.41 & - & 97 & 1,054 & Yes & Yes & No & $\mathrm{FE}$ \\
\hline DEX vs. fentanyl & -0.10 & 14.44 & - & 83 & 286,217 & No & No & No & $\mathrm{AE}$ \\
\hline Discharge time from PACU & & & - & & & & & & \\
\hline DEX vs. placebo & -0.75 & 36.06 & - & 99 & 176,960 & No & No & No & $\mathrm{AE}$ \\
\hline DEX vs. midazolam & -0.94 & 31.10 & - & 0 & 1,107 & No & No & No & $\mathrm{AE}$ \\
\hline
\end{tabular}

TSA, trial sequential analysis; EA, emergence agitation; RRR, relative risk reduction; IIA, the incidence in the intervention arm; ICA, the incidence in the control arm; $D^{2}$, diversity; IS, information size; TSMB, trial sequential monitoring boundary; FB, futility boundary; FE, firm evidence; AE, absent evidence; MD, mean difference. Error a and $1-\beta$ were defined as $5 \%$ and $80 \%$, respectively, in each model; For dichotomous data, RRR was defined as $30 \%$, ICA was calculated from the average incidence in the control group, $D^{2}$ was set as model variance-based; For continuous data, MD and Variance were calculated from the low risk of bias studies, $D^{2}$ was set as model variance-based.

The pooled results showed that low (RR $0.33,95 \%$ CI: 0.24-0.45, $\mathrm{P}<0.00001, \mathrm{I}^{2}=51 \%$ ), medium (RR 0.38, 95\% CI: $\left.0.29-0.50, \mathrm{P}<0.00001, \mathrm{I}^{2}=45 \%\right)$ or high dose (RR $0.24,95 \%$ CI: $\left.0.18-0.31, \mathrm{P}<0.00001, \mathrm{I}^{2}=0 \%\right)$ of $\mathrm{DEX}$ could significantly reduce the incidence of EA (Figure S4, Table 3). There is a significant difference among the three subgroups $(\mathrm{P}=0.04)$, suggesting that the high dose of DEX may be more effective in reducing EA incidence. TSA showed Z-curves crossed TSMB and reached the IS for all three subgroups (Table 2). GRADE evidence for the low and medium dose of DEX showed low quality due to inconsistency and publication bias. While GRADE for high dose DEX was classified as moderate-quality evidence (Appendix 1).

\section{Relationship between the dose of DEX and incidence of $E A$}

Nine studies reported the incidence of EA according to the different dose of DEX compared to placebo $(22,30,33,43,44,56,75,76,79)$. We conducted a metaregression analysis to show the relationship between the dose of DEX and EA incidence, which revealed statistically significant evidence for an association between the log risk ratio for EA and the dose of DEX ( $\mathrm{P}=0.013)$ (Figure 11). This underlines that the incidence of EA decreases as the dose of DEX increases.

\section{Secondary outcomes}

\section{Emergence time}

Compared with placebo, DEX had a significantly delayed effect on emergence time in children (MD 2.28, 95\% CI: 1.49-3.08, $\mathrm{P}<0.00001, \mathrm{I}^{2}=97 \%$ ) (Table 4). The TSA showed $\mathrm{Z}$-curves reached the IS and crossed the TSMB (Table 2). However, the quality of evidence was judged to be exceptionally low due to serious inconsistency and publication bias (Egger's tests $\mathrm{P}=0.000$ ) (Appendix 1). The pooled results revealed no significant differences between DEX and midazolam (MD 0.45, 95\% CI: $-1.45-2.35$, $\mathrm{P}=0.64, \mathrm{I}^{2}=96 \%$ ) or fentanyl (MD $-0.46,95 \% \mathrm{CI}:-1.94-$ $1.02, \mathrm{P}=0.54, \mathrm{I}^{2}=80 \%$ ) (Table 4) while lacking firm evidence by TSA (Table 2) and very low quality (Appendix 1).

\section{Time to discharge from PACU}

Compared with midazolam, DEX significantly reduced the time to discharge from the PACU (MD -0.94, 95\% CI: $-1.82-0.06, \mathrm{P}=0.04, \mathrm{I}^{2}=0 \%$ ) (Table 4 ). The TSA showed $\mathrm{Z}$-curves crossed the conventional boundary for benefit but did not cross both TSMB and IS (Table 2). It might reveal a possible false-positive effect of DEX in 


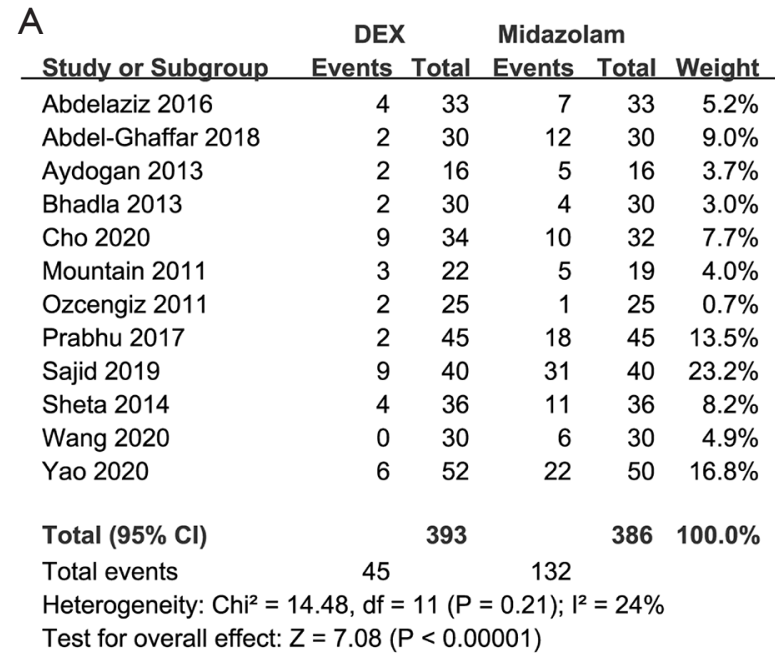

Risk Ratio Risk Ratio

M-H, Fixed, 95\% Cl

$0.57[0.18,1.77]$

$0.17[0.04,0.68]$

$0.40[0.09,1.77]$

$0.50[0.10,2.53]$

$0.85[0.40,1.81]$

$0.52[0.14,1.89]$

$2.00[0.19,20.67]$

$0.11[0.03,0.45]$

$0.29[0.16,0.53]$

$0.36[0.13,1.04]$

$0.08[0.00,1.31]$

$0.26[0.12,0.59]$

$0.34[0.25,0.45]$

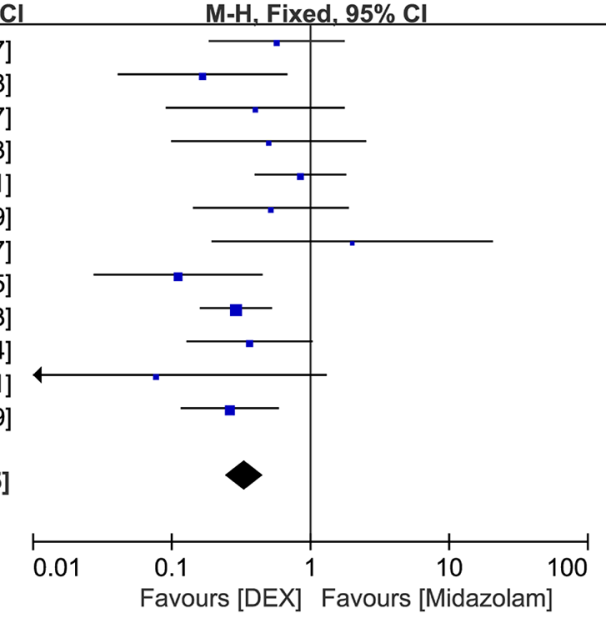

B

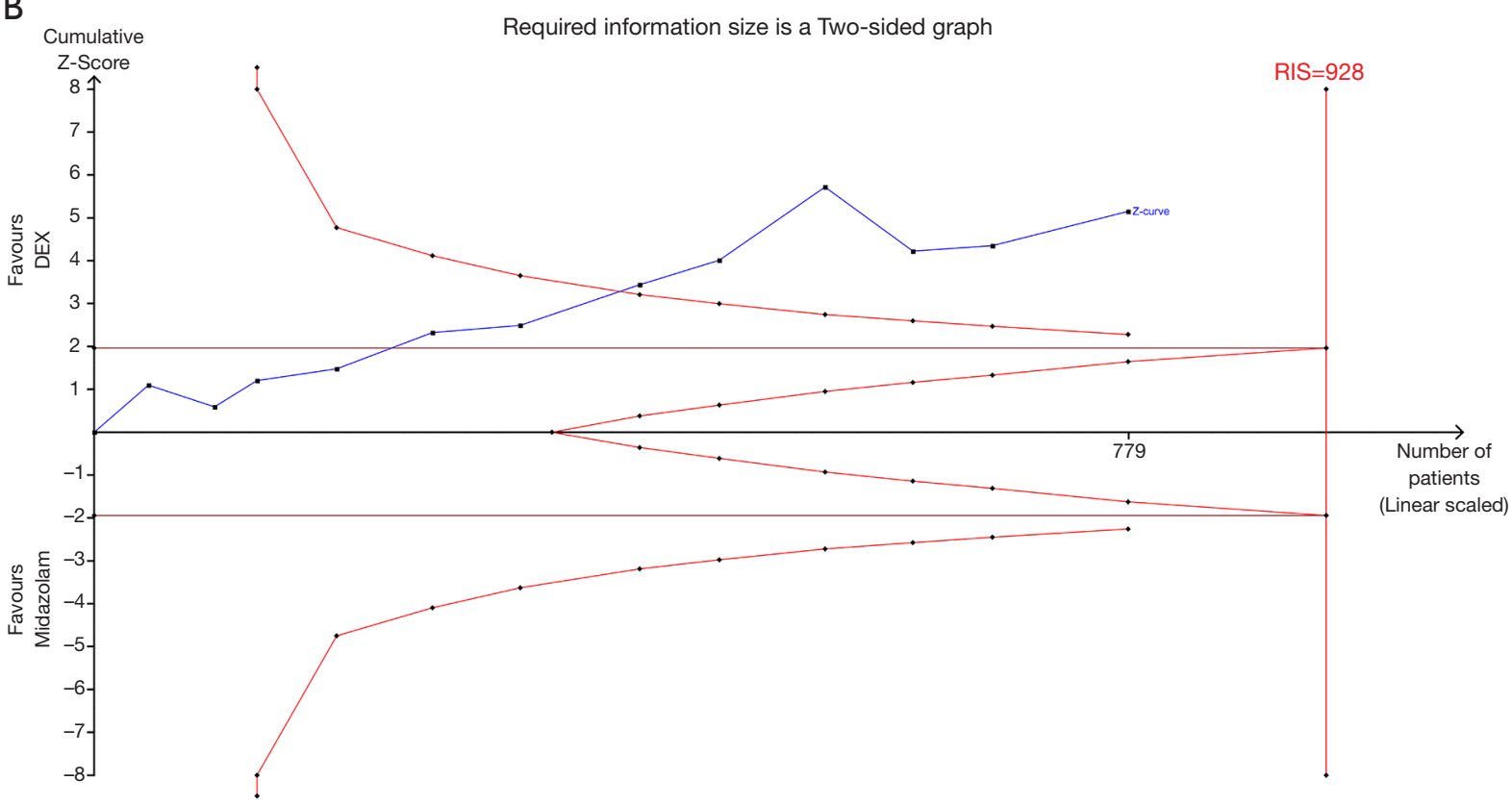

Figure 8 EA incidence: DEX vs. midazolam. (A) forest plot for EA incidence. (B) trial sequential analyses for EA incidence. EA, emergence agitation; DEX, dexmedetomidine.

reducing the time to discharge from the PACU compared to midazolam. GRADE quality of evidence was moderate due to imprecision (Appendix 1). No significant differences were observed between the DEX and placebo (MD 1.27, 95\% CI: $\left.-2.43-4.96, \mathrm{P}=0.50, \mathrm{I}^{2}=99 \%\right)$ or fentanyl (MD 3.68, 95\% CI: $-3.00-10.37, \mathrm{P}=0.28, \mathrm{I}^{2}=63 \%$ ) (Table 4), while lacking firm evidence by TSA (Table 2). The quality of evidence was graded as very low for the placebo group and low for the fentanyl group (Appendix 1).
The number of patients requiring rescue analgesia

Compared with placebo, the number of patients requiring rescue analgesia was significantly lower in the DEX group (RR 0.43, 95\% CI: 0.31-0.59, P<0.00001, $\mathrm{I}^{2}=77 \%$ ) (Table 4). TSA showed that although the pooled sample size did not exceed the IS, the Z-curve crossed the conventional boundary and TSMB (Table 2). However, the GRADE quality of evidence was low due to inconsistency and publication bias (Egger's tests $\mathrm{P}=0.002$ ) (Appendix 1). We also 


\begin{tabular}{|c|c|c|c|c|c|c|c|c|c|c|}
\hline Study or Subgroup & $\begin{array}{l}\text { DEX } \\
\text { Events }\end{array}$ & Total & $\begin{array}{l}\text { fentan } \\
\text { Events }\end{array}$ & $\begin{array}{l}\text { yl } \\
\text { Total }\end{array}$ & Weight & $\begin{array}{l}\text { Risk Ratio } \\
\text { M-H, Random. } 95 \% \text { Cl }\end{array}$ & & $\begin{array}{r}\text { Risk } \\
\text { M-H, Rand }\end{array}$ & $\begin{array}{l}\text { Ratio } \\
\text { dom, } 95 \% \mathrm{Cl}\end{array}$ & \\
\hline Asaad 2011 & 5 & 30 & 6 & 28 & $18.2 \%$ & $0.78[0.27,2.27]$ & & - & & \\
\hline Erdil 2009 & 5 & 30 & 4 & 30 & $15.7 \%$ & $1.25[0.37,4.21]$ & & & & \\
\hline Park 2017 & 5 & 28 & 8 & 29 & $19.8 \%$ & $0.65[0.24,1.74]$ & & & & \\
\hline Patel 2010 & 11 & 61 & 28 & 61 & $29.4 \%$ & $0.39[0.22,0.72]$ & & - & & \\
\hline Pestieau 2011 & 14 & 51 & 3 & 23 & $16.8 \%$ & $2.10[0.67,6.62]$ & & & & \\
\hline Total $(95 \% \mathrm{Cl})$ & & 200 & & 171 & $100.0 \%$ & $0.78[0.42,1.44]$ & & & & \\
\hline Total events & 40 & & 49 & & & & & & & \\
\hline \multicolumn{7}{|c|}{$\begin{array}{l}\text { Heterogeneity: } \mathrm{Tau}^{2}=0.24 ; \mathrm{Chi}^{2}=8.00, \mathrm{df}=4(P=0.09) ; I^{2}=50 \% \\
\text { Test for overall effect: } Z=0.79(P=0.43)\end{array}$} & 0.01 & $\begin{array}{l}0.1 \\
\text { Favours [DEX] }\end{array}$ & $\begin{array}{lr}1 & 1 \\
& \end{array}$ & 10100 \\
\hline
\end{tabular}

\begin{tabular}{|c|c|c|c|c|c|}
\hline \multirow[b]{2}{*}{ Study or Subgroup } & \multirow{2}{*}{$\begin{array}{r}\text { DEX } \\
\text { Events }\end{array}$} & \multicolumn{3}{|c|}{ Propofol } & \multirow[b]{2}{*}{ Weight } \\
\hline & & Total & Events & Total & \\
\hline Abdel-Ma'boud 2014 & 3 & 20 & 4 & 20 & $18.4 \%$ \\
\hline Ali 2013 & 5 & 40 & 13 & 40 & $59.9 \%$ \\
\hline Makkar 2016 & 3 & 32 & 5 & 36 & $21.7 \%$ \\
\hline Total $(95 \% \mathrm{Cl})$ & & 92 & & 96 & $100.0 \%$ \\
\hline Total events & 11 & & 22 & & \\
\hline $\begin{array}{l}\text { Heterogeneity: } \mathrm{Chi}^{2}= \\
\text { Test for overall effect }\end{array}$ & $\begin{array}{l}82, \mathrm{df}=2 \\
=1.97(\mathrm{P}\end{array}$ & $\begin{array}{l}(P=0 \\
=0.05\end{array}$ & $66) ;\left.\right|^{2}=($ & & \\
\hline
\end{tabular}
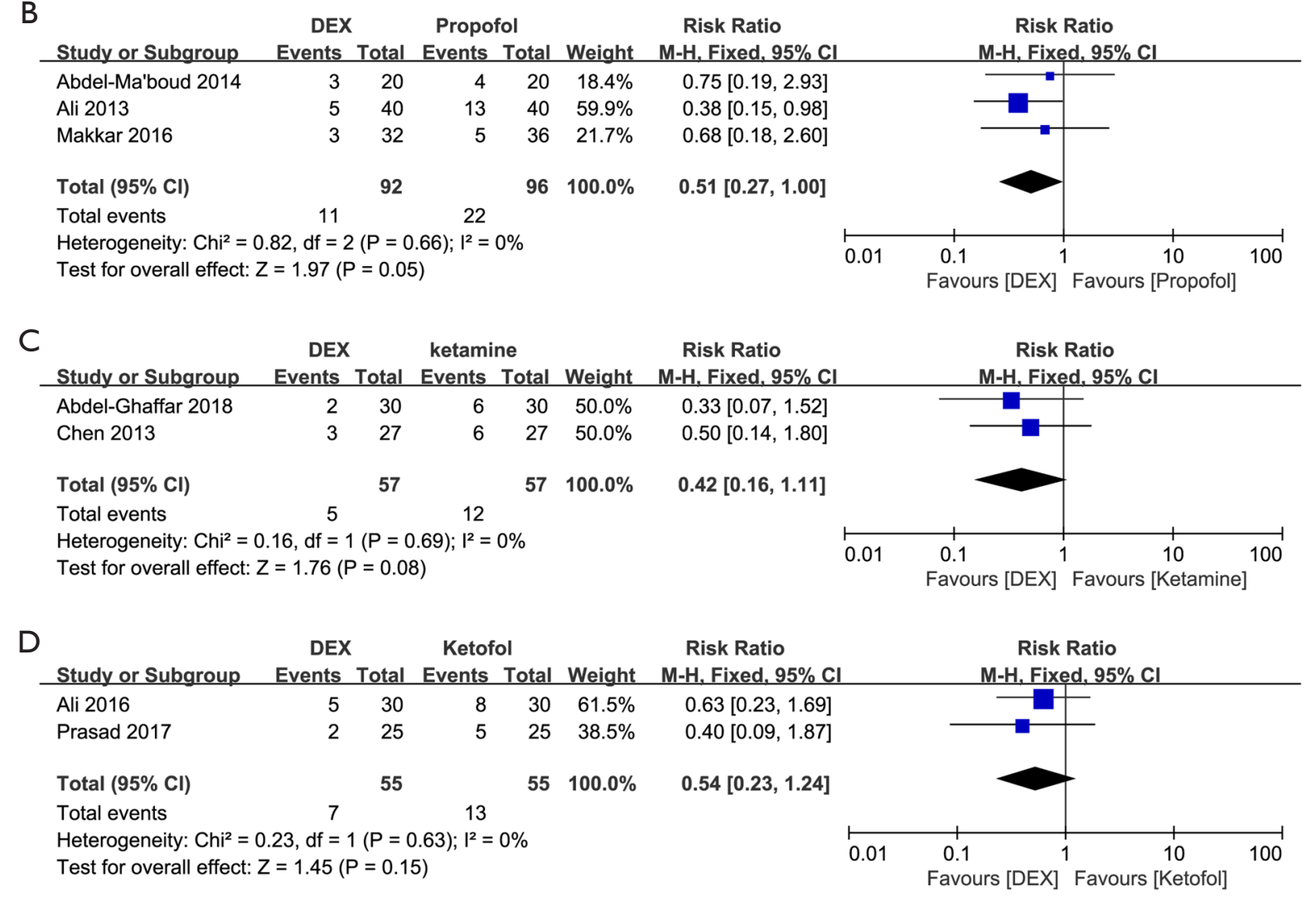

Figure 9 Forest plot for EA incidence: DEX vs. other active comparators. (A) DEX vs. fentanyl. (B) DEX vs. propofol. (C) DEX vs. ketamine. (D) DEX vs. ketofol. EA, emergence agitation; DEX, dexmedetomidine.

found the proportion of patients requiring rescue analgesia was significantly lower in the DEX group compared with midazolam (RR $0.58,95 \%$ CI: $0.36-0.94, \mathrm{P}=0.03, \mathrm{I}^{2}=0 \%$ ) or fentanyl (RR 0.39, 95\% CI: 0.22-0.66, $\mathrm{P}=0.0005, \mathrm{I}^{2}=0 \%$ ) (Table 4). However, TSA revealed an absence of evidence (Table 2) with moderate quality (Appendix 1).

\section{Incidence of PONV}

The pooled results showed that DEX reduced the incidence of PONV compared to placebo (RR 0.43, 95\% CI: 0.33$0.55, \mathrm{P}<0.00001, \mathrm{I}^{2}=0 \%$ ) (Table 4). The TSA showed the Z-curves crossed the conventional boundary, TSMB, and IS (calculated as 1,479). TSA of pooled meta-analysis had firm evidence for the expected intervention effect (Table 2), while GRADE evidence was strong (Appendix 1). We also found the incidence of PONV was significantly lower in the DEX subgroup compared with the midazolam subgroup (RR 0.48, 95\% CI: $0.27-0.85, \mathrm{P}=0.01, \mathrm{I}^{2}=0 \%$ ) (Table 4). However, 


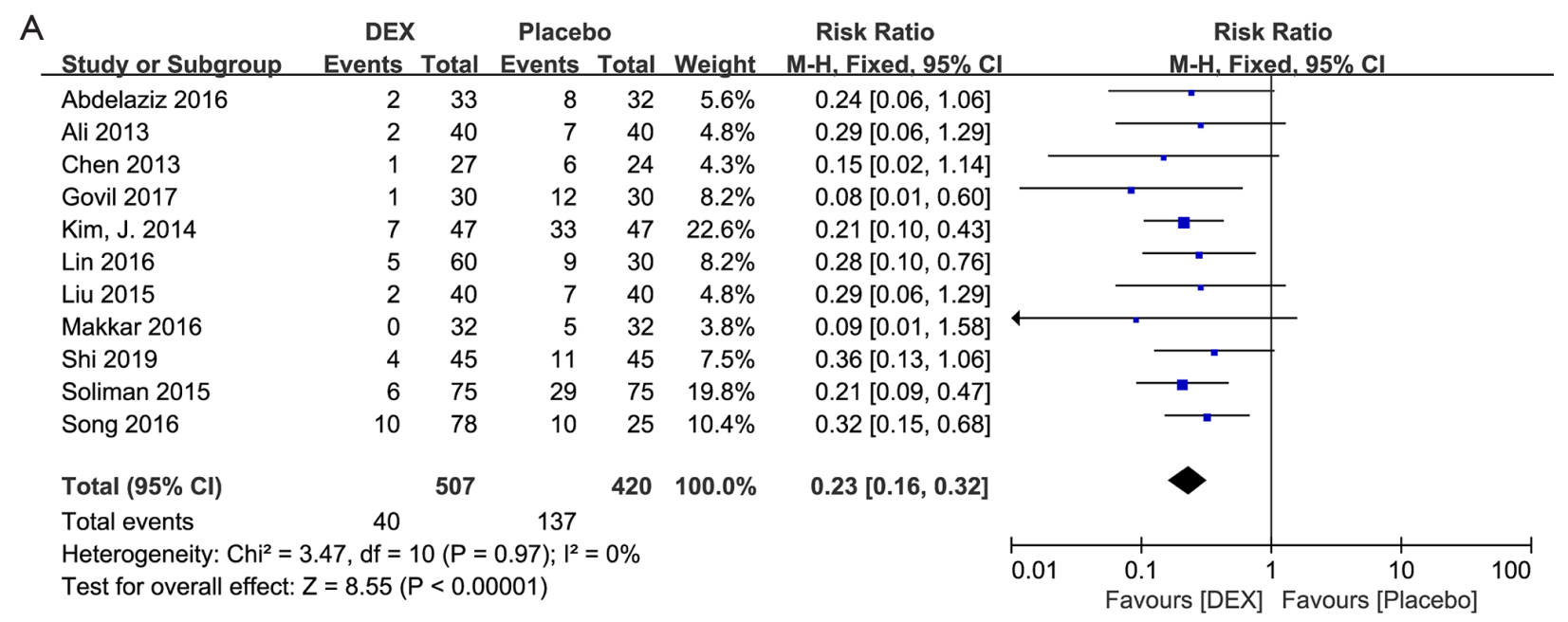

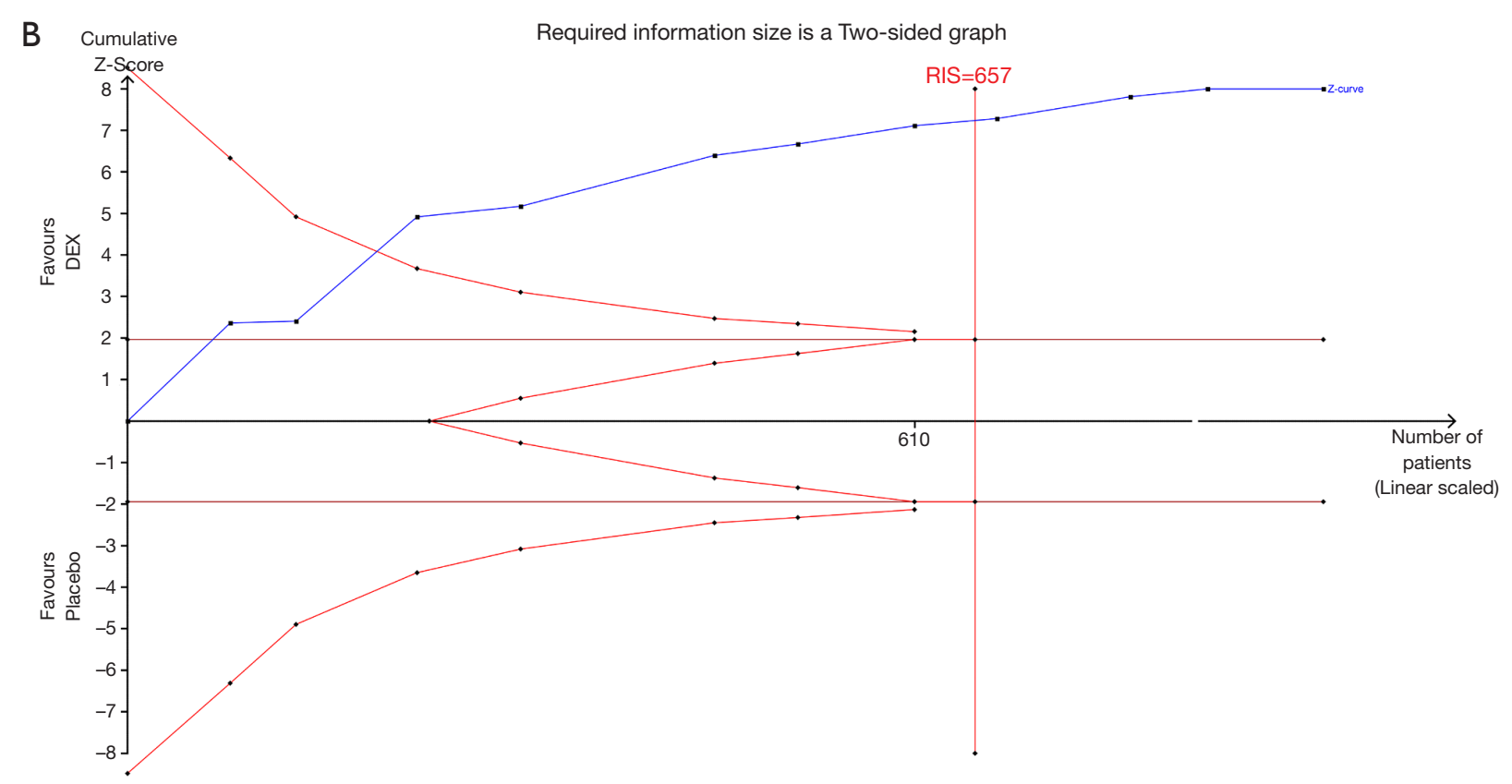

Figure 10 Severe EA incidence: DEX vs. placebo. (A) forest plot for severe EA incidence. (B) trial sequential analyses for severe EA incidence. EA, emergence agitation; DEX, dexmedetomidine.

TSA showed an absence of evidence for this result (Table 2). There was no significant difference between DEX and ketamine (RR 0.58, 95\% CI: 0.19-1.82, P=0.35, $\mathrm{I}^{2}=69 \%$ ) (Table 4), while lacking firm evidence by TSA (Table 2) and low quality (Appendix 1).

\section{Incidence of hypertension}

Twenty studies (20,22,23,29,37-42,45,46,51,53,57,70,74,8082 ) including 1,868 patients showed there was no difference in hypotension incidence between DEX and placebo group (RR 1.50, 95\% CI: 0.90-2.50, $\mathrm{P}=0.12, \mathrm{I}^{2}=0 \%$ ) (Table 4). The results are lacking firm evidence in TSA (Table 2), and quality of evidence was graded as low due to serious imprecision (Appendix 1).

\section{Incidence of bradycardia}

Twenty-six studies with 2,333 patients were included in the present meta-analysis for incidence of bradycardia. 
Table 3 Subgroup analysis results

\begin{tabular}{|c|c|c|c|c|c|c|c|}
\hline Outcomes/subgroup & $\begin{array}{l}\text { No. of } \\
\text { studies }\end{array}$ & $\begin{array}{c}\text { No. of } \\
\text { participants }\end{array}$ & Heterogeneity & Model of pool & Effect size (95\% Cl:) & $P$ value & $\begin{array}{l}\text { Subgroup } \\
\text { Difference }\end{array}$ \\
\hline Different administration routes & & & & & & & $P=0.65$ \\
\hline Intranasal & 8 & 685 & $I^{2}=45 \%$ & Random effect & RR $0.29[0.20,0.43]$ & $<0.00001$ & \\
\hline Different administration timing & & & & & & & $P=0.71$ \\
\hline Premedication & 11 & 941 & $I^{2}=20 \%$ & Random effect & RR $0.27[0.20,0.36]$ & $<0.00001$ & \\
\hline After induction of anesthesia & 36 & 2,615 & $\mathrm{I}^{2}=35 \%$ & Random effect & RR $0.30[0.25,0.37]$ & $<0.00001$ & \\
\hline Continuous dosage & 12 & 837 & $\mathrm{I}^{2}=0 \%$ & Random effect & RR $0.25[0.18,0.33]$ & $<0.00001$ & \\
\hline Different administration dose & & & & & & & $P=0.04$ \\
\hline Low dose & 15 & 972 & $I^{2}=51 \%$ & Random effect & RR $0.33[0.24,0.45]$ & $<0.00001$ & \\
\hline Medium dose & 16 & 1,427 & $I^{2}=45 \%$ & Random effect & RR $0.38[0.29,0.50]$ & $<0.00001$ & \\
\hline High dose & 20 & 1,109 & $\mathrm{I}^{2}=0 \%$ & Random effect & RR $0.24[0.18,0.31]$ & $<0.00001$ & \\
\hline
\end{tabular}

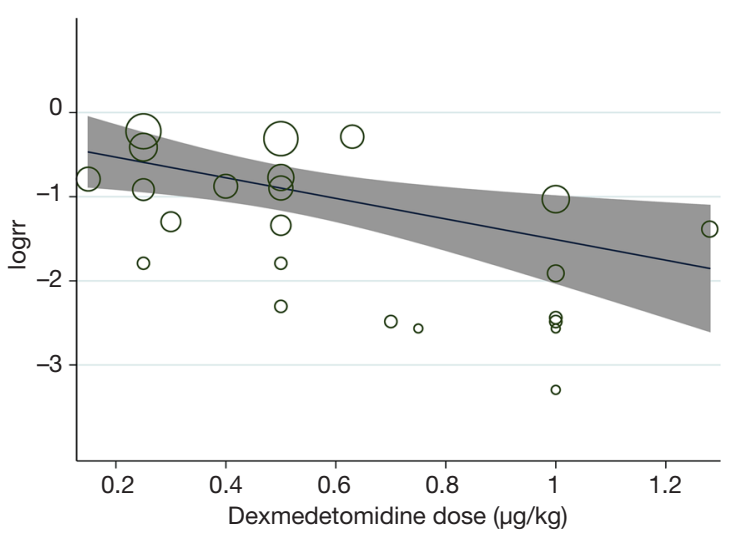

Figure 11 Scatterplot of the relationship between the dose of DEX and Log risk ratio for the incidence of EA. EA, emergence agitation; DEX, dexmedetomidine.

It revealed that DEX was associated with an increased bradycardia incidence compared to placebo (RR 3.47, 95\% CI: $1.86-6.44, \mathrm{P}<0.0001, \mathrm{I}^{2}=0 \%$ ) (Table 4). The TSA showed $\mathrm{Z}$-curves crossed the conventional boundary but did not cross both TSMB and IS (Table 2), and the quality of evidence was graded as very low due to serious imprecision and publication bias (Appendix 1).

\section{Discussion}

To the best of our knowledge, this is the first comprehensive systematic review and meta-analysis of RCTs assessing the effects of different administration and dosage of DEX on EA in children using TSA and GRADE tools. This metaanalysis's main finding can be summarized as follows: (I) DEX could decrease the EA incidence and severe EA incidence after general anesthesia in children with the firm and moderate-to high-quality evidence evaluated by TSA and GRADE. (II) DEX was superior to midazolam for preventing EA in children with the firm and high-quality evidence. (III) Subgroup analyses revealed that, except for oral administration, DEX reduced EA incidence regardless of administration routes, timing, patterns, and doses. However, the firm and high-grade evidence were found only in the perineural route, premedication, continuous dosage, and high dose subgroups. (IV) DEX reduced the incidence of PONV compared to placebo, with firm 
Table 4 Meta-analytic findings of secondary outcomes

\begin{tabular}{|c|c|c|c|c|c|c|}
\hline Outcomes/subgroup & No. of studies & No. of participants & Heterogeneity & Model of pool & Effect size $(95 \% \mathrm{Cl})$ & $P$ value \\
\hline DEX vs. placebo & 45 & 3,451 & $I^{2}=97 \%$ & Random effect & MD $2.28[1.49,3.08]$ & $<0.00001$ \\
\hline DEX vs. midazolam & 6 & 456 & $I^{2}=96 \%$ & Random effect & MD $0.45[-1.45,2.35]$ & 0.64 \\
\hline DEX vs. Fentanyl & 5 & 371 & $I^{2}=80 \%$ & Random effect & MD $-0.46[-1.94,1.02]$ & 0.54 \\
\hline DEX vs. placebo & 31 & 2,725 & $I^{2}=99 \%$ & Random effect & MD $1.27[-2.43,4.96]$ & 0.50 \\
\hline DEX vs. midazolam & 4 & 307 & $I^{2}=0 \%$ & Fixed effect & MD -0.94 [-1.82, -0.06] & 0.04 \\
\hline DEX vs. fentanyl & 3 & 189 & $\mathrm{I}^{2}=63 \%$ & Random effect & MD $3.68[-3.00,10.37]$ & 0.28 \\
\hline \multicolumn{7}{|c|}{ Patients requiring rescue analgesia } \\
\hline DEX vs. fentanyl & 3 & 253 & $I^{2}=0 \%$ & Fixed effect & RR $0.39[0.22,0.66]$ & 0.0005 \\
\hline \multicolumn{7}{|l|}{ Incidence of PONV } \\
\hline DEX vs. placebo & 32 & 2,616 & $\mathrm{I}^{2}=0 \%$ & Fixed effect & $\operatorname{RR} 0.43[0.33,0.55]$ & $<0.00001$ \\
\hline DEX vs. midazolam & 5 & 366 & $I^{2}=0 \%$ & Fixed effect & $\operatorname{RR} 0.48[0.27,0.85]$ & 0.01 \\
\hline DEX vs. ketamine & 3 & 204 & $\mathrm{I}^{2}=69 \%$ & Random effect & RR $0.58[0.19,1.82]$ & 0.35 \\
\hline Incidence of hypotension & 20 & 1,868 & $I^{2}=0 \%$ & Fixed effect & $\operatorname{RR} 1.50[0.90,2.50]$ & 0.12 \\
\hline Incidence of bradycardia & 26 & 2,333 & $\mathrm{I}^{2}=0 \%$ & Fixed effect & RR $3.47[1.86,6.44]$ & $<0.0001$ \\
\hline
\end{tabular}

evidence by TSA and high quality of GRADE. (V) Evidence for DEX's influence on emergence time, time in PACU, rescue analgesia, hypotension, and bradycardia is thus far insufficient to draw any valid conclusion.

The high incidence and extensive harm of EA in children have brought many troubles to clinical practice. Various drugs have been investigated to prevent EA in pediatric patients (2). Earlier network meta-analyses $(85,86)$ suggested that DEX may be the most effective drug to prevent EA in children. At present, the exact mechanism by which DEX reduces the incidence of EA is still poorly understood. Several unique pharmacological properties of DEX may account for this effect. First, unlike other sedatives, DEX does not interfere with physiologic sleep patterns and lacks significant anticholinergic effects (6). Second, DEX has proven to have opioid-sparing properties, and pain is one of the most important risk factors for EA in children (1). Third, recent studies revealed that DEX might have antiinflammatory, organ-protective, and neuroprotective effects, which may play a key role in preventing EA $(1,87,88)$.
The preventive effect of DEX on EA in children has been documented in several meta-analyses (7-13). Although four relevant meta-analyses (7-10) published during 20142015 seemed to confirm the superiority of DEX on EA in children, the limited number of included studies reduced the reliability of outcomes. In 2020, three meta-analyses were conducted to study the effect of DEX on EA in children. Tang et al. (11) included 24 trials and reported that DEX has positive effects on preventing EA in children undergoing general anesthesia with sevoflurane. Yang et al. (12) included 33 studies and revealed using DEX was associated with a reduced incidence of EA in children. Recently, Rao et al. (13) conducted a meta-analysis with 63 trials, which showed the effectiveness of DEX in preventing EA in children. However, including non-randomized case-control and high heterogeneity studies decreased the reliability of the conclusion.

None of these meta-analyses evaluated the evidence quality using either TSA or GRADE tools, which conclusions would be unreliable. Compared with the earlier 
meta-analyses, we added the latest evidence from 67 RCTs and confirmed the beneficial effects of DEX on EA in pediatric patients. Notably, we found that DEX significantly reduced severe EA incidence in children, which is more harmful and requires added drug therapy. Also, in our study, TSA showed firm evidence, and the quality of evidence was graded as moderate to high. Therefore, the evidence from our meta-analysis suffices to support that DEX should be considered for children to prevent EA and severe EA.

Our meta-analysis suggested that DEX was superior to midazolam for preventing EA in children, in line with the findings of Lang et al. (89) and Rao et al. (13). TSA and GRADE results revealed that the level of evidence about the DEX's superiority over midazolam in reducing EA incidence was sufficient. However, compared with fentanyl, propofol, ketamine, or ketofol, DEX did not significantly reduce the $\mathrm{EA}$ incidence. TSA results showed that $\mathrm{Z}$-curves did not cross any of the boundaries, and further evidence with a large sample size is needed.

The European Society of Anaesthesiology suggested that DEX should be used intravenously, intranasally, or epidurally to reduce the risk of EA in children (90). However, no suggestions were given for the best administration, timing, patterns, or dosages of DEX in EA prevention. Therefore, we performed the pre-specified subgroup analyses with different administration routes, timing, patterns, and DEX dosages.

Subgroup analysis revealed that DEX significantly reduced EA incidence when administered intravenously, intranasally, and perineurally. However, no significant difference was found when DEX was administered orally, with only two trials included $(20,60)$. Zhang et al. (7) and Zhu et al. (10) reported that intravenous or intranasal DEX could decrease EA incidence in children undergoing general anesthesia. Our meta-analysis confirmed the beneficial effects of DEX by including a larger number of studies. Interestingly, perineural DEX improved EA incidence with high-quality and firm evidence. DEX was found to supply analgesic effects through supraspinal, ganglionic, spinal, and peripheral actions when it is perineurally administered (91), reducing EA incidence. Andersen et al. (92) reported that perineural DEX could double the nerve block duration better than intravenous administration.

A recent meta-analysis (93) showed that caudal DEX could prolong postoperative analgesia with less pain and decrease intraoperative end-tidal sevoflurane concentration. Collectively, combining this study with earlier research, one can state with great confidence that perineural DEX can effectively reduce EA incidence in children. However, the best dose and side effects of perineural DEX cannot be set up due to insufficient detailed data, and the effects of other routes of DEX administration on EA in children also need to be further studied.

Subgroup analysis was performed for the timing of DEX administration, and the result showed that DEX decreases EA incidence regardless of the timing when DEX was administered preoperatively, after induction of anesthesia, and before the end of surgery. TSA revealed firm evidence for each subgroup. The GRADE-rated evaluation showed the moderate and low quality of evidence for afterinduction and the before-the-end-of-surgery subgroup due to inconsistency and publication bias. However, the evidence for the premedication subgroup was of high quality. This may be due to the higher dose $(0.5-4 \mu \mathrm{g} / \mathrm{kg})$ and the more uniform route (transnasal or oral) of DEX administration in the premedication subgroup, leading to a more consistent DEX effect in reducing the incidence of EA. Preoperative administration of DEX has been shown to have several significant benefits, including a lower incidence of EA, reduced agitation severity, and a shorter duration of agitation (94). Therefore, high-quality evidence supports preoperative DEX administration to prevent EA in children. Further, studies focusing on the merits of other DEX administration timing would be of the greatest benefit.

Our further subgroup analysis, with different DEX administration patterns, revealed that DEX administered as bolus dosage or as continuous dosage has a similar effect in reducing EA incidence in children. This result was consistent with the finding of the earlier meta-analysis by Zhu et al. (10). TSA showed Z-curves reached the IS and crossed TSMB for both patterns, suggesting a sufficient level of evidence has been reached. GRADE evidence for bolus dosage subgroup showed low due to inconsistency and publication bias. However, GRADE for the continuous dosage subgroup had high-quality evidence, proving that the beneficial effects of continuous administration of DEX on EA incidence were more reliable. Continuous infusion of DEX resulted in higher dosage and longer duration of DEX action, leading to more robust EA prevention effects. Thus, our evidence supported continuous DEX injection to prevent EA in children. Further studies should compare the efficacy and safety of different DEX administration patterns for EA in children.

To further investigate the preventive effect of DEX on EA in children, we performed an added subgroup analysis 
for different intravenous DEX doses. The pooled results showed that all doses of DEX significantly reduced the incidence of EA in children. There is a significant difference among the three subgroups $(\mathrm{P}=0.04)$, suggesting that a high dose of DEX $(\geq 1 \mu \mathrm{g} / \mathrm{kg})$ may be more effective than a low and medium dose of DEX in reducing the incidence of EA. TSA showed firm evidence for all three subgroups. However, only the high-dose DEX subgroup had moderatequality GRADE evidence. In our included studies, DEX showed its effect in decreasing EA from the lowest dose of $0.15 \mu \mathrm{g} / \mathrm{kg}$ (26) to the highest dose of $1.86 \mu \mathrm{g} / \mathrm{kg}$ (41). Nine studies directly compared the effects of different doses of DEX on EA in children $(22,30,33,43,44,56,75,76,79)$. The meta-regression analysis for these nine studies showed a statistically significant association between EA incidence and DEX dose $(\mathrm{P}<0.05)$. It is not surprising that EA incidence decreases with an increase in DEX dose. A high dose of DEX may be associated with some side effects, including hypotension, bradycardia, and delayed emergence (95). However, we did not analyze the relationship between different doses of DEX and side effects due to insufficient detailed data. At present, there is no clear conclusion on the greatest dose of DEX for preventing EA in children. Zhang et al. (96) revealed that intravenous DEX infusion at $0.30 \mu \mathrm{g} / \mathrm{kg}$ could prevent half of or all EA after general anesthesia during pediatric tonsillectomy and adenoidectomy. Manning et al. (97) suggested that intravenous DEX $0.5 \mu \mathrm{g} / \mathrm{kg}$ could significantly reduce EA incidence in children with minimal side effects. However, Bhat et al. (30) reported that a single dose of DEX $1 \mu \mathrm{g} /$ $\mathrm{kg}$ was more effective than $0.5 \mu \mathrm{g} / \mathrm{kg}$ in reducing EA. Therefore, further studies are needed to find the best DEX dose, considering the different administration routes, timing, and side effects.

PONV is a frequent complication after general anesthesia in children. The analysis for PONV showed that patients who received DEX were associated with a lower incidence of PONV than placebo. The results strengthened the findings of earlier meta-analyses (10-12). The TSA results showed that the current sample size exceeded the required IS, and the present evidence for anticipated intervention effects was sufficient. While high-quality evidence from GRADE strongly supported the results. The prophylactic effect of DEX on PONV may be related to the sparing effects of opioids and inhaled anesthetics $(98,99)$. We also found that DEX had a better preventive effect on PONV than midazolam. However, TSA showed an absence of evidence with low quality. Therefore, high- quality studies with a large sample size are needed to confirm this result.

We also investigated the emergency time, time to discharge from PACU, and the number of patients requiring rescue analgesia. Our pooled results showed that DEX prolonged the emergence time but did not increase the time to discharge from PACU, which was consistent with the recent meta-analysis found by Yang et al. (12). However, the results should be interpreted with caution due to the high levels of heterogeneity across the studies. Some data were re-calculated; the median and range were transformed into the mean and variance. These may be the main source of heterogeneity. Our study suggested that DEX could reduce the proportion of rescue analgesia than placebo with TSA firm evidence. Compared with other anesthetics, including midazolam and fentanyl, DEX may be more effective in reducing rescue analgesia. However, low-to moderatequality evidence reveals further research is needed to draw definitive conclusions.

The most reported adverse events of DEX are hypotension and bradycardia. In our meta-analysis, DEX significantly increased the occurrence of bradycardia but did not increase the risk of hypotension. The TSA suggested the evidence was insufficient for both results, and the quality of evidence was graded as low or very low due to serious imprecision and publication bias. Data on side effects were sparse in all studies, while some studies reported no hypotension or bradycardia was collected, which was known as "zero events". Therefore, it is currently unreasonable to conclude the relationship between DEX and bradycardia or hypotension due to insufficient information. More clinical trials and samples are needed to verify the safety of DEX.

This systematic review and meta-analysis have several potential limitations. First, the included studies' sample sizes were small, with only 10 of the 67 studies having more than 100 subjects. Therefore, our meta-analysis may be subject to small study effect bias. Second, patient age, type of operation, and EA evaluation method differ among the included studies. These variables might have produced the clinical heterogeneity that influenced the results, but we did not perform subgroup analyses for such variables. According to the Galbraith plot analysis, we found a moderate heterogeneity within EA incidence, which is due to the inclusion of three studies $(42,70,75)$. A sensitivity analysis that excluded the three studies confirmed the robustness of the conclusion. We identified high heterogeneity in some secondary outcomes, including emergence time, time to discharge from PACU, and the 
number of patients requiring rescue analgesia. These results should be interpreted with caution. Third, Egger's test results suggested a potential publication bias in one of the primary outcomes (EA incidence). Although the trim-and-fill analysis was performed to reduce the missing studies' influence, the potential publication bias could still affect the conclusions' reliability. Finally, our study suggested a dose-dependent effect of DEX on preventing EA in children, but we did not study the effects of different doses of DEX on side effects due to insufficient sufficient data. It is unreasonable to emphasize the benefit of DEX in preventing EA without considering its side effects. The optimal dose of DEX for preventing EA with minimal side effects in children requires further investigation.

\section{Conclusions}

In summary, the present meta-analysis showed that perioperative administration of DEX significantly reduced the incidence of $\mathrm{EA}$, severe $\mathrm{EA}$, and $\mathrm{PONV}$ in children. TSA and GRADE supplied sufficient evidence to support the efficacy of DEX in the prevention of EA in children when the perineural route administered DEX, as premedication, as continuous dosage, and at a high dose. However, the best dose, route, and timing of DEX and influence on other outcomes call for further studies.

\section{Acknowledgments}

Funding: The present study was supported by the Guangxi Key Research and Development Program (grant no. AB18221031), the Guangxi Natural Science Foundation of China (grant no. 2020GXNSFDA238025), the National Natural Science Foundation of China (grant no. 81373498), the Guangxi Medical and Health Appropriate Technology Development and Popularization Application Project (grant no. S2020014).

\section{Footnote}

Reporting Checklist: The authors have completed the PRISMA reporting checklist. Available at http://dx.doi. org/10.21037/tp-21-105

Conflicts of Interest: All authors have completed the ICMJE uniform disclosure form (available at http://dx.doi. org/10.21037/tp-21-105). The authors have no conflicts of interest to declare.
Ethical Statement: The authors are accountable for all aspects of the work in ensuring that questions related to the accuracy or integrity of any part of the work are appropriately investigated and resolved.

Open Access Statement: This is an Open Access article distributed in accordance with the Creative Commons Attribution-NonCommercial-NoDerivs 4.0 International License (CC BY-NC-ND 4.0), which permits the noncommercial replication and distribution of the article with the strict proviso that no changes or edits are made and the original work is properly cited (including links to both the formal publication through the relevant DOI and the license). See: https://creativecommons.org/licenses/by-nc-nd/4.0/.

\section{References}

1. Moore AD, Anghelescu DL. Emergence Delirium in Pediatric Anesthesia. Paediatr Drugs 2017;19:11-20.

2. Urits I, Peck J, Giacomazzi S, et al. Emergence Delirium in Perioperative Pediatric Care: A Review of Current Evidence and New Directions. Adv Ther 2020;37:1897-909.

3. Rosen HD, Mervitz D, Cravero JP. Pediatric emergence delirium: Canadian Pediatric Anesthesiologists' experience. Paediatr Anaesth 2016;26:207-12.

4. Dahmani S, Delivet H, Hilly J. Emergence delirium in children: an update. Curr Opin Anaesthesiol 2014;27:309-15.

5. Mahmoud M, Mason KP. Dexmedetomidine: review, update, and future considerations of paediatric perioperative and periprocedural applications and limitations. Br J Anaesth 2015;115:171-82.

6. Mahmoud M, Barbi E, Mason KP. Dexmedetomidine: What's New for Pediatrics? A Narrative Review. J Clin Med 2020;9:2724.

7. Zhang $\mathrm{C}, \mathrm{Hu} \mathrm{J}$, Liu $\mathrm{X}$, et al. Effects of intravenous dexmedetomidine on emergence agitation in children under sevoflurane anesthesia: a meta-analysis of randomized controlled trials. PLoS One 2014;9:e99718.

8. Sun L, Guo R, Sun L. Dexmedetomidine for preventing sevoflurane-related emergence agitation in children: a meta-analysis of randomized controlled trials. Acta Anaesthesiol Scand 2014;58:642-50.

9. Ni J, Wei JF, Yao YS, et al. Effect of Dexmedetomidine on Preventing Postoperative Agitation in Children: A MetaAnalysis. Plos One 2015;10:e0128450.

10. Zhu M, Wang H, Zhu A, et al. Meta-analysis of 
dexmedetomidine on emergence agitation and recovery profiles in children after sevoflurane anesthesia: different administration and different dosage. PLoS One 2015;10:e0123728.

11. Tang W, He D, Liu Y. Effect of Dexmedetomidine in children undergoing general anaesthesia with sevoflurane: a meta-analysis and systematic review. J Int Med Res 2020;48:300060520927530.

12. Yang X, Hu Z, Peng F, et al. Effects of Dexmedetomidine on Emergence Agitation and Recovery Quality Among Children Undergoing Surgery Under General Anesthesia: A Meta-Analysis of Randomized Controlled Trials. Front Pediatr 2020;8:580226.

13. Rao Y, Zeng R, Jiang X, et al. The Effect of Dexmedetomidine on Emergence Agitation or Delirium in Children After Anesthesia-A Systematic Review and MetaAnalysis of Clinical Studies. Front Pediatr 2020;8:329.

14. Wetterslev J, Jakobsen JC, Gluud C. Trial Sequential Analysis in systematic reviews with meta-analysis. BMC Med Res Methodol 2017;17:39.

15. Shah A, Smith A. Trial sequential analysis: adding a new dimension to meta-analysis. Anaesthesia 2020;75:15-20.

16. Thorlund K, Engstrøm J, Wetterslev J, et al. User manual for trial sequential analysis (TSA). Copenhagen Trial Unit, Centre for Clinical Intervention Research, Copenhagen, Denmark, 2011;1:1-115.

17. Bong CL, Lim E, Allen JC, et al. A comparison of singledose dexmedetomidine or propofol on the incidence of emergence delirium in children undergoing general anaesthesia for magnetic resonance imaging. Anaesthesia 2015;70:393-9.

18. Abdelaziz HMM, Bakr RH, Kasem AA. Effect of intranasal dexmedetomidine or intranasal midazolam on prevention of emergence agitation in pediatric strabismus surgery: A randomized controlled study. Egypt J Anaesth 2016;32:285-91.

19. Abdel-Ghaffar HS, Kamal SM, El Sheriff FA, et al. Comparison of nebulised dexmedetomidine, ketamine, or midazolam for premedication in preschool children undergoing bone marrow biopsy. Br J Anaesth 2018;121:445-52.

20. Abdel-Ghaffar HS, Abdel-Wahab AH, Roushdy MM. Oral trans-mucosal dexmedetomidine for controlling of emergence agitation in children undergoing tonsillectomy: a randomized controlled trial. Rev Bras Anestesiol 2019;69:469-76.

21. Abdel-Ma'boud MA. Effect of dexemeditomedine and propofol on the prevention of emergence agitation following sevoflurane anesthesia in Egyptian children. J Egypt Soc Parasitol 2014;44:687-94.

22. Abdel-Rahman KA, Abd-Elshafy SK, Sayed JA. Effect of two different doses of dexmedetomidine on the incidence of emergence agitation after strabismus surgery: a randomized clinical trial. Rev Bras Anestesiol 2018;68:571-6.

23. Ali MA, Abdellatif AA. Prevention of sevoflurane related emergence agitation in children undergoing adenotonsillectomy: A comparison of dexmedetomidine and propofol. Saudi J Anaesth 2013;7:296-300.

24. Ali WA, Mohammed AK, Elshorbagy HM.

Dexmedetomidine versus ketofol effect on the incidence of emergence agitation associated with sevoflurane-based anesthesia in children undergoing orthopedic surgery. Egypt J Anaesth 2016;32:277-84.

25. Al-Zaben KR, Qudaisat IY, Alja'bari AN, et al. The effects of caudal or intravenous dexmedetomidine on postoperative analgesia produced by caudal bupivacaine in children: a A randomized controlled double-blinded study. J Clin Anesth 2016;33:386-94.

26. Asaad OM, Hafez M, Mohamed MY, et al. Comparative study between prophylactic single dose of fentanyl and dexmedetomidine in the management of agitation after sevoflurane anesthesia in children. Egypt J Anaesth 2011;27:31-7.

27. Aydogan MS, Korkmaz MF, Ozgül U, et al. Pain, fentanyl consumption, and delirium in adolescents after scoliosis surgery: dexmedetomidine vs midazolam. Paediatr Anaesth 2013;23:446-52.

28. Bhadla S, Prajapati D, Louis T, et al. Comparison between dexmedetomidine and midazolam premedication in pediatric patients undergoing ophthalmic day-care surgeries. Anesth Essays Res 2013;7:248-56.

29. Bharti N, Praveen R, Bala I. A dose-response study of caudal dexmedetomidine with ropivacaine in pediatric day care patients undergoing lower abdominal and perineal surgeries: a randomized controlled trial. Paediatr Anaesth 2014;24:1158-63.

30. Bhat R, Mudukanagoudar M, Shetty S, et al. Study of dose related effects of dexmedetomidine on laryngeal mask airway removal in children -a double blind randomized study. Anaesthesia Pain \& Intensive Care 2018;22:368-73.

31. Bi Y, Ma Y, Ni J, et al. Efficacy of premedication with intranasal dexmedetomidine for removal of inhaled foreign bodies in children by flexible fiberoptic bronchoscopy: a randomized, double-blind, placebo-controlled clinical 
trial. BMC Anesthesiol 2019;19:219.

32. Chen JY, Jia JE, Liu TJ, et al. Comparison of the effects of dexmedetomidine, ketamine, and placebo on emergence agitation after strabismus surgery in children. Can J Anaesth 2013;60:385-92.

33. Chen F, Wang C, Lu Y, et al. Efficacy of different doses of dexmedetomidine as a rapid bolus for children: a doubleblind, prospective, randomized study. BMC Anesthesiol 2018;18:103.

34. Cho JE, Kim JY, Park SJ, et al. The Effect of $1 \mu \mathrm{g} /$ $\mathrm{kg}$ Dexmedetomidine Combined with High-Volume/ Low-Concentration Caudal Ropivacaine in Children Undergoing Ambulatory Orchiopexy. Biol Pharm Bull 2015;38:1020-5.

35. Cho EA, Cha YB, Shim JG, et al. Comparison of single minimum dose administration of dexmedetomidine and midazolam for prevention of emergence delirium in children: a randomized controlled trial. J Anesth 2020;34:59-65.

36. Di M, Huang C, Chen F, et al. Effect of single-dose dexmedetomidine on recovery profiles after sevoflurane anesthesia with spontaneous respiration in pediatric patients undergoing cleft lip and palate repair. Zhonghua Yi Xue Za Zhi 2014;94:1466-9.

37. El-Hamid AMA, Yassin HM. Effect of intranasal dexmedetomidine on emergence agitation after sevoflurane anesthesia in children undergoing tonsillectomy and/or adenoidectomy. Saudi J Anaesth 2017;11:137-43.

38. Erdil F, Demirbilek S, Begec Z, et al. The effects of dexmedetomidine and fentanyl on emergence characteristics after adenoidectomy in children. Anaesth Intensive Care 2009;37:571-6.

39. Govil N, Dadu S, Singh VP, et al. Dexmedetomidine improves surgical field in cochlear implant surgery: a randomized, double-blind, placebo-controlled trial. Anaesthesia Pain \& Intensive Care 2017;21:147-53.

40. Guler G, Akin A, Tosun Z, et al. Single-dose dexmedetomidine reduces agitation and provides smooth extubation after pediatric adenotonsillectomy. Paediatr Anaesth 2005;15:762-6.

41. Gupta N, Rath GP, Prabhakar H, et al. Effect of intraoperative dexmedetomidine on postoperative recovery profile of children undergoing surgery for spinal dysraphism. J Neurosurg Anesthesiol 2013;25:271-8.

42. Hauber JA, Davis PJ, Bendel LP, et al. Dexmedetomidine as a Rapid Bolus for Treatment and Prophylactic Prevention of Emergence Agitation in Anesthetized
Children. Anesth Analg 2015;121:1308-15.

43. He L, Wang X, Zheng S, et al. Effects of dexmedetomidine infusion on laryngeal mask airway removal and postoperative recovery in children anaesthetised with sevoflurane. BMC Anesthesiol 2015;15:145.

44. Ibacache ME, Munoz HR, Brandes V, et al. Single-dose dexmedetomidine reduces agitation after sevoflurane anesthesia in children. Anesthesia And Analgesia 2004;98:60-3.

45. Isik B, Arslan M, Tunga AD, et al. Dexmedetomidine decreases emergence agitation in pediatric patients after sevoflurane anesthesia without surgery. Paediatr Anaesth 2006;16:748-53.

46. Kim J, Kim SY, Lee JH, et al. Low-dose dexmedetomidine reduces emergence agitation after desflurane anaesthesia in children undergoing strabismus surgery. Yonsei Med J 2014;5 5:508-16.

47. Kim NY, Kim SY, Yoon HJ, et al. Effect of dexmedetomidine on sevoflurane requirements and emergence agitation in children undergoing ambulatory surgery. Yonsei Med J 2014;55:209-15.

48. Li Y, Xu LJ, Wang YB. Effection of combining dexmedetomidine with lidocaine cream on response to tracheal extubation in pediatric tonsillectomy. Zhonghua Yi Xue Za Zhi 2017;97:2510-5.

49. Li H, Zhang L, Shi M, et al. Impact of Dexmedetomidine on Pediatric Agitation in the Postanesthesia Care Unit. J Perianesth Nurs 2018;33:53-7.

50. Lili X, Jianjun S, Haiyan Z. The application of dexmedetomidine in children undergoing vitreoretinal surgery. J Anesth 2012;26:556-61.

51. Lin Y, Chen Y, Huang J, et al. Efficacy of premedication with intranasal dexmedetomidine on inhalational induction and postoperative emergence agitation in pediatric undergoing cataract surgery with sevoflurane. J Clin Anesth 2016;33:289-95.

52. Lin L, Yueming Z, Meisheng L, et al. Effect of dexmedetomidine on emergence agitation after general anesthesia in children undergoing odontotherapy in daysurgery operating room. Hua Xi Kou Qiang Yi Xue Za Zhi 2017;35:613-7.

53. Liu Y, Kang DL, Na HY, et al. Consequence of dexmedetomidine on emergence delirium following sevoflurane anesthesia in children with cerebral palsy. Int J Clin Exp Med 2015;8:16238-44.

54. Lundblad M, Marhofer D, Eksborg S, et al. Dexmedetomidine as adjunct to ilioinguinal/iliohypogastric 
nerve blocks for pediatric inguinal hernia repair: an exploratory randomized controlled trial. Paediatr Anaesth 2015;25:897-905.

55. Makkar JK, Bhatia N, Bala I, et al. A comparison of single dose dexmedetomidine with propofol for the prevention of emergence delirium after desflurane anaesthesia in children. Anaesthesia 2016;71:50-7.

56. Meng QT, Xia ZY, Luo T, et al. Dexmedetomidine reduces emergence agitation after tonsillectomy in children by sevoflurane anesthesia: a case-control study. Int J Pediatr Otorhinolaryngol 2012;76:1036-41.

57. Mohamed AA. Prevention of sevoflurane agitation in children undergoing congenital hernia repair, impact of adding dexmedetomidine to caudal analgesia. Egypt J Anaesth 2015;31:227-31.

58. Mountain BW, Smithson L, Cramolini M, et al. Dexmedetomidine as a pediatric anesthetic premedication to reduce anxiety and to deter emergence delirium. Aana $j$ 2011;79:219-24.

59. Mukherjee A, Das A, Basunia SR, et al. Emergence agitation prevention in paediatric ambulatory surgery: A comparison between intranasal Dexmedetomidine and Clonidine. J Res Pharm Pract 2015;4:24-30.

60. Ozcengiz D, Gunes Y, Ozmete O. Oral melatonin, dexmedetomidine, and midazolam for prevention of postoperative agitation in children. J Anesth 2011;25:184-8.

61. Park SJ, Shin S, Kim SH, et al. Comparison of Dexmedetomidine and Fentanyl as an Adjuvant to Ropivacaine for Postoperative Epidural Analgesia in Pediatric Orthopedic Surgery. Yonsei Med J 2017;58:650-7.

62. Patel A, Davidson M, Tran MC, et al. Dexmedetomidine infusion for analgesia and prevention of emergence agitation in children with obstructive sleep apnea syndrome undergoing tonsillectomy and adenoidectomy. Anesth Analg 2010;111:1004-10.

63. Peng $W$, Zhang TJ. Dexmedetomidine decreases the emergence agitation in infant patients undergoing cleft palate repair surgery after general anesthesia. BMC Anesthesiol 2015;15:1-7.

64. Pestieau SR, Quezado ZM, Johnson YJ, et al. The effect of dexmedetomidine during myringotomy and pressureequalizing tube placement in children. Paediatr Anaesth 2011;21:1128-35.

65. Prabhu MK, Mehandale SG. Comparison of oral dexmedetomidine versus oral midazolam as premedication to prevent emergence agitation after sevoflurane anaesthesia in paediatric patients. Indian J Anaesth 2017;61:131-6.

66. Prasad K, Sophia P, Lakshmi BS. Bolus Doses of Ketofol versus Dexmedetomidine for the Prevention of Emergence Agitation in Children: A Prospective Randomized Controlled Clinical Trial. Int J Sci Study 2017;5:171-6.

67. Saadawy I, Boker A, Elshahawy MA, et al. Effect of dexmedetomidine on the characteristics of bupivacaine in a caudal block in pediatrics. Acta Anaesthesiol Scand 2009;53:251-6.

68. Sajid B, Mohamed T, Jumaila M. A comparison of oral dexmedetomidine and oral midazolam as premedicants in children. J Anaesthesiol Clin Pharmacol 2019;35:36-40.

69. Sato M, Shirakami G, Tazuke-Nishimura M, et al. Effect of single-dose dexmedetomidine on emergence agitation and recovery profiles after sevoflurane anesthesia in pediatric ambulatory surgery. J Anesth 2010;24:675-82.

70. Sharma K, Kumar M, Gandhi R. Effect of Single-Dose Dexmedetomidine on Intraoperative Hemodynamics and Postoperative Recovery during Pediatric Adenotonsillectomy. Anesth Essays Res 2019;13:63-7.

71. Sheta SA, Al-Sarheed MA, Abdelhalim AA. Intranasal dexmedetomidine vs midazolam for premedication in children undergoing complete dental rehabilitation: a double-blinded randomized controlled trial. Paediatr Anaesth 2014;24:181-9.

72. Shi M, Miao S, Gu T, et al. Dexmedetomidine for the prevention of emergence delirium and postoperative behavioral changes in pediatric patients with sevoflurane anesthesia: a double-blind, randomized trial. Drug Des Devel Ther 2019;13:897-905.

73. Shukry M, Clyde MC, Kalarickal PL, et al. Does dexmedetomidine prevent emergence delirium in children after sevoflurane-based general anesthesia? Paediatr Anaesth 2005;15:1098-104.

74. Soliman R, Alshehri A. Effect of dexmedetomidine on emergence agitation in children undergoing adenotonsillectomy under sevoflurane anesthesia: A randomized controlled study. Egypt J Anaesth 2015;31:283-9.

75. Song IA, Seo KS, Oh AY, et al. Dexmedetomidine Injection during Strabismus Surgery Reduces Emergence Agitation without Increasing the Oculocardiac Reflex in Children: A Randomized Controlled Trial. PLoS One 2016;11:e0162785.

76. Sun Y, Li Y, Sun Y, et al. Dexmedetomidine Effect 
on Emergence Agitation and Delirium in Children Undergoing Laparoscopic Hernia Repair: a Preliminary Study. J Int Med Res 2017;45:973-83.

77. Tsiotou AG, Malisiova A, Kouptsova E, et al. Dexmedetomidine for the reduction of emergence delirium in children undergoing tonsillectomy with propofol anesthesia: A double-blind, randomized study. Paediatr Anaesth 2018;28:632-8.

78. Wang L, Huang L, Zhang T, et al. Comparison of Intranasal Dexmedetomidine and Oral Midazolam for Premedication in Pediatric Dental Patients under General Anesthesia: A Randomised Clinical Trial. Biomed Res Int 2020;2020:5142913.

79. Xiao CL, Zhao T, Zhang YP. Optimal dosage of three dexmedetomidine doses on prevention of agitation induced by sevoflurane anesthesia in children. Journal of Dalian Medical University 2015;37:379-81+84.

80. Yao Y, Qian B, Lin Y, et al. Intranasal dexmedetomidine premedication reduces minimum alveolar concentration of sevoflurane for laryngeal mask airway insertion and emergence delirium in children: a prospective, randomized, double-blind, placebo-controlled trial. Paediatr Anaesth 2015;25:492-8.

81. Yao Y, Yu C, Zhang X, et al. Caudal and intravenous dexmedetomidine similarly prolong the duration of caudal analgesia in children: A randomized controlled trial. Paediatr Anaesth 2018;28:888-96.

82. Yao Y, Sun Y, Lin J, et al. Intranasal dexmedetomidine versus oral midazolam premedication to prevent emergence delirium in children undergoing strabismus surgery: A randomised controlled trial. Eur J Anaesthesiol 2020;37:1143-9.

83. Ye W, Hu Y, Wu Y, et al. Retrobulbar dexmedetomidine in pediatric vitreoretinal surgery eliminates the need for intraoperative fentanyl and postoperative analgesia: A randomized controlled study. Indian J Ophthalmol 2019;67:922-7.

84. Zhang $\mathrm{S}$, Zhang RD, Cai MH, et al. Intranasal dexmedetomidine premedication in children with recent upper respiratory tract infection undergoing interventional cardiac catheterisation A randomised controlled trial. Eur J Anaesthesiol 2020;37:85-90.

85. Jiao H, Wang H, Jiang Z, et al. Comparative efficacy of ancillary drugs in sevoflurane-related emergence agitation after paediatric adenotonsillectomy: A Bayesian network meta-analysis. J Clin Pharm Ther 2020;45:1039-49.

86. Tan D, Xia H, Sun S, et al. Effect of ancillary drugs on sevoflurane related emergence agitation in children undergoing ophthalmic surgery: a Bayesian network metaanalysis. BMC Anesthesiol 2019;19:138.

87. Li R, Lai I, Pan J, et al. Dexmedetomidine Exerts an Antiinflammatory Effect via $\alpha 2$ Adrenoceptors to Prevent Lipopolysaccharide-induced Cognitive Decline in Mice. Anesthesiology 2020;133:393-407.

88. Jiang L, Hu M, Lu Y, et al. The protective effects of dexmedetomidine on ischemic brain injury: A metaanalysis. J Clin Anesth 2017;40:25-32.

89. Lang B, Zhang L, Zhang W, et al. A comparative evaluation of dexmedetomidine and midazolam in pediatric sedation: A meta-analysis of randomized controlled trials with trial sequential analysis. CNS Neurosci Ther 2020;26:862-75.

90. Aldecoa C, Bettelli G, Bilotta F, et al. European Society of Anaesthesiology evidence-based and consensus-based guideline on postoperative delirium. Eur J Anaesthesiol 2017;34:192-214.

91. Zhang X, Bai X. New therapeutic uses for an alpha2 adrenergic receptor agonist--dexmedetomidine in pain management. Neurosci Lett 2014;561:7-12.

92. Andersen JH, Jaeger P, Grevstad U, et al. Systemic dexmedetomidine is not as efficient as perineural dexmedetomidine in prolonging an ulnar nerve block. Reg Anesth Pain Med 2019;44:333-40.

93. Wang XX, Dai J, Dai L, et al. Caudal dexmedetomidine in pediatric caudal anesthesia: A systematic review and meta-analysis of randomized controlled trials. Medicine (Baltimore) 2020;99:e21397.

94. Kim JC, Kim J, Kwak H, et al. Premedication with dexmedetomidine to reduce emergence agitation: a randomized controlled trial. BMC Anesthesiol 2019;19:144.

95. Mahmoud M, Mason KP. Dexmedetomidine: review, update, and future considerations of paediatric perioperative and periprocedural applications and limitations. Br J Anaesth 2015;115:171-82.

96. Zhang YZ, Wang X, Wu JM, et al. Optimal Dexmedetomidine Dose to Prevent Emergence Agitation Under Sevoflurane and Remifentanil Anesthesia During Pediatric Tonsillectomy and Adenoidectomy. Front Pharmacol 2019;10:1091.

97. Manning AN, Bezzo LK, Hobson JK, et al. Dexmedetomidine Dosing to Prevent Pediatric Emergence Delirium. AANA J 2020;88:359-64.

98. Gurbet A, Basagan-Mogol E, Turker G, et al. Intraoperative infusion of dexmedetomidine reduces perioperative analgesic requirements. Can J Anaesth 
2006;53:646-52.

99. Jin S, Liang D, Chen C, et al. Dexmedetomidine prevent postoperative nausea and vomiting on patients during general anesthesia: A PRISMA-compliant meta analysis of randomized controlled trials. Medicine 2017;96:e5770.

(English Language Editor: J. Chapnick)

Cite this article as: Zhang $\mathrm{X}$, Bai Y, Shi M, Ming S, Jin $\mathrm{X}$, Xie Y. Effect of different administration and dosage of dexmedetomidine in the reduction of emergence agitation in children: a meta-analysis of randomized controlled trials with sequential trial analysis. Transl Pediatr 2021;10(4):929-957. doi: $10.21037 /$ tp-21-105 


\section{Supplementary}

Table S1 Search strategy

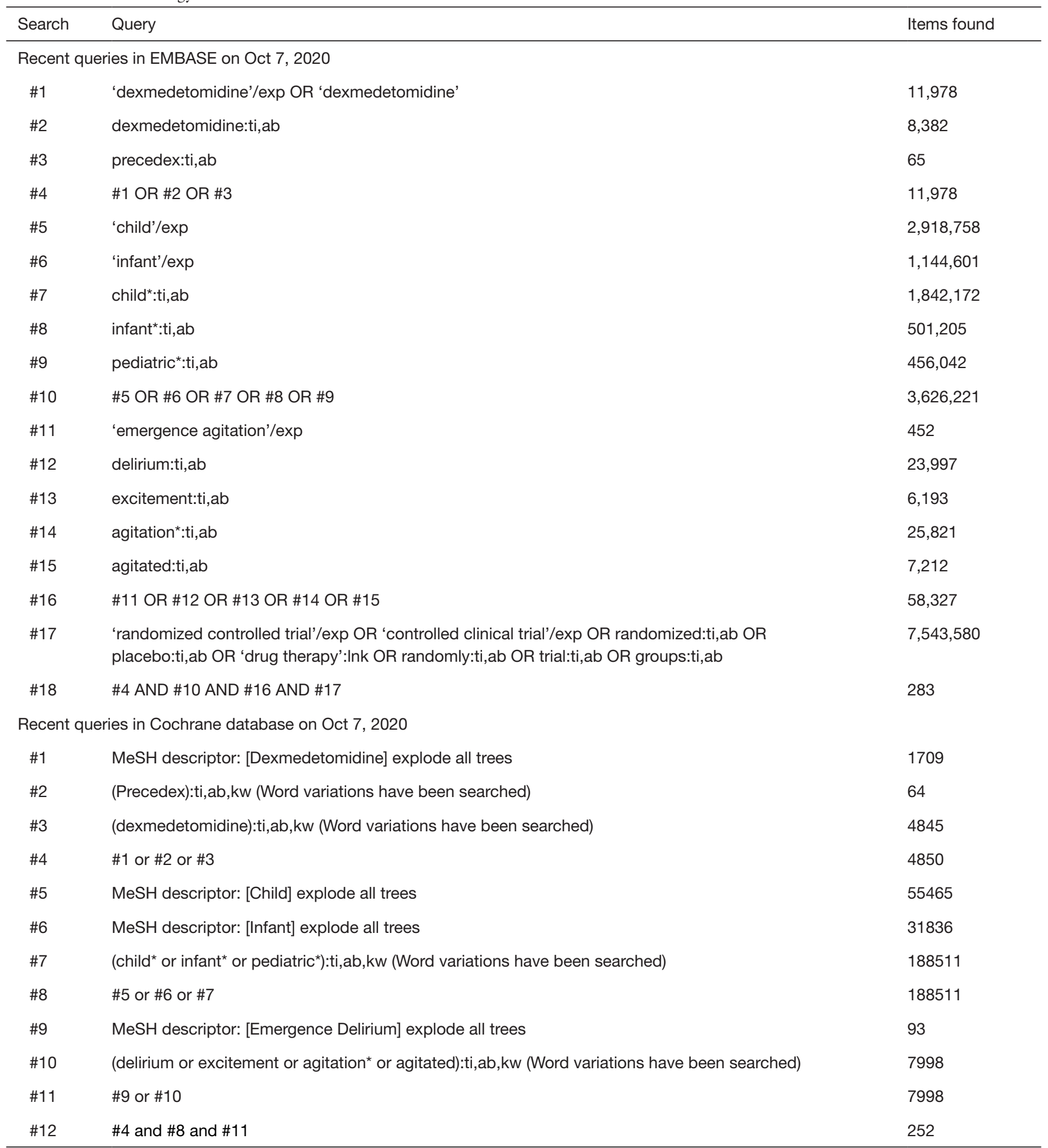

Table S1 (continued) 
Table S1 (continued)

\begin{tabular}{|c|c|c|}
\hline Search & Query & Items found \\
\hline \#1 & Search: ((“Dexmedetomidine”[Mesh]) OR (dexmedetomidine[Title/Abstract]))) OR (precedex[Title/Abstract]) & 6,373 \\
\hline \#2 & $\begin{array}{l}\text { Search: ((((““Emergence Delirium”[Mesh]) OR (emergence agitation[Title/Abstract])) OR } \\
\text { (delirium[Title/Abstract])) OR (excitement[Title/Abstract])) OR (agitation*[Title/Abstract])) OR } \\
\text { (agitated[Title/Abstract]) }\end{array}$ & 39,455 \\
\hline \#4 & $\begin{array}{l}\text { Search: "randomized controlled trial"[pt] OR "controlled clinical trial"[pt] OR randomized[tiab] OR } \\
\text { placebo[tiab] OR "drug therapy"[sh] OR randomly[tiab] OR trial[tiab] OR groups[tiab] }\end{array}$ & $5,001,523$ \\
\hline \#5 & $\begin{array}{l}\text { Search: }(((((((“ C h i l d ”[M e s h]) \text { OR (“Infant”[Mesh])) OR (child*[Title/Abstract])) OR (infant*[Title/Abstract])) OR } \\
\text { (pediatric*[Title/Abstract])) AND (((“Dexmedetomidine"[Mesh]) OR (dexmedetomidine[Title/Abstract]))) OR } \\
\text { (precedex[Title/Abstract]))) AND ((((((“Emergence Delirium”[Mesh]) OR (emergence agitation[Title/Abstract])) } \\
\text { OR (delirium[Title/Abstract])) OR (excitement[Title/Abstract])) OR (agitation*[Title/Abstract])) OR } \\
\text { (agitated[Title/Abstract]))) AND (“randomized controlled trial”[pt] OR "controlled clinical trial”[pt] OR } \\
\text { randomized[tiab] OR placebo[tiab] OR “drug therapy”[sh] OR randomly[tiab] OR trial[tiab] OR groups[tiab]) }\end{array}$ & 158 \\
\hline \multicolumn{3}{|c|}{ Recent queries in Web of Sciences on Oct 7, 2020} \\
\hline$\# 1$ & $\mathrm{TS}=($ dexmedetomidine $) \mathrm{OR}$ (precedex) & 7,815 \\
\hline \#2 & TS $=$ (child) OR (infant) OR (child*) OR (infant*) OR (pediatric*) & $2,115,883$ \\
\hline \#3 & $\mathrm{TS}=\left(\right.$ emergence agitation) OR (delirium) OR (excitement) OR (agitation $\left.{ }^{\star}\right)$ OR (agitated) & 60,181 \\
\hline \#4 & \#1 AND \#2 AND \#3 & 339 \\
\hline
\end{tabular}


DEX Placebo Risk Ratio Risk Ratio

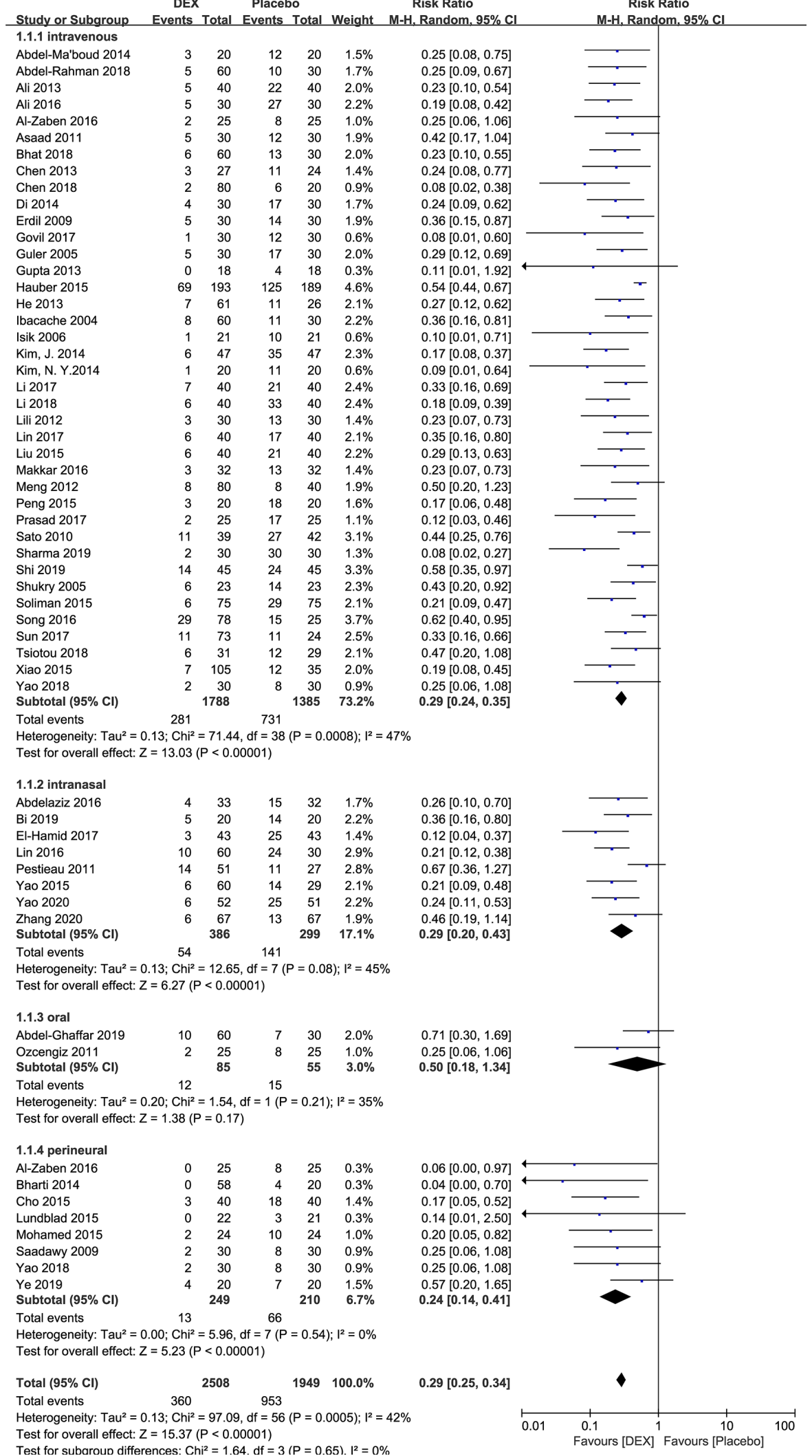

Figure S1 Subgroup analysis of EA incidence: different routs. EA, emergence agitation. 


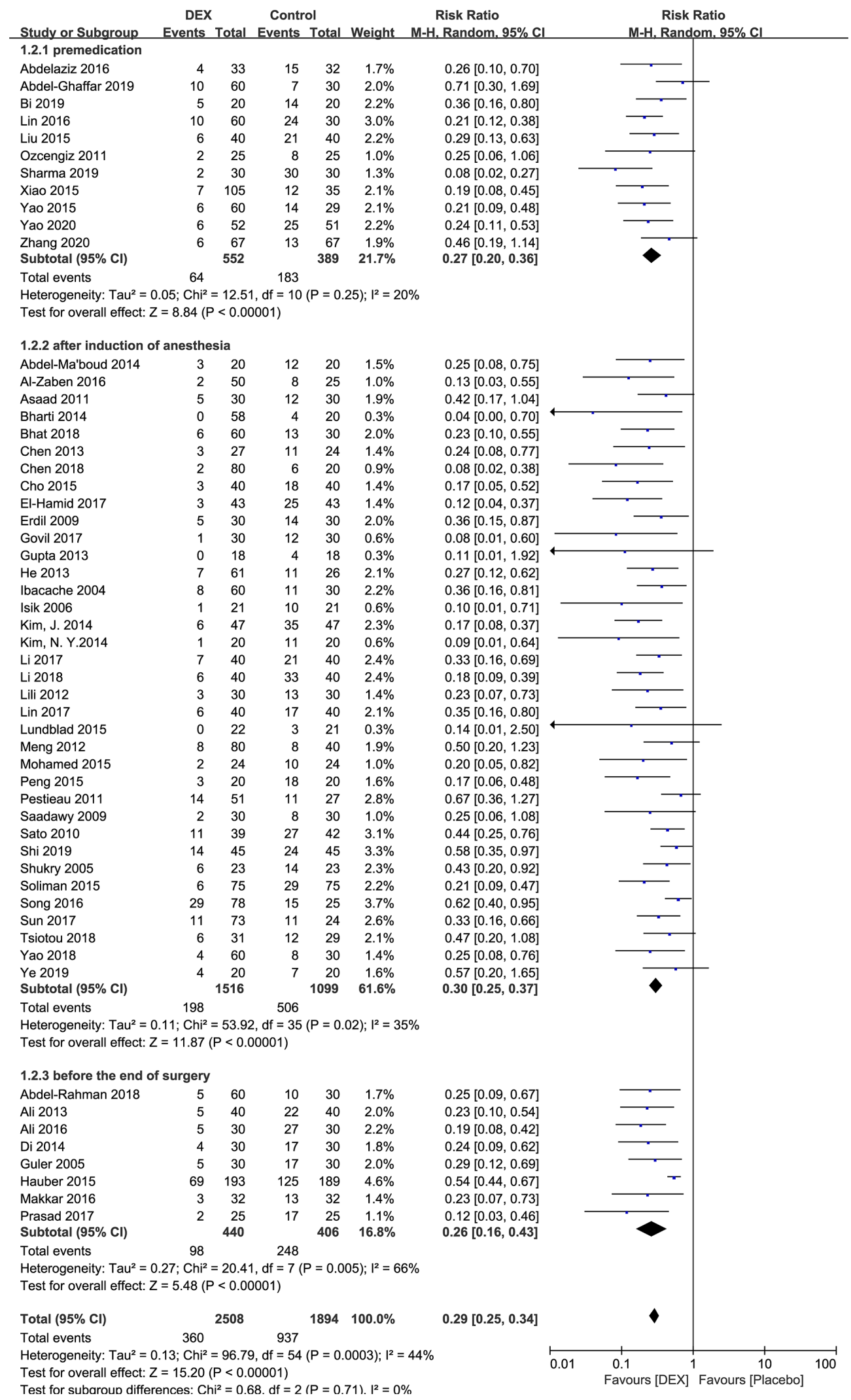

Figure S2 Subgroup analysis of EA incidence: different timing. EA, emergence agitation. 
$\begin{array}{llll}\text { DEX Control Risk Ratio } & \text { Risk Ratio }\end{array}$

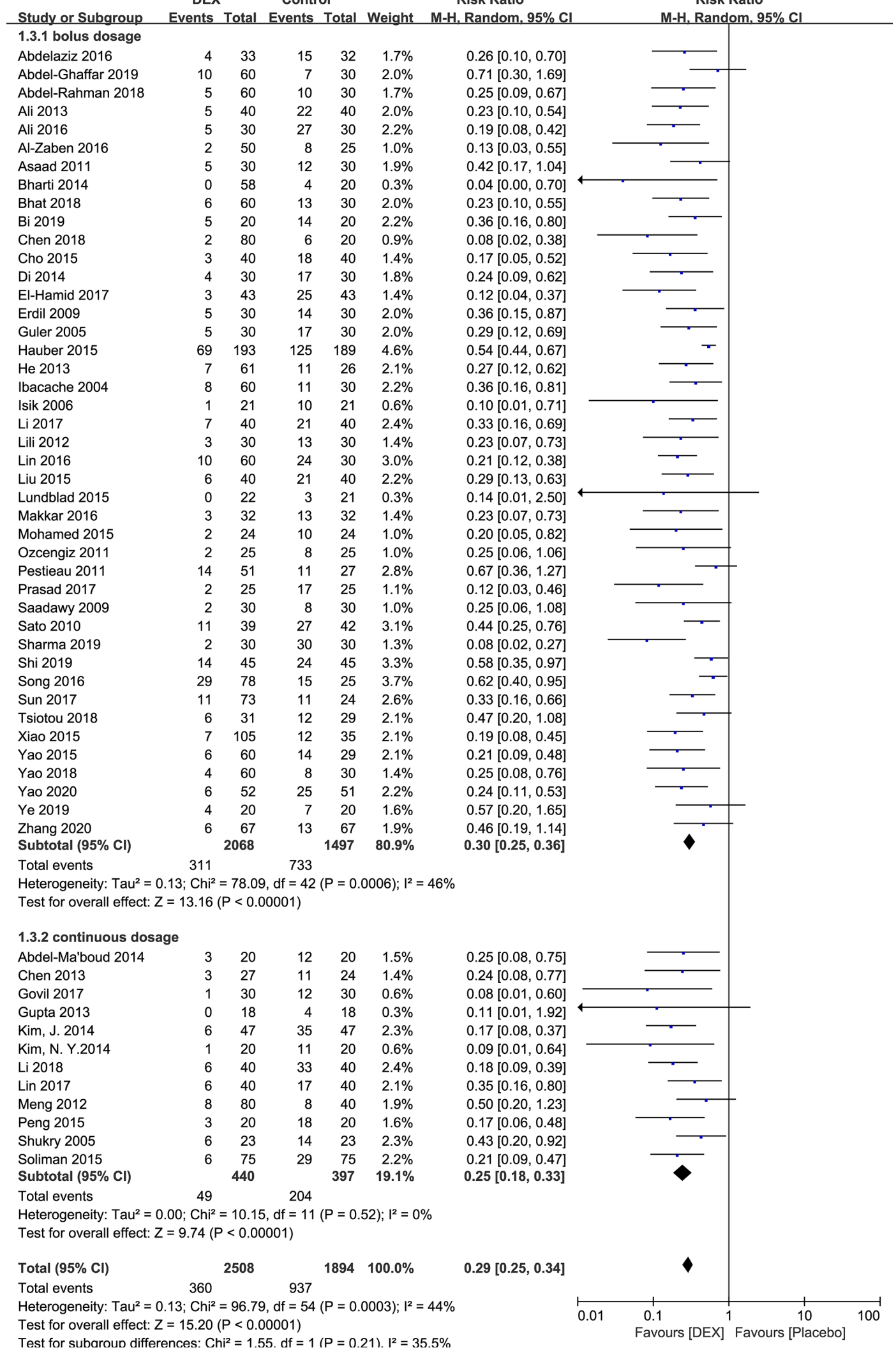

Figure S3 Subgroup analysis of EA incidence: different patterns. EA, emergence agitation. 


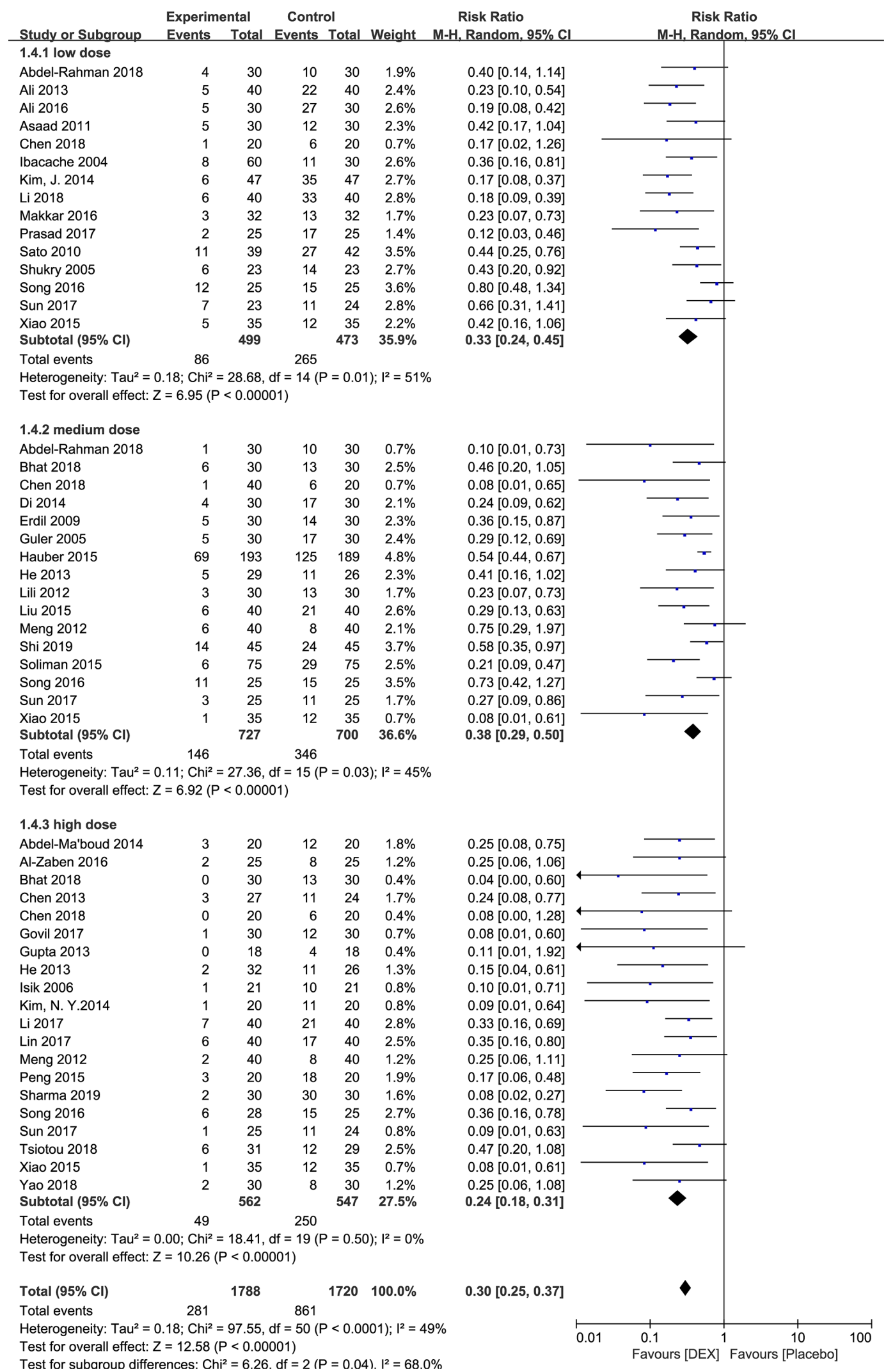

Figure S4 Subgroup analysis of EA incidence: different dose. EA, emergence agitation. 


\section{Appendix 1}

GRADE results

DEX compared to placebo or comparator for EA in children

Bibliography: DEX for EA in children. Cochrane Database of Systematic Reviews [Year], Issue [Issue].

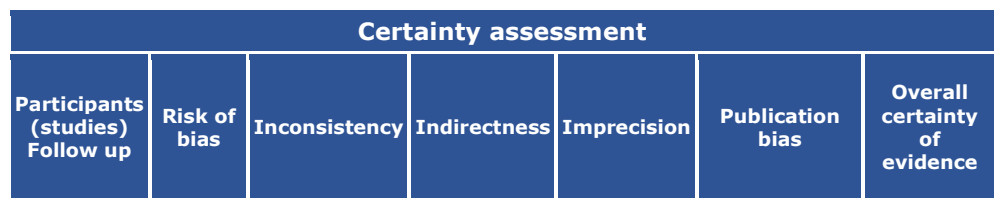

\begin{tabular}{|c|c|c|c|c|}
\hline \multicolumn{5}{|c|}{ Summary of findings } \\
\hline \multicolumn{2}{|c|}{ Study event rates (\%) } & \multirow{2}{*}{$\begin{array}{c}\text { Relative } \\
\text { effect } \\
\text { (95\% CI) }\end{array}$} & \multicolumn{2}{|c|}{$\begin{array}{l}\text { Anticipated absolute } \\
\text { effects }\end{array}$} \\
\hline $\begin{array}{c}\text { With } \\
\text { placebo or } \\
\text { comparater }\end{array}$ & With DEX & & \begin{tabular}{|l|} 
Risk with \\
placebo or \\
comparater
\end{tabular} & $\begin{array}{l}\text { Risk } \\
\text { difference } \\
\text { with DEX }\end{array}$ \\
\hline
\end{tabular}

EA incidence: dexmedetomidine vs placebo

\begin{tabular}{|c|c|c|c|c|c|c|c|c|c|c|c|}
\hline $\begin{array}{c}4402 \\
(55 \text { RCTs })\end{array}$ & $\begin{array}{c}\text { not } \\
\text { serious }\end{array}$ & not serious & not serious & not serious & $\begin{array}{c}\text { publication bias } \\
\text { strongly } \\
\text { suspected a }\end{array}$ & $\begin{array}{c}\oplus \oplus \oplus \bigcirc \\
\text { MODERATE }\end{array}$ & $\begin{array}{c}937 / 1894 \\
(49.5 \%)\end{array}$ & $\begin{array}{c}360 / 2508 \\
(14.4 \%)\end{array}$ & $\begin{array}{c}\text { RR 0.29 } \\
(0.25 \text { to } 0.34)\end{array}$ & $\begin{array}{c}495 \text { per } \\
1,000\end{array}$ & $\begin{array}{c}\mathbf{3 5 1} \text { fewer per } \\
\mathbf{1 , 0 0 0} \\
\text { (from } 371 \\
\text { fewer to } 327 \\
\text { fewer) }\end{array}$ \\
\hline
\end{tabular}

EA incidence subgroup: different route - intravenous

\begin{tabular}{|c|c|c|c|c|c|c|c|c|c|c|c|}
\hline $\begin{array}{c}3173 \\
(39 \text { RCTs) }\end{array}$ & $\begin{array}{c}\text { not } \\
\text { serious }\end{array}$ & not serious $^{b}$ & not serious & not serious & $\begin{array}{c}\text { publication bias } \\
\text { strongly } \\
\text { suspected }\end{array}$ & $\begin{array}{l}\oplus \oplus \oplus \bigcirc \\
\text { MODERATE }\end{array}$ & $\begin{array}{c}731 / 1385 \\
(52.8 \%)\end{array}$ & $\begin{array}{c}281 / 1788 \\
(15.7 \%)\end{array}$ & $\begin{array}{c}\text { RR } 0.29 \\
(0.24 \text { to } 0.35)\end{array}$ & $\begin{array}{c}528 \text { per } \\
1,000\end{array}$ & $\begin{array}{c}\mathbf{3 7 5} \text { fewer per } \\
\mathbf{1 , 0 0 0} \\
\text { (from } 401 \\
\text { fewer to } 343 \\
\text { fewer) }\end{array}$ \\
\hline
\end{tabular}

EA incidence subgroup: different route - intranasal

\begin{tabular}{|c|c|c|c|c|c|c|c|c|c|c|c|}
\hline $\begin{array}{c}685 \\
\text { (8 RCTs) }\end{array}$ & $\begin{array}{c}\text { not } \\
\text { serious }\end{array}$ & serious & not serious & not serious & none & $\begin{array}{c}\oplus \oplus \oplus \bigcirc \\
\text { MODERATE }\end{array}$ & $\begin{array}{l}141 / 299 \\
(47.2 \%)\end{array}$ & $\begin{array}{c}54 / 386 \\
(14.0 \%)\end{array}$ & $\begin{array}{c}\text { RR } 0.29 \\
(0.20 \text { to } 0.43)\end{array}$ & $\begin{array}{c}472 \text { per } \\
1,000\end{array}$ & $\begin{array}{c}\mathbf{3 3 5} \text { fewer per } \\
\mathbf{1 , 0 0 0} \\
\text { (from } 377 \\
\text { fewer to } 269 \\
\text { fewer) }\end{array}$ \\
\hline \multicolumn{12}{|c|}{ EA incidence subgroup: different route - oral } \\
\hline $\begin{array}{c}140 \\
(2 \text { RCTs) }\end{array}$ & $\begin{array}{c}\text { not } \\
\text { serious }\end{array}$ & not serious & not serious & serious ${ }^{d}$ & none & $\begin{array}{c}\oplus \oplus \oplus \bigcirc \\
\text { MODERATE }\end{array}$ & $\begin{array}{c}15 / 55 \\
(27.3 \%)\end{array}$ & $\begin{array}{c}12 / 85 \\
(14.1 \%)\end{array}$ & $\begin{array}{c}\mathbf{R R} \mathbf{0 . 5 0} \\
(0.18 \text { to } 1.34)\end{array}$ & $\begin{array}{c}273 \text { per } \\
1,000\end{array}$ & $\begin{array}{c}136 \text { fewer per } \\
\mathbf{1 , 0 0 0} \\
\text { (from } 224 \\
\text { fewer to } 93 \\
\text { more) }\end{array}$ \\
\hline
\end{tabular}

EA incidence subgroup: different route - caudal or nerve-blocking

\begin{tabular}{|c|c|c|c|c|c|c|c|c|c|c|c|}
\hline $\begin{array}{c}459 \\
\text { (8 RCTs) }\end{array}$ & $\begin{array}{c}\text { not } \\
\text { serious }\end{array}$ & not serious & not serious & not serious & none & $\begin{array}{c}\oplus \bigoplus \bigoplus \bigoplus \oplus \\
\mathrm{HIGH}\end{array}$ & $\begin{array}{l}66 / 210 \\
(31.4 \%)\end{array}$ & $\begin{array}{l}13 / 249 \\
(5.2 \%)\end{array}$ & $\begin{array}{c}\text { RR } \mathbf{0 . 2 4} \\
(0.14 \text { to } 0.41)\end{array}$ & $\begin{array}{c}314 \text { per } \\
1,000\end{array}$ & $\begin{array}{c}239 \text { fewer per } \\
\mathbf{1 , 0 0 0} \\
\text { (from } 270 \\
\text { fewer to } 185 \\
\text { fewer) }\end{array}$ \\
\hline
\end{tabular}

EA incidence subgroup: different time - premedication

\begin{tabular}{|c|c|c|c|c|c|c|c|c|c|c|c|}
\hline $\begin{array}{c}941 \\
\text { (11 RCTs) }\end{array}$ & $\begin{array}{l}\text { not } \\
\text { serious }\end{array}$ & not serious & not serious & not serious & none & $\underset{\mathrm{HIGH}}{\oplus \bigoplus \bigoplus \bigoplus}$ & $\begin{array}{l}183 / 389 \\
(47.0 \%)\end{array}$ & $\begin{array}{c}64 / 552 \\
(11.6 \%)\end{array}$ & $\begin{array}{c}\text { RR } \mathbf{0 . 2 7} \\
(0.20 \text { to } 0.36)\end{array}$ & $\begin{array}{c}470 \text { per } \\
1,000\end{array}$ & $\begin{array}{c}\mathbf{3 4 3} \text { fewer per } \\
\mathbf{1 , 0 0 0} \\
\text { (from } 376 \\
\text { fewer to } 301 \\
\text { fewer) }\end{array}$ \\
\hline
\end{tabular}

EA incidence subgroup: different time - after induction of anesthesia

\begin{tabular}{|c|c|c|c|c|c|c|c|c|c|c|c|}
\hline $\begin{array}{c}2615 \\
\text { (36 RCTs) }\end{array}$ & $\begin{array}{c}\text { not } \\
\text { serious }\end{array}$ & not serious & not serious & not serious & \begin{tabular}{|} 
publication bias \\
strongly \\
suspected e
\end{tabular} & $\begin{array}{c}\oplus \oplus \oplus \bigcirc \\
\text { MODERATE }\end{array}$ & $\begin{array}{c}506 / 1099 \\
(46.0 \%)\end{array}$ & $\begin{array}{c}198 / 1516 \\
(13.1 \%)\end{array}$ & $\begin{array}{c}\text { RR } \mathbf{0 . 3 0} \\
(0.25 \text { to } 0.37)\end{array}$ & $\begin{array}{c}460 \text { per } \\
1,000\end{array}$ & $\begin{array}{c}322 \text { fewer per } \\
\mathbf{1 , 0 0 0} \\
\text { (from } 345 \\
\text { fewer to } 290 \\
\text { fewer) }\end{array}$ \\
\hline
\end{tabular}

EA incidence subgroup: different time - before the end of surgery

\begin{tabular}{|c|c|c|c|c|c|c|c|c|c|c|c|}
\hline $\begin{array}{c}846 \\
\text { (8 RCTs) }\end{array}$ & $\begin{array}{c}\text { not } \\
\text { serious }\end{array}$ & serious $^{f}$ & not serious & not serious & \begin{tabular}{|c|} 
publication bias \\
strongly \\
suspected 9
\end{tabular} & $\underset{\text { LOW }}{\oplus \oplus \bigcirc \bigcirc}$ & $\begin{array}{l}248 / 406 \\
(61.1 \%)\end{array}$ & $\begin{array}{c}98 / 440 \\
(22.3 \%)\end{array}$ & $\begin{array}{c}\text { RR } \mathbf{0 . 2 6} \\
(0.16 \text { to } 0.43)\end{array}$ & $\begin{array}{c}611 \text { per } \\
1,000\end{array}$ & \begin{tabular}{|c|}
$\mathbf{4 5 2}$ fewer per \\
$\mathbf{1 , 0 0 0}$ \\
(from 513 \\
fewer to 348 \\
fewer)
\end{tabular} \\
\hline
\end{tabular}


EA incidence subgroup: bolus or continuous dosage - bolus dosage

\begin{tabular}{|c|c|c|c|c|c|c|c|c|c|c|c|}
\hline $\begin{array}{c}3565 \\
(43 \text { RCTs) }\end{array}$ & $\begin{array}{c}\text { not } \\
\text { serious }\end{array}$ & serious $^{h}$ & not serious & not serious & $\begin{array}{c}\text { publication bias } \\
\text { strongly } \\
\text { suspected f,i }\end{array}$ & $\begin{array}{c}\oplus \oplus \bigcirc \bigcirc \\
\text { LOW }\end{array}$ & $\begin{array}{c}733 / 1497 \\
(49.0 \%)\end{array}$ & $\begin{array}{c}311 / 2068 \\
(15.0 \%)\end{array}$ & $\begin{array}{c}\mathbf{R R} \mathbf{0 . 3 0} \\
(0.25 \text { to } 0.36)\end{array}$ & $\begin{array}{c}490 \text { per } \\
1,000\end{array}$ & $\begin{array}{c}\mathbf{3 4 3} \text { fewer per } \\
\mathbf{1 , 0 0 0} \\
\text { (from } 367 \\
\text { fewer to } 313 \\
\text { fewer) }\end{array}$ \\
\hline
\end{tabular}

EA incidence subgroup: bolus or continuous dosage - continuous dosage

\begin{tabular}{|c|c|c|c|c|c|c|c|c|c|c|c|}
\hline $\begin{array}{c}837 \\
\text { (12 RCTs) }\end{array}$ & $\begin{array}{c}\text { not } \\
\text { serious }\end{array}$ & not serious & not serious & not serious & none & $\begin{array}{c}\bigoplus \bigoplus \bigoplus \bigoplus \\
\mathrm{HIGH}\end{array}$ & $\begin{array}{l}204 / 397 \\
(51.4 \%)\end{array}$ & $\begin{array}{c}49 / 440 \\
(11.1 \%)\end{array}$ & $\begin{array}{c}\mathbf{R R} \mathbf{0 . 2 5} \\
(0.18 \text { to } 0.33)\end{array}$ & $\begin{array}{c}514 \text { per } \\
1,000\end{array}$ & $\begin{array}{c}385 \text { fewer per } \\
\mathbf{1 , 0 0 0} \\
\text { (from } 421 \\
\text { fewer to } 344 \\
\text { fewer) }\end{array}$ \\
\hline
\end{tabular}

EA incidence: dexmedetomidine vs midazolam

\begin{tabular}{|c|c|c|c|c|c|c|c|c|c|c|c|}
\hline $\begin{array}{c}779 \\
\text { (12 RCTs) }\end{array}$ & $\begin{array}{c}\text { not } \\
\text { serious }\end{array}$ & not serious & not serious & not serious & none & $\underset{\mathrm{HIGH}}{\bigoplus \oplus \bigoplus \bigoplus}$ & $\begin{array}{l}132 / 386 \\
(34.2 \%)\end{array}$ & $\begin{array}{c}45 / 393 \\
(11.5 \%)\end{array}$ & $\begin{array}{c}\text { RR 0.34 } \\
(0.25 \text { to } 0.45)\end{array}$ & $\begin{array}{c}342 \text { per } \\
1,000\end{array}$ & $\begin{array}{c}226 \text { fewer per } \\
\mathbf{1 , 0 0 0} \\
\text { (from } 256 \\
\text { fewer to } 188 \\
\text { fewer) }\end{array}$ \\
\hline
\end{tabular}

\section{EA incidence: Dexmedetomidine vs fentanyl}

\begin{tabular}{|c|c|c|c|c|c|c|c|c|c|c|c|}
\hline $\begin{array}{c}371 \\
\text { (5 RCTs) }\end{array}$ & $\begin{array}{c}\text { not } \\
\text { serious }\end{array}$ & serious $^{j}$ & not serious & serious ${ }^{k}$ & none & $\underset{\text { LOW }}{\oplus \oplus \bigcirc}$ & $\begin{array}{c}49 / 171 \\
(28.7 \%)\end{array}$ & $\begin{array}{l}40 / 200 \\
(20.0 \%)\end{array}$ & $\begin{array}{c}\mathbf{R R} \mathbf{0 . 7 8} \\
\text { (0.42 to } 1.44)\end{array}$ & $\begin{array}{c}287 \text { per } \\
1,000\end{array}$ & $\begin{array}{c}\mathbf{6 3} \text { fewer per } \\
\mathbf{1 , 0 0 0} \\
\text { (from } 166 \\
\text { fewer to } 126 \\
\text { more) }\end{array}$ \\
\hline
\end{tabular}

EA incidence: Dexmedetomidine vs propofol

\begin{tabular}{|c|c|c|c|c|c|c|c|c|c|c|c|}
\hline $\begin{array}{c}188 \\
\text { (3 RCTs) }\end{array}$ & $\begin{array}{c}\text { not } \\
\text { serious }\end{array}$ & not serious & not serious & very serious ${ }^{\prime}$ & none & $\begin{array}{c}\oplus \oplus \bigcirc \bigcirc \\
\text { LOW }\end{array}$ & $\begin{array}{c}22 / 96 \\
(22.9 \%)\end{array}$ & $\begin{array}{c}11 / 92 \\
(12.0 \%)\end{array}$ & $\begin{array}{c}\text { RR } \mathbf{0 . 5 1} \\
(0.27 \text { to } 1.00)\end{array}$ & $\begin{array}{c}229 \text { per } \\
1,000\end{array}$ & $\begin{array}{c}112 \text { fewer per } \\
\mathbf{1 , 0 0 0} \\
\text { (from } 167\end{array}$ \\
\hline & & & & & & & & & & & $\begin{array}{c}\text { fewer to } 0 \\
\text { fewer) }\end{array}$ \\
\hline
\end{tabular}

EA incidence: Dexmedetomidine vs ketamine

\begin{tabular}{|c|c|c|c|c|c|c|c|c|c|c|c|}
\hline $\begin{array}{c}114 \\
\text { (2 RCTs) }\end{array}$ & $\begin{array}{c}\text { not } \\
\text { serious }\end{array}$ & not serious & not serious & $\underset{\mathrm{m}}{\text { very serious }}$ & none & $\underset{\text { LOW }}{\oplus \oplus \bigcirc \bigcirc}$ & $\begin{array}{c}12 / 57 \\
(21.1 \%)\end{array}$ & $\begin{array}{c}5 / 57 \\
(8.8 \%)\end{array}$ & $\begin{array}{c}\text { RR 0.42 } \\
(0.16 \text { to } 1.11)\end{array}$ & $\begin{array}{c}211 \text { per } \\
1,000\end{array}$ & $\begin{array}{c}122 \text { fewer per } \\
\mathbf{1 , 0 0 0} \\
\text { (from } 177 \\
\text { fewer to } 23 \\
\text { more) }\end{array}$ \\
\hline
\end{tabular}

\section{EA incidence: Dexmedetomidine vs ketofol}

\begin{tabular}{|c|c|c|c|c|c|c|c|c|c|c|c|}
\hline $\begin{array}{c}110 \\
(2 \text { RCTs })\end{array}$ & $\begin{array}{c}\text { not } \\
\text { serious }\end{array}$ & not serious & not serious & $\begin{array}{c}\text { very serious } \\
\mathrm{n}\end{array}$ & none & $\begin{array}{c}\oplus \oplus \bigcirc \bigcirc \\
\text { LOW }\end{array}$ & $\begin{array}{c}13 / 55 \\
(23.6 \%)\end{array}$ & $\begin{array}{c}7 / 55 \\
(12.7 \%)\end{array}$ & $\begin{array}{c}\mathbf{R R} \mathbf{0 . 5 4} \\
(0.23 \text { to } 1.24)\end{array}$ & $\begin{array}{c}236 \text { per } \\
1,000\end{array}$ & $\begin{array}{c}\mathbf{1 0 9} \text { fewer per } \\
\mathbf{1 , 0 0 0} \\
\text { (from } 182 \\
\text { fewer to } 57 \\
\text { more })\end{array}$ \\
\hline
\end{tabular}

\section{different Dose}

\begin{tabular}{|c|c|c|c|c|c|c|c|c|c|c|c|}
\hline $\begin{array}{c}3508 \\
\text { (39 RCTs) }\end{array}$ & $\begin{array}{c}\text { not } \\
\text { serious }\end{array}$ & serious ${ }^{\circ}$ & not serious & not serious & $\begin{array}{l}\text { publication bias } \\
\text { strongly } \\
\text { suspected }{ }^{\mathrm{P}}\end{array}$ & $\underset{\text { LOW }}{\oplus \oplus \bigcirc \bigcirc}$ & $\begin{array}{c}861 / 1720 \\
(50.1 \%)\end{array}$ & $\begin{array}{c}281 / 1788 \\
(15.7 \%)\end{array}$ & $\begin{array}{c}\text { RR 0.30 } \\
(0.25 \text { to } 0.37)\end{array}$ & $\begin{array}{c}501 \text { per } \\
1,000\end{array}$ & \begin{tabular}{|c}
$\mathbf{3 5 0}$ fewer per \\
$\mathbf{1 , 0 0 0}$ \\
(from 375 \\
fewer to 315 \\
fewer)
\end{tabular} \\
\hline
\end{tabular}

\section{different Dose - low dose}

\begin{tabular}{|c|c|c|c|c|c|c|c|c|c|c|c|}
\hline $\begin{array}{c}972 \\
(15 \text { RCTs })\end{array}$ & $\begin{array}{c}\text { not } \\
\text { serious }\end{array}$ & serious 9 & not serious & not serious & $\begin{array}{c}\text { publication bias } \\
\text { strongly } \\
\text { suspected }\end{array}$ & $\begin{array}{c}\oplus \oplus \bigcirc \bigcirc \\
\text { LOW }\end{array}$ & $\begin{array}{c}265 / 473 \\
(56.0 \%)\end{array}$ & $\begin{array}{c}86 / 499 \\
(17.2 \%)\end{array}$ & $\begin{array}{c}\text { RR 0.33 } \\
(0.24 \text { to } 0.45)\end{array}$ & $\begin{array}{c}560 \text { per } \\
1,000\end{array}$ & $\begin{array}{c}\mathbf{3 7 5} \text { fewer per } \\
\mathbf{1 , 0 0 0} \\
\text { (from } 426 \\
\text { fewer to } 308 \\
\text { fewer) }\end{array}$ \\
\hline
\end{tabular}

different Dose - medium dose 


\begin{tabular}{|c|c|c|c|c|c|c|c|c|c|c|c|}
\hline $\begin{array}{c}1427 \\
(16 \text { RCTs) }\end{array}$ & $\begin{array}{c}\text { not } \\
\text { serious }\end{array}$ & serious ${ }^{\mathrm{s}}$ & not serious & not serious & $\begin{array}{c}\text { publication bias } \\
\text { strongly } \\
\text { suspected f,t }\end{array}$ & $\underset{\text { LOW }}{\oplus \oplus \bigcirc \bigcirc}$ & $\begin{array}{l}346 / 700 \\
(49.4 \%)\end{array}$ & $\begin{array}{l}146 / 727 \\
(20.1 \%)\end{array}$ & $\begin{array}{c}\text { RR } \mathbf{0 . 3 8} \\
(0.29 \text { to } 0.50)\end{array}$ & $\begin{array}{c}494 \text { per } \\
1,000\end{array}$ & $\begin{array}{c}\mathbf{3 0 6} \text { fewer per } \\
\mathbf{1 , 0 0 0} \\
\text { (from } 351 \\
\text { fewer to } 247 \\
\text { fewer) }\end{array}$ \\
\hline
\end{tabular}

different Dose - high dose

\begin{tabular}{|c|c|c|c|c|c|c|c|c|c|c|c|}
\hline $\begin{array}{c}1109 \\
\text { (20 RCTs) }\end{array}$ & $\begin{array}{c}\text { not } \\
\text { serious }\end{array}$ & not serious & not serious & not serious & $\begin{array}{l}\text { publication bias } \\
\text { strongly } \\
\text { suspected }\end{array}$ & $\begin{array}{c}\oplus \oplus \oplus \bigcirc \\
\text { MODERATE }\end{array}$ & $\begin{array}{l}250 / 547 \\
(45.7 \%)\end{array}$ & $\begin{array}{l}49 / 562 \\
(8.7 \%)\end{array}$ & $\begin{array}{c}\text { RR } \mathbf{0 . 2 4} \\
(0.18 \text { to } 0.31)\end{array}$ & $\begin{array}{c}457 \text { per } \\
1,000\end{array}$ & $\begin{array}{c}\mathbf{3 4 7} \text { fewer per } \\
\mathbf{1 , 0 0 0} \\
\text { (from } 375 \\
\text { fewer to } 315 \\
\text { fewer) }\end{array}$ \\
\hline
\end{tabular}

CI: Confidence interval; RR: Risk ratio

\title{
Explanations
}

\author{
a. Egger's tests $P=0.000$ \\ b. Heterogeneity: $\operatorname{Tau}^{2}=0.13 ; \mathrm{Chi}^{2}=71.44, \mathrm{df}=38(\mathrm{P}=0.0008) ; \mathrm{I}^{2}=47 \%$ \\ c. Egger's tests $\mathrm{P}=0.000$ \\ d. Heterogeneity: $\mathrm{Tau}^{2}=0.27 ; \mathrm{Chi}^{2}=20.41, \mathrm{df}=7(\mathrm{P}=0.005) ; \mathrm{I}^{2}=66 \%$ \\ e. Egger's tests $P=0.000$ \\ f. Heterogeneity: $\mathrm{Tau}^{2}=0.27 ; \mathrm{Chi}^{2}=20.41, \mathrm{df}=7(\mathrm{P}=0.005) ; \mathrm{I}^{2}=66 \%$ \\ g. Egger's tests $P=0.000$ \\ h. Heterogeneity: $\mathrm{Tau}^{2}=0.13 ; \mathrm{Chi}^{2}=78.09, \mathrm{df}=42(\mathrm{P}=0.0006) ; \mathrm{I}^{2}=46 \%$ \\ i. Egger's tests $\mathrm{P}=0.000$ \\ j. Heterogeneity: $\mathrm{Tau}^{2}=0.24 ; \mathrm{Chi}^{2}=8.00, \mathrm{df}=4(\mathrm{P}=0.09) ; \mathrm{I}^{2}=50 \%$ \\ k. cumulative Z-curve did not enter the futility area or crossed TSMB \\ I. cumulative Z-curve did not enter the futility area or crossed TSMB \\ m. cumulative Z-curve did not enter the futility area or crossed TSMB \\ n. cumulative Z-curve did not enter the futility area or crossed TSMB \\ o. Heterogeneity: $\mathrm{Tau}^{2}=0.18 ; \mathrm{Chi}^{2}=97.55, \mathrm{df}=50(\mathrm{P}<0.0001) ; \mathrm{I}^{2}=49 \%$ \\ p. Egger's tests $P=0.000$ \\ q. Heterogeneity: $\operatorname{Tau}^{2}=0.18 ; \mathrm{Chi}^{2}=28.68, \mathrm{df}=14(\mathrm{P}=0.01) ; \mathrm{I}^{2}=51 \%$ \\ r. Egger's tests $P=0.027$ \\ s. Heterogeneity: $\mathrm{Tau}^{2}=0.11 ; \mathrm{Chi}^{2}=27.36, \mathrm{df}=15(\mathrm{P}=0.03) ; \mathrm{I}^{2}=45 \%$ \\ t. Egger's tests $\mathrm{P}=0.001$ \\ u. Egger's tests $P=0.000$
}


DEX compared to placebo for severe EA in children

Bibliography: . DEX for EA in children. Cochrane Database of Systematic Reviews [Year], Issue [Issue].

\begin{tabular}{|c|c|c|c|c|c|c|c|c|c|c|c|}
\hline \multicolumn{7}{|c|}{ Certainty assessment } & \multicolumn{5}{|c|}{ Summary of findings } \\
\hline \multirow{2}{*}{$\begin{array}{c}\text { Participants } \\
\text { (studies) } \\
\text { Follow up }\end{array}$} & \multirow[b]{2}{*}{$\begin{array}{c}\text { Risk } \\
\text { of bias }\end{array}$} & \multirow[b]{2}{*}{ Inconsistency } & \multirow[b]{2}{*}{ Indirectness } & \multirow[b]{2}{*}{ Imprecision } & \multirow[b]{2}{*}{$\begin{array}{l}\text { Publication } \\
\text { bias }\end{array}$} & \multirow{2}{*}{$\begin{array}{c}\text { Overall } \\
\text { certainty } \\
\text { of } \\
\text { evidence }\end{array}$} & \multicolumn{2}{|c|}{$\begin{array}{c}\text { Study event rates } \\
(\%)\end{array}$} & \multirow{2}{*}{$\begin{array}{c}\text { Relative } \\
\text { effect } \\
(95 \% \mathrm{CI})\end{array}$} & \multicolumn{2}{|c|}{$\begin{array}{c}\text { Anticipated absolute } \\
\text { effects }\end{array}$} \\
\hline & & & & & & & $\begin{array}{l}\text { With } \\
\text { placebo }\end{array}$ & With DEX & & $\begin{array}{l}\text { Risk with } \\
\text { placebo }\end{array}$ & $\begin{array}{c}\text { Risk } \\
\text { difference } \\
\text { with DEX }\end{array}$ \\
\hline \multicolumn{12}{|c|}{ Severe EA incidence: DEX vs Placebo } \\
\hline $\begin{array}{c}927 \\
\text { (11 RCTs) }\end{array}$ & \begin{tabular}{|c|} 
not \\
serious
\end{tabular} & not serious & not serious & not serious & none & $\begin{array}{c}\oplus \bigoplus \bigoplus \oplus \\
\mathrm{HIGH}\end{array}$ & $\begin{array}{l}137 / 420 \\
(32.6 \%)\end{array}$ & $\begin{array}{l}40 / 507 \\
(7.9 \%)\end{array}$ & $\begin{array}{c}\mathbf{R R} \mathbf{0 . 2 3} \\
(0.16 \text { to } \\
0.32)\end{array}$ & $\begin{array}{c}326 \text { per } \\
1,000\end{array}$ & $\begin{array}{l}\mathbf{2 5 1} \text { fewer } \\
\text { per 1,000 } \\
\text { (from } 274 \\
\text { fewer to } 222 \\
\text { fewer) }\end{array}$ \\
\hline
\end{tabular}

CI: Confidence interval; RR: Risk ratio

DEX compared to placebo or compatater for emergence time in children

Bibliography: . DEX for EA in children. Cochrane Database of Systematic Reviews [Year], Issue [Issue].

\begin{tabular}{|c|c|c|c|c|c|c|c|c|c|c|c|}
\hline \multicolumn{7}{|c|}{ Certainty assessment } & \multicolumn{5}{|c|}{ Summary of findings } \\
\hline \multirow{2}{*}{$\begin{array}{c}\text { Participants } \\
\text { (studies) } \\
\text { Follow up }\end{array}$} & \multirow{2}{*}{$\begin{array}{l}\text { Risk } \\
\text { of } \\
\text { bias }\end{array}$} & \multirow[b]{2}{*}{ Inconsistency } & \multirow[b]{2}{*}{ Indirectness } & \multirow[b]{2}{*}{ Imprecision } & \multirow{2}{*}{$\begin{array}{c}\text { Publication } \\
\text { bias }\end{array}$} & \multirow{2}{*}{$\begin{array}{c}\text { Overall } \\
\text { certainty } \\
\text { of } \\
\text { evidence }\end{array}$} & \multicolumn{2}{|c|}{$\begin{array}{c}\text { Study event rates } \\
(\%)\end{array}$} & \multirow{2}{*}{$\begin{array}{c}\text { Relative } \\
\text { effect } \\
(95 \% \text { CI) }\end{array}$} & \multicolumn{2}{|c|}{$\begin{array}{c}\text { Anticipated absolute } \\
\text { effects }\end{array}$} \\
\hline & & & & & & & $\begin{array}{c}\text { With } \\
\text { placebo or } \\
\text { compatater }\end{array}$ & $\begin{array}{l}\text { With } \\
\text { DEX }\end{array}$ & & $\begin{array}{l}\text { Risk with } \\
\text { placebo or } \\
\text { compatater }\end{array}$ & $\begin{array}{c}\text { Risk } \\
\text { difference } \\
\text { with DEX }\end{array}$ \\
\hline
\end{tabular}

Emergence time: DEX vs Placebo

\begin{tabular}{|c|c|c|c|c|c|c|c|c|c|c|c|}
\hline $\begin{array}{c}3451 \\
(45 \text { RCTs) }\end{array}$ & $\begin{array}{c}\text { not } \\
\text { serious }\end{array}$ & very serious ${ }^{a}$ & not serious & not serious & $\begin{array}{c}\text { publication } \\
\text { bias strongly } \\
\text { suspected }^{\mathrm{b}}\end{array}$ & $\begin{array}{c}\oplus \bigcirc \bigcirc \\
\bigcirc \\
\text { VERY } \\
\text { LOW }\end{array}$ & 1462 & 1989 & - & $\begin{array}{c}\text { The mean } \\
\text { emergence } \\
\text { time: DEX } \\
\text { vs Placebo } \\
\text { was } \mathbf{0}\end{array}$ & $\begin{array}{c}\text { MD } 2.28 \\
\text { higher } \\
\text { (1.49 higher } \\
\text { to } 3.08 \\
\text { higher) }\end{array}$ \\
\hline
\end{tabular}

Emergence time: DEX vs Midazolam

\begin{tabular}{|c|c|c|c|c|c|c|c|c|c|c|c|}
\hline $\begin{array}{c}456 \\
\text { (6 RCTs) }\end{array}$ & $\begin{array}{c}\text { not } \\
\text { serious }\end{array}$ & very serious $^{\mathrm{c}}$ & not serious & serious $^{d}$ & none & $\begin{array}{c}\oplus \bigcirc \bigcirc \\
\bigcirc \\
\text { VERY } \\
\text { LOW }\end{array}$ & 226 & 230 & - & $\begin{array}{c}\text { The mean } \\
\text { emergence } \\
\text { time: DEX } \\
\text { vs } \\
\text { Midazolam } \\
\text { was } 0\end{array}$ & $\begin{array}{c}\text { MD } \mathbf{0 . 4 5} \\
\text { higher } \\
\text { (1.45 lower } \\
\text { to } 2.35 \\
\text { higher) }\end{array}$ \\
\hline
\end{tabular}

\section{Emergence time: DEX vs Fentanyl}

\begin{tabular}{|c|c|c|c|c|c|c|c|c|c|c|c|}
\hline $\begin{array}{c}371 \\
\text { (5 RCTs) }\end{array}$ & $\begin{array}{c}\text { not } \\
\text { serious }\end{array}$ & very serious ${ }^{\mathrm{e}}$ & not serious & serious $^{f}$ & none & $\begin{array}{c}\oplus \bigcirc \bigcirc \\
\bigcirc \\
\text { VERY } \\
\text { LOW }\end{array}$ & 171 & 200 & - & $\begin{array}{l}\text { The mean } \\
\text { emergence } \\
\text { time: DEX } \\
\text { vs Fentanyl } \\
\text { was } \mathbf{0}\end{array}$ & $\begin{array}{c}\text { MD } 0.46 \\
\text { lower } \\
\text { (1.94 lower } \\
\text { to } 1.02 \\
\text { higher) }\end{array}$ \\
\hline
\end{tabular}

CI: Confidence interval; MD: Mean difference

\section{Explanations}

\footnotetext{
a. Heterogeneity: Tau $^{2}=0.83 ; \mathrm{Chi}^{2}=622.02, \mathrm{df}=44(\mathrm{P}<0.00001) ; \mathrm{I}^{2}=93 \%$

b. Egger's tests $P=0.000$

c. Heterogeneity: $\mathrm{Tau}^{2}=5.33 ; \mathrm{Chi}^{2}=125.26, \mathrm{df}=5(\mathrm{P}<0.00001) ; \mathrm{I}^{2}=96 \%$

d. the cumulative Z-curve did not enter the futility area or crossed TSMB

e. Heterogeneity: $\mathrm{Tau}^{2}=2.12 ; \mathrm{Chi}^{2}=19.55, \mathrm{df}=4(\mathrm{P}=0.0006) ; \mathrm{I}^{2}=80 \%$

f. the cumulative Z-curve did not enter the futility area or crossed TSMB
} 
DEX compared to placebo or comparater for discharge time from recovery room in children Bibliography: . DEX for EA in children. Cochrane Database of Systematic Reviews [Year], Issue [Issue].

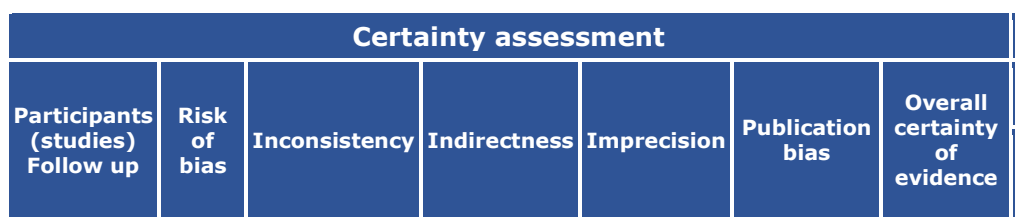

\begin{tabular}{|c|c|c|c|c|}
\hline \multicolumn{5}{|c|}{ Summary of findings } \\
\hline \multicolumn{2}{|c|}{$\begin{array}{l}\text { Study event rates } \\
(\%)\end{array}$} & \multirow{2}{*}{$\begin{array}{l}\text { Relative } \\
\text { effect } \\
(95 \% \mathrm{CI})\end{array}$} & \multicolumn{2}{|c|}{$\begin{array}{l}\text { Anticipated absolute } \\
\text { effects }\end{array}$} \\
\hline $\begin{array}{c}\text { With } \\
\text { placebo or } \\
\text { comparater }\end{array}$ & $\begin{array}{l}\text { With } \\
\text { DEX }\end{array}$ & & $\begin{array}{l}\text { Risk with } \\
\text { placebo or } \\
\text { comparater }\end{array}$ & $\begin{array}{l}\text { Risk } \\
\text { difference } \\
\text { with DEX }\end{array}$ \\
\hline
\end{tabular}

Discharge time: DEX vs placebo

\begin{tabular}{|c|c|c|c|c|c|c|c|c|c|c|c|}
\hline $\begin{array}{c}2725 \\
\text { (31 RCTs) }\end{array}$ & $\begin{array}{c}\text { not } \\
\text { serious }\end{array}$ & very serious $^{a}$ & not serious & serious $^{b}$ & none & $\begin{array}{l}\oplus \bigcirc \bigcirc \bigcirc \\
\text { VERY LOW }\end{array}$ & 1186 & 1539 & - & $\begin{array}{c}\text { The mean } \\
\text { discharge } \\
\text { time: DEX } \\
\text { vs placebo } \\
\text { was } \mathbf{0}\end{array}$ & $\begin{array}{c}\text { MD 1.27 } \\
\text { higher } \\
\text { (2.43 lower } \\
\text { to } 4.96 \\
\text { higher) }\end{array}$ \\
\hline
\end{tabular}

Discharge time: DEX vs Midazolam

\begin{tabular}{|c|c|c|c|c|c|c|c|c|c|c|c|}
\hline $\begin{array}{c}307 \\
\text { (4 RCTs) }\end{array}$ & $\begin{array}{c}\text { not } \\
\text { serious }\end{array}$ & not serious & not serious & serious $^{c}$ & none & $\begin{array}{c}\bigoplus \bigoplus \oplus \bigcirc \\
\text { MODERATE }\end{array}$ & 152 & 155 & - & $\begin{array}{c}\text { The mean } \\
\text { discharge } \\
\text { time: DEX } \\
\text { vs } \\
\text { Midazolam } \\
\text { was } \mathbf{0}\end{array}$ & $\begin{array}{c}\text { MD } \mathbf{0 . 9 4} \\
\text { lower } \\
\text { (1.82 lower } \\
\text { to } 0.06 \\
\text { lower) }\end{array}$ \\
\hline
\end{tabular}

\section{Discharge time: DEX vs Fentanyl}

\begin{tabular}{|c|c|c|c|c|c|c|c|c|c|c|c|}
\hline $\begin{array}{c}189 \\
\text { (3 RCTs) }\end{array}$ & $\begin{array}{c}\text { not } \\
\text { serious }\end{array}$ & serious $^{d}$ & not serious & serious ${ }^{e}$ & none & $\underset{\text { LOW }}{\oplus \oplus \bigcirc \bigcirc}$ & 80 & 109 & - & $\begin{array}{c}\text { The mean } \\
\text { discharge } \\
\text { time: DEX } \\
\text { vs Fentanyl } \\
\text { was } \mathbf{0}\end{array}$ & $\begin{array}{c}\text { MD } 3.68 \\
\text { higher } \\
\text { (3 lower to } \\
10.37 \\
\text { higher) }\end{array}$ \\
\hline
\end{tabular}

CI: Confidence interval; MD: Mean difference

\section{Explanations}
a. Heterogeneity: $\mathrm{Tau}^{2}=100.60 ; \mathrm{Chi}^{2}=2343.93, \mathrm{df}=30(\mathrm{P}<0.00001) ; \mathrm{I}^{2}=99 \%$
b. the cumulative Z-curve did not enter the futility area or crossed TSMB
C. the cumulative Z-curve did not enter the futility area or crossed TSMB
d. Heterogeneity: $\mathrm{Tau}^{2}=21.16 ; \mathrm{Chi}^{2}=5.46, \mathrm{df}=2(\mathrm{P}=0.07) ; \mathrm{I}^{2}=63 \%$
e. the cumulative Z-curve did not enter the futility area or crossed TSMB 
DEX compared to placebo or comparater for Patients requiring rescue analgesia in children Bibliography: . DEX for EA in children. Cochrane Database of Systematic Reviews [Year], Issue [Issue].

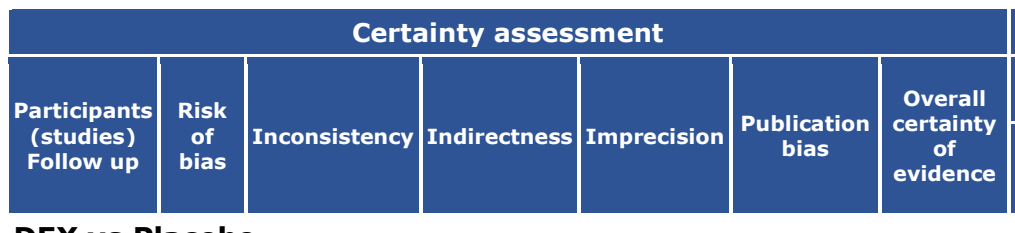

\begin{tabular}{|c|c|c|c|c|}
\hline \multicolumn{5}{|c|}{ Summary of findings } \\
\hline \multicolumn{2}{|c|}{$\begin{array}{c}\text { Study event rates } \\
(\%)\end{array}$} & \multirow{2}{*}{$\begin{array}{c}\text { Relative } \\
\text { effect } \\
(95 \% \mathrm{CI})\end{array}$} & \multicolumn{2}{|c|}{$\begin{array}{c}\text { Anticipated absolute } \\
\text { effects }\end{array}$} \\
\hline $\begin{array}{c}\text { With } \\
\text { placebo or } \\
\text { comparater }\end{array}$ & $\begin{array}{l}\text { With } \\
\text { DEX }\end{array}$ & & $\begin{array}{l}\text { Risk with } \\
\text { placebo or } \\
\text { comparater }\end{array}$ & $\begin{array}{c}\text { Risk } \\
\text { difference } \\
\text { with DEX }\end{array}$ \\
\hline
\end{tabular}

DEX vs Placebo

\begin{tabular}{|c|c|c|c|c|c|c|c|c|c|c|c|}
\hline $\begin{array}{c}2031 \\
(23 \text { RCTs) }\end{array}$ & $\begin{array}{c}\text { not } \\
\text { serious }\end{array}$ & serious $^{a}$ & not serious & not serious & $\begin{array}{c}\text { publication } \\
\text { bias strongly } \\
\text { suspected }^{\mathrm{b}}\end{array}$ & $\underset{\text { LOW }}{\oplus \oplus \bigcirc \bigcirc}$ & $\begin{array}{l}334 / 893 \\
(37.4 \%)\end{array}$ & $\begin{array}{c}212 / 1138 \\
(18.6 \%)\end{array}$ & $\begin{array}{c}\mathbf{R R} \mathbf{0 . 4 3} \\
(0.31 \text { to } \\
0.59)\end{array}$ & $\begin{array}{c}374 \text { per } \\
1,000\end{array}$ & $\begin{array}{l}\mathbf{2 1 3} \text { fewer } \\
\text { per 1,000 } \\
\text { (from } 258 \\
\text { fewer to } 153 \\
\text { fewer) }\end{array}$ \\
\hline
\end{tabular}

\section{DEX vs Midazolam}

\begin{tabular}{|c|c|c|c|c|c|c|c|c|c|c|c|}
\hline $\begin{array}{c}396 \\
\text { (5 RCTs) }\end{array}$ & $\begin{array}{c}\text { not } \\
\text { serious }\end{array}$ & not serious & not serious & serious $^{c}$ & none & $\begin{array}{c}\oplus \bigoplus \bigoplus \bigcirc \\
\text { MODERATE }\end{array}$ & $\begin{array}{c}31 / 196 \\
(15.8 \%)\end{array}$ & $\begin{array}{l}18 / 200 \\
(9.0 \%)\end{array}$ & $\begin{array}{c}\mathbf{R R} \mathbf{0 . 5 8} \\
(0.36 \text { to } \\
0.94)\end{array}$ & $\begin{array}{c}158 \text { per } \\
1,000\end{array}$ & $\begin{array}{c}\mathbf{6 6} \text { fewer } \\
\text { per } \mathbf{1 , 0 0 0} \\
\text { (from } 101 \\
\text { fewer to } 9 \\
\text { fewer) }\end{array}$ \\
\hline
\end{tabular}

DEX vs fentanyl

\begin{tabular}{|c|c|c|c|c|c|c|c|c|c|c|c|}
\hline $\begin{array}{c}253 \\
(3 \mathrm{RCTs})\end{array}$ & \begin{tabular}{|c|} 
not \\
serious
\end{tabular} & not serious & not serious & serious $^{d}$ & none & $\begin{array}{c}\bigoplus \bigoplus \bigoplus \bigcirc \\
\text { MODERATE }\end{array}$ & $\begin{array}{c}35 / 113 \\
(31.0 \%)\end{array}$ & $\begin{array}{c}16 / 140 \\
(11.4 \%)\end{array}$ & $\begin{array}{c}\mathbf{R R} \mathbf{0 . 3 9} \\
(0.22 \text { to } \\
0.66)\end{array}$ & $\begin{array}{c}310 \text { per } \\
1,000\end{array}$ & $\begin{array}{c}189 \text { fewer } \\
\text { per 1,000 } \\
\text { (from } 242 \\
\text { fewer to } 105 \\
\text { fewer) }\end{array}$ \\
\hline
\end{tabular}

CI: Confidence interval; RR: Risk ratio

\section{Explanations}
a. Heterogeneity: $\mathrm{Tau}^{2}=0.27 ; \mathrm{Chi}^{2}=86.75, \mathrm{df}=20(\mathrm{P}<0.00001) ; \mathrm{I}^{2}=77 \%$
b. Egger's tests $P=0.002$
c. the cumulative Z-curve did not enter the futility area or crossed TSMB
d. the cumulative Z-curve did not enter the futility area or crossed TSMB 
DEX compared to placebo or compatater for PONV in children

Bibliography: . DEX for EA in children. Cochrane Database of Systematic Reviews [Year], Issue [Issue].

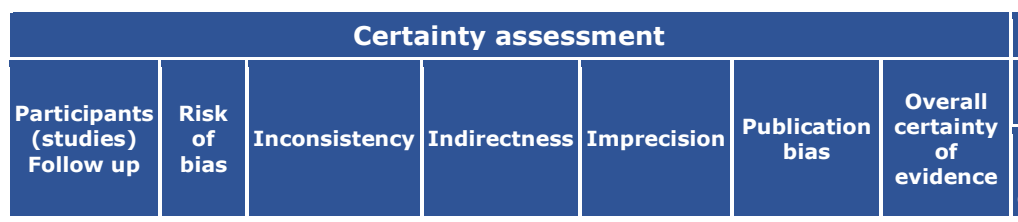

\begin{tabular}{|c|c|c|c|c|}
\hline \multicolumn{3}{|c}{ Summary of findings } \\
\hline $\begin{array}{c}\text { Study event rates } \\
(\%)\end{array}$ & $\begin{array}{c}\text { Relative } \\
\text { effect } \\
(95 \% \text { CI })\end{array}$ & $\begin{array}{c}\text { Anticipated absolute } \\
\text { effects }\end{array}$ \\
\cline { 1 - 1 } $\begin{array}{c}\text { With } \\
\text { placebo or } \\
\text { placebo or } \\
\text { compatater }\end{array}$ & $\begin{array}{c}\text { With } \\
\text { DEX }\end{array}$ & $\begin{array}{c}\text { Risk } \\
\text { difference } \\
\text { with DEX }\end{array}$ \\
\hline
\end{tabular}

PONV incidence between DEX and Placebo

\begin{tabular}{|c|c|c|c|c|c|c|c|c|c|c|c|}
\hline $\begin{array}{c}2616 \\
\text { (32 RCTs) }\end{array}$ & $\begin{array}{c}\text { not } \\
\text { serious }\end{array}$ & not serious & not serious & not serious & none & $\begin{array}{c}\bigoplus \bigoplus \bigoplus \bigoplus \\
\mathrm{HIGH}\end{array}$ & $\begin{array}{c}149 / 1204 \\
(12.4 \%)\end{array}$ & $\begin{array}{c}64 / 1412 \\
(4.5 \%)\end{array}$ & $\begin{array}{c}\mathbf{R R} \mathbf{0 . 4 3} \\
(0.33 \text { to } \\
0.55)\end{array}$ & $\begin{array}{c}124 \text { per } \\
1,000\end{array}$ & $\begin{array}{c}71 \text { fewer } \\
\text { per 1,000 } \\
\text { (from } 83 \\
\text { fewer to } 56 \\
\text { fewer) }\end{array}$ \\
\hline
\end{tabular}

\section{DEX vs Midazolam}

\begin{tabular}{|c|c|c|c|c|c|c|c|c|c|c|c|}
\hline $\begin{array}{c}366 \\
\text { (5 RCTs) }\end{array}$ & \begin{tabular}{|c|} 
not \\
serious
\end{tabular} & not serious & not serious & serious ${ }^{a}$ & none & $\begin{array}{l}\oplus \bigoplus \bigoplus \bigcirc \\
\text { MODERATE }\end{array}$ & $\begin{array}{c}31 / 181 \\
(17.1 \%)\end{array}$ & $\begin{array}{l}15 / 185 \\
(8.1 \%)\end{array}$ & $\begin{array}{c}\mathbf{R R} \mathbf{0 . 4 8} \\
(0.27 \text { to } \\
0.85)\end{array}$ & $\begin{array}{c}171 \text { per } \\
1,000\end{array}$ & $\begin{array}{c}\mathbf{8 9} \text { fewer } \\
\text { per 1,000 } \\
\text { (from } 125 \\
\text { fewer to } 26 \\
\text { fewer) }\end{array}$ \\
\hline
\end{tabular}

\section{DEX vs Ketamine}

\begin{tabular}{|c|c|c|c|c|c|c|c|c|c|c|c|}
\hline $\begin{array}{c}204 \\
\text { (3 RCTs) }\end{array}$ & $\begin{array}{c}\text { not } \\
\text { serious }\end{array}$ & serious $^{b}$ & not serious & serious $^{c}$ & none & $\underset{\text { LOW }}{\oplus \oplus \bigcirc \bigcirc}$ & $\begin{array}{c}29 / 87 \\
(33.3 \%)\end{array}$ & $\begin{array}{c}38 / 117 \\
(32.5 \%)\end{array}$ & $\begin{array}{c}\mathbf{R R} \mathbf{0 . 5 8} \\
(0.19 \text { to } \\
1.82)\end{array}$ & $\begin{array}{c}333 \text { per } \\
1,000\end{array}$ & $\begin{array}{c}140 \text { fewer } \\
\text { per } \mathbf{1 , 0 0 0} \\
\text { (from } 270 \\
\text { fewer to } 273 \\
\text { more) }\end{array}$ \\
\hline
\end{tabular}

CI: Confidence interval; RR: Risk ratio

\section{Explanations}
a. the cumulative Z-curve did not enter the futility area or crossed TSMB
b. Heterogeneity: $\mathrm{Tau}^{2}=0.62 ; \mathrm{Chi}^{2}=6.53, \mathrm{df}=2(\mathrm{P}=0.04) ; \mathrm{I}^{2}=69 \%$
c. the cumulative Z-curve did not enter the futility area or crossed TSMB 
DEX compared to placebo for Hypotension incidence in children

Bibliography: . DEX for EA in children. Cochrane Database of Systematic Reviews [Year], Issue [Issue].

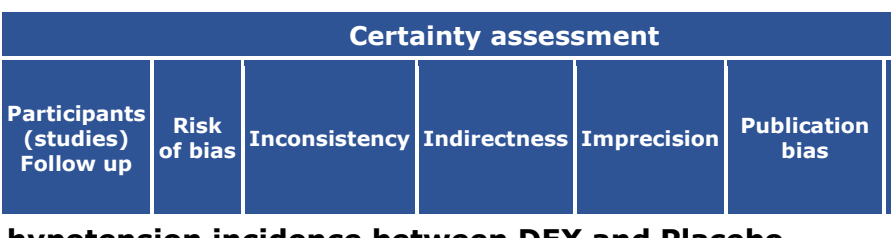

\begin{tabular}{|c|}
\hline $\begin{array}{c}\text { Overall } \\
\text { certainty } \\
\text { of } \\
\text { evidence }\end{array}$ \\
\cline { 2 - 2 }
\end{tabular}

\begin{tabular}{|c|}
\hline \multicolumn{2}{|c}{ Sumn } \\
\hline \multirow{2}{*}{$\begin{array}{c}\text { Study event rates } \\
(\%)\end{array}$} \\
\cline { 2 - 2 } $\begin{array}{c}\text { With } \\
\text { placebo }\end{array}$ \\
\end{tabular}

\section{Summary of findings}

hypotension incidence between DEX and Placebo

\begin{tabular}{|c|c|c|c|c|c|c|c|c|c|c|c|}
\hline $\begin{array}{c}1868 \\
(20 \text { RCTs })\end{array}$ & $\begin{array}{c}\text { not } \\
\text { serious }\end{array}$ & not serious & not serious & very serious & none & $\oplus \oplus \bigcirc \bigcirc$ & $\begin{array}{c}19 / 837 \\
\text { LaW } \\
(2.3 \%)\end{array}$ & $\begin{array}{c}30 / 1031 \\
(2.9 \%)\end{array}$ & $\begin{array}{c}\text { RR 1.5 } \\
(0.9 \text { to } 2.5)\end{array}$ & $\begin{array}{c}23 \text { per } \\
1,000\end{array}$ & $\begin{array}{c}\mathbf{1 1} \text { more per } \\
\mathbf{1 , 0 0 0} \\
\text { (from } 2 \text { fewer } \\
\text { to } 34 \text { more })\end{array}$ \\
\hline
\end{tabular}

CI: Confidence interval; RR: Risk ratio

\section{Explanations}

a. the cumulative Z-curve did not enter the futility area or crossed TSMB 
DEX compared to placebo for bradycardia incidence in children

Bibliography: . DEX for EA in children. Cochrane Database of Systematic Reviews [Year], Issue [Issue].

\begin{tabular}{|c|c|c|c|c|c|c|c|c|c|c|c|}
\hline \multicolumn{7}{|c|}{ Certainty assessment } & \multicolumn{5}{|c|}{ Summary of findings } \\
\hline Participants & & & & & & Overall & Study ev & $\begin{array}{l}\text { ent rates } \\
\text { o) }\end{array}$ & & $\begin{array}{r}\text { Anticipat } \\
\text { ef }\end{array}$ & $\begin{array}{l}\text { d absolute } \\
\text { ects }\end{array}$ \\
\hline $\begin{array}{l}\text { (studies) } \\
\text { Follow up }\end{array}$ & of bias & Inconsistency & Indirectness & Imprecision & $\begin{array}{l}\text { Publiation } \\
\text { bias }\end{array}$ & $\begin{array}{l}\text { Certalnity } \\
\text { of } \\
\text { evidence }\end{array}$ & $\begin{array}{c}\text { With } \\
\text { placebo }\end{array}$ & With DEX & $\begin{array}{c}\text { effect } \\
(95 \% \mathrm{CI})\end{array}$ & $\begin{array}{c}\text { Risk with } \\
\text { placebo }\end{array}$ & $\begin{array}{c}\text { Risk } \\
\text { difference } \\
\text { with DEX }\end{array}$ \\
\hline
\end{tabular}

\section{Bradycardia incidence between DEX and Placebo}

\begin{tabular}{|c|c|c|c|c|c|c|c|c|c|c|c|}
\hline $\begin{array}{c}2333 \\
\text { (26 RCTs) }\end{array}$ & $\begin{array}{c}\text { not } \\
\text { serious }\end{array}$ & not serious & not serious & $\begin{array}{c}\text { very serious } \\
\text { a }\end{array}$ & $\begin{array}{l}\text { publication } \\
\text { bias strongly } \\
\text { suspected }^{\mathrm{b}}\end{array}$ & $\begin{array}{l}\oplus \bigcirc \bigcirc \bigcirc \\
\text { VERY LOW }\end{array}$ & $\begin{array}{l}9 / 1027 \\
(0.9 \%)\end{array}$ & $\begin{array}{c}51 / 1306 \\
(3.9 \%)\end{array}$ & $\begin{array}{c}\text { RR } \mathbf{3 . 4 7} \\
(1.86 \text { to } \\
6.44)\end{array}$ & $\begin{array}{l}9 \text { per } \\
1,000\end{array}$ & $\begin{array}{c}\mathbf{2 2} \text { more per } \\
\mathbf{1 , 0 0 0} \\
\text { (from } 8 \text { more } \\
\text { to } 48 \text { more) }\end{array}$ \\
\hline
\end{tabular}

\section{Explanations}
a. the cumulative Z-curve did not enter the futility area or crossed TSMB
b. Egger's tests $P=0.015$ 